\title{
The Performance of Chlorine-Free Binary Zeotropic Refrigerant Mixtures in a Heat Pump
}

\author{
Jürgen Pannock \\ David A. Didion
}

Building and Fire Research Laboratory

Gaithersburg, Maryland 20899 



\section{The Performance of Chlorine-Free Binary Zeotropic Refrigerant Mixtures in a Heat Pump}

Jürgen Pannock

David A.Didion

IAG DW 13934749

EPA-600-R-92-017

December 1991

Building and Fire Research Laboratory

National Institute of Standards and Technology

Gaithersburg, MD 20899

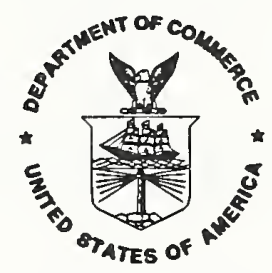

U.S. Department of Commerce Rockwell A. Schnabel, Acting Secretary Technology Administration

Robert M. White, Under Secretary for Technology National Institute of Standards and Technology John W. Lyons, Director

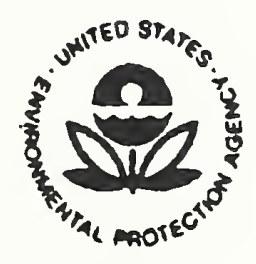

Prepared for:

Electric Power Research Institute

Prepared for:

U.S. Environmental Protection Agency

Powell A. Joyner, Ph.D.

Robert V. Hendriks, Project Officer

Manager, Advanced Projects

Air \& Energy Engineering Research Laboratory

Custom Devision, Residential Program

Research Triangle Park, NC 27711

Palo Alto, CA 94303 



\section{Abstract}

The phaseout of the currently used refrigerants during the next decade requires fast and accurate methods to evaluate possible alternatives for the existing refrigerants. This report investigates possible replacement refrigerants for $\mathrm{R} 22$, where the replacements are binary zeotropic mixtures of the following hydrofluorocarbons (HFCs): R23, R32, R125, R134a, R143a and R152a. The method that was chosen is based on three steps:

1) determining possible mixture components.

2) evaluating all fifteen possible mixtures, using a simulation program developed by NIST and determining the best performing mixtures based on the simulation results.

3) evaluating the best performing mixtures in a test facility built at NIST.

Following this path, two refrigerant mixtures, R32/R134a and $\mathrm{R} 32 / \mathrm{R} 152 \mathrm{a}$, were found to perform better than $\mathrm{R} 22$ with respect to COP and volumetric capacity for certain composition ranges using counterflow heat exchangers.

The simulation model proved to be a very precise tool in finding possible replacement fluids and their possible performance advantages.

The results give confidence that this time saving combination of simulating and testing is a very powerful engineering tool. 


\section{Acknowledgements}

This study was jointly sponsored by the Residential Building Equipment \& Systems Division of the Electric Power Research Institute, Palo Alto, CA, under the direction of Powell A. Joyner and the Air and Energy Engineering Research Laboratory of the United States Environmental Protection Agency, Research Triangle Park, N.C under the direction of Robert V. Hendriks. The Authors would like to thank P.A. Domanski, R.Hampson, M.A. Kedzerski, G. Morrison, W.J. Mulroy of NIST and R. Radermacher of the University of Maryland for their helpful interactions on several occasions. 
Abstract . . . . . . . . . . . . . . . . . iii Acknowledgements . . . . . . . . . . . . . . iv List of Figures . . . . . . . . . . . . . . . viii List of Tables . . . . . . . . . . . . . . . . xii Nomenclature . . . . . . . . . . . . . . xiii 1. Introduction . . . . . . . . . . . . . . 1 2. Simulations .................. 1 2.1 Description of Input Data and Output Data . . . . 2 2.2 Approach to Choose the Input Variables . . . . . 4 2.2.1 Input Variables Describing the Refrigeration

2.2.2 Input Variables Describing the Operation

2.2.3 Processing the Simulation Results . . . . . 7

3. Selection Mixture Components . . . . . . . . . . . 7

4. Pure Refrigerants . . . . . . . . . . . . 8

4.1 General Remarks . . . . . . . . . . . 8

4.2 R23 . . . . . . . . . . . 10

4.3 R32 . . . . . . . . . . . . 10

4.4 R125 . . . . . . . . . . . . . 10

4.5 R143a . . . . . . . . . . 10

4.6 R134a . . . . . . . . . . . . 11

4.7 R152a . . . . . . . . . . . 11 
5. Results of the simulation study . . . . . . . . 12

5.1 General Remarks . . . . . . . . . . . 12

5.2 The Mixtures and their Projected Performance . . . 12

5.2.1 R23/R32 . . . . . . . . . . . . 13

5.2.2 R23/R125 .............. 13

5.2.3 R23/R143a . . . . . . . . . . . 14

5.2.4 R23/R134a .............. 14

5.2.5 R23/R152a .............. 14

5.2.6 R32/R125 .............. 14

5.2.7 R32/R143a . . . . . . . . . . 15

5.2.8 R32/R134a . . . . . . . . . 15

5.2.9 R32/R152a . . . . . . . . . . 16

5.2.10 R125/R143a . . . . . . . . . . 17

5.2.11 R125/R134a . . . . . . . . . . 17

5.2.12 R125/R152a .............. 17

5.2.13 R143a/R134a ............ 18

5.2.14 R143a/R152a . . . . . . . . . 18

5.2.15 R134a/R152a . . . . . . . . . 18

6. Discussion of the Simulation Results . . . . . . 18

7. The Mini-Breadboard Heat Pump . . . . . . . 20

7.1 General Remarks .............. 20

7.2 System Design . . . . . . . . . . 20

7.3 System Instrumentation . . . . . . . . . 22

7.4 Test Criteria . . . . . . . . . . 23 
8. Test Results . . . . . . . . . . . . . . . 25

8.1 General Remarks . . . . . . . . . . . . . 25

8.2 High Temperature Cooling Test (test condition 1A) - 25

8.3 Low Temperature Cooling Test (test condition 1B) - 26

8.4 High Temperature Heating Test (test condition 1C) . 27

8.5 Low Temperature Heating Test (test condition 1D) • 28

8.6 Liquid Line Heat Exchange (test condition 1A-LLHX) 29

8.7 Test Conclusions . . . . . . . . . . . . 31

9. Comparability of Computer study and Test Results . . . . 32

10. Conclusions . . . . . . . . . . . . . . . . 34

11. Further Research . . . . . . . . . . . . . . . 35

12. References . . . . . . . . . . . . . . . 36

APPENDIX A: Simulation Data . . . . . . . . . . . . 37

APPENDIX B: Test Data . . . . . . . . . . . . . . 42

APPENDIX C: Uncertainty Analysis . . . . . . . . . . . 61

vii 
Fig. 1: Key Point Locations of the Simulation Program CYCLE11 3

Fig. 2: Vapor Pressure Curves of Selected Refrigerants [lg $\mathrm{p} /(1 / \mathrm{T})$ scale] . . . . . . . . . . . . 9

Fig. 3: System setup of the Mini-Breadboard Heat Pump . . . 21

Fig. 4: Instrumentation of the Mini-Breadboard Heat Pump $\quad 23$

Fig. A1 : Relative COP of R32/R134a \& R32/R152a vs. R32 content; high temperature cooling condition

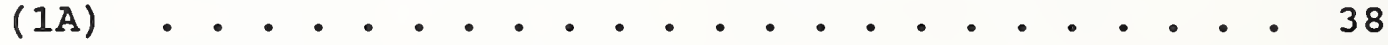

Fig. A2 : Relative vol. capacity of R32/R134a \& R32/R152a vs. R32 content; high temperature cooling condition . . . . . . . . . . . . . 38

Fig. A3 : Relative COP of R32/R134a \& R32/R152a vs. R32 content; low temperature cooling condition (1A)

Fig. A4 : Relative vol. capacity of R32/R134a \& R32/R152a vs. R32 content; low temperature cooling condition . . . . . . . . . . . . . . 39

Fig. A5 : Relative COP of R32/R134a \& R32/R152a vs. R32 content; high temperature heating condition $(1 \mathrm{~A})$

Fig. A6 : Relative vol. capacity of R32/R134a \& R32/R152a vs. R32 content; high temperature heating condition................ 40

Fig. A7 : Relative COP of R32/R134a \& R32/R152a vs. R32 content; low temperature heating condition (1A)

Fig. A8 : Relative vol. capacity of R32/R134a \& R32/R152a vs. R32 content; low temperature heating condition . . . . . . . . . . . . .

Fig. B1.1: Compressor speed vs. R32 mass fraction; high temperature cooling condition (1A)

Fig. B1.2 : Compressor speed vs. R32 mass fraction; low temperature cooling condition (1B) . . . 
Fig. B1.3 : Compressor speed vs. R32 mass fraction; high temperature heating condition (1C) . . . 44

Fig. B1.4 : Compressor speed vs. R32 mass fraction; low temperature heating condition (1D) . . . 44

Fig. B1.5 : Compressor speed vs. R32 mass fraction; high temperature cooling condition with LLHX $(1 \mathrm{~A}-\mathrm{LLHX})$. . . . . . . . . . . 4 45

Fig. B2.1 : Cooling COP vs. R32 mass fraction; high temperature cooling condition (1A) • . . 45

Fig. B2.2 : Cooling COP vs. R32 mass fraction; low temperature cooling condition (1B) . . . 46

Fig. B2.3 : Heating COP vs. R32 mass fraction; high temperature heating condition (1C) • . 46

Fig. B2.4 : Heating COP vs. R32 mass fraction; low temperature heating condition (1D) • . . 47

Fig. B2.5 : Cooling COP vs. R32 mass fraction; high temperature cooling condition with LLHX $(1 \mathrm{~A}-\mathrm{LLHX})$. . . . . . . . . . . . .

Fig. B3.1 :

Relative cooling COP vs. R32 mass fraction; high temperature cooling condition (1A) . . . 48

Fig. B3.2 : Relative cooling COP vs. R32 mass fraction; low temperature cooling condition (1B) . . . 48

Fig. B3.3 : Relative heating COP vs. R32 mass fraction; high temperature heating condition (1C) . . . 49

Fig. B3.4 : Relative heating COP vs. R32 mass fraction; low temperature heating condition (ID) . . . 49

Fig. B3.5 : Relative cooling COP vs. R32 mass fraction; high temperature cooling condition with LLHX $(1 \mathrm{~A}-\mathrm{LLHX})$. . . . . . . . . . . 50

Fig. B4.1 : Suction pressure vs. R32 mass fraction; high temperature cooling condition (1A) . . 50

Fig. B4.2 : Suction pressure vs. R32 mass fraction; low temperature cooling condition (1B) . . . 51

Fig. B4.3 : Suction pressure vs. R32 mass fraction; high temperature heating condition (1C) • • 51 
Fig. B4.4:

Fig. B4.5 :

Fig. B5.1 :

Fig. B5.2 :

Fig. B5.3 :

Fig. B5. 4 :

Fig. B5.5 :

Fig. B6.1 :

Fig. B6.2 :

Fig. B6.3 :

Fig. B6. 4 :

Fig. B6.5 :

Fig. B7.1 :

Fig. B7.2 :

Fig. B7.3 :

Fig. B7. 4 :

Suction pressure vs. R32 mass fraction; low temperature heating condition (1D) . . .

Suction pressure vs. R32 mass fraction; high temperature cooling condition with LLHX $(1 \mathrm{~A}-\mathrm{LLHX})$

Discharge pressure vs. R32 mass fraction; high temperature cooling condition (1A)

Discharge pressure vs. R32 mass fraction; low temperature cooling condition (1B) . . .

Discharge pressure vs. R32 mass fraction;

high temperature heating condition (1C)

Discharge pressure vs. R32 mass fraction; low temperature heating condition (ID) . . .

Discharge pressure vs. R32 mass fraction; high temperature cooling condition with LLHX $(1 A-I L H X)$

Suction temperature vs. R32 mass fraction; high temperature cooling condition (1A)

Suction temperature vs. R32 mass fraction; low temperature cooling condition (1B)

Suction temperature vs. R32 mass fraction; high temperature heating condition (1C)

Suction temperature vs. R32 mass fraction; low temperature heating condition (1D)

Suction temperature vs. R32 mass fraction; high temperature cooling condition with LLHX (1A-LLHX)

Discharge temperature vs. R32 mass fraction; high temperature cooling condition (1A)

Discharge temperature vs. R32 mass fraction; low temperature cooling condition

Discharge temperature vs. R32 mass fraction; high temperature heating condition (1C) 59 Discharge temperature vs. R32 mass fraction; low temperature heating condition 
Fig. B7.5 : Discharge temperature vs. R32 mass fraction; high temperature cooling condition with LLHX $(1 \mathrm{~A}-\mathrm{LLHX})$. . . . . . . . . . . . 60

Fig. C1 : Specific heat regression curve for the heat transfer fluid (40 \%-mass ethylene-glycol, $60 \%$-mass water) 64

Fig. C2 : Mass flow meter calibration curve for evaporator heat transfer fluid measurements . . . . . . . . 66

Fig. C3 : Mass flow meter calibration curve for condenser heat transfer fluid measurements . . . . . . . . 66 


\section{IIST OF TABLES}

1. Heat Transfer Fluid Temperatures by ANSI/ASHRAE Standard 116-1983 . . . . . . . . . . . . . . . 6

2. Heat Transfer Fluid Temperatures Used for the Computer Simulations . . . . . . . . . . . . . . . . . 7 


\section{Nomenclature}

\begin{tabular}{|c|c|c|}
\hline CFC & - & Chlorofluorocarbon \\
\hline COP & - & Coefficient of Performance \\
\hline GWP & - & Global Warming Potential \\
\hline $\mathbf{h}$ & - & enthalpy (kJ/kg) \\
\hline $\mathrm{HCFC}$ & - & Hydrochlor ofluorocarbon \\
\hline HFC & - & Hydrofluorocarbon \\
\hline $\mathrm{HTF}$ & - & Heat Transfer Fluid \\
\hline LLHX & - & Liquid Line Heat Exchanger \\
\hline MBHP & - & Mini-Breadboard Heat Pump \\
\hline ODP & - & Ozone Depletion Potential \\
\hline$\rho$ & - & density $\left(\mathrm{kg} / \mathrm{m}^{\wedge} 3\right)$ \\
\hline $\mathrm{v}$ & - & specific volume $\left(\mathrm{m}^{\wedge} 3 / \mathrm{kg}\right)$ \\
\hline$q$ & - & specific capacity (kJ/kg) \\
\hline$q_{\mathrm{vol}}$ & - & volumetric capacity $\left(\mathrm{kJ} / \mathrm{m}^{\wedge} 3\right)$ \\
\hline $\mathrm{v}$ & - & specific volume $\left(\mathrm{m}^{\wedge} 3 / \mathrm{kg}\right)$ \\
\hline VFRC & - & Volumetric Flow Rate in the condenser \\
\hline VFRE & - & Volumetric Flow Rate in the Evaporator \\
\hline
\end{tabular}

SUBSCRIPTS

numbers -

position of properties with respect to Fig. 1 



\section{Introduction}

The growing concern about the environmental compatibility of currently used refrigerants requires the research of new refrigerants and different refrigerating methods. The incompatibility of the current CFC and HCFC refrigerants with the Earth's ozone layer and the high greenhouse warming potential (GWP) of most of the currently used refrigerants form the justification for this research project. In this study, ozone-safe refrigerants with relatively low GWP are investigated as zeotropic mixtures for heat pump applications. Until now, this field was dominated by the refrigerant $\mathrm{R} 22$.

The refrigerants considered in this study are chemical derivatives of methane and ethane. With the requirement that the ozoneDepletion Potential (ODP) of the substances considered had to be zero, it followed that they were not allowed to contain any chlorine or bromine (chlorine and bromine are the main catalytic substances destroying the ozone layer). These requirements, together with the goal to find a suitable working fluid for heat pump applications, resulted in the selection of the following substances as possible mixture components: R23, R32, R125, R134a, R143a, R152a. In order to evaluate their performance, the refrigerants are compared to $\mathrm{R} 22$, which is the commonly used refrigerant in residential heat pumps in the USA.

In the theoretical part of this research, suitable refrigerant mixtures for the possible replacement of R22 were determined. This was accomplished by means of the application of the NIST-developed simulation program CYCLE11 [1]. The results of this computer study are compared and analyzed with respect to their performance data such as COP, volumetric capacity, discharge temperatures, discharge pressure, and suction pressure.

The experimental part of this research project consisted of tests, using the theoretically best performing refrigerant mixtures as working fluids, in the Mini-Breadboard Heat Pump (MBHP) that was developed and built at NIST. Those tested binary zeotropic mixtures are R32/R134a and R32/R152a.

\section{Simulations}

In order to screen an initially 15 possible refrigerant mixtures on a theoretical basis over their whole composition range, a simplified refrigeration cycle program, CYCLE11, was used. The program simulates a vapor-compression cycle that takes into account common deviations of the heat pump cycle from the theoretical process. The operating conditions are prescribed in terms of the temperatures of the external heat transfer fluids. The heat exchangers (condenser and evaporator) are generalized by an average 
effective temperature difference between the heat transfer fluid and the refrigerant. An isenthalpic expansion across the expansion device is assumed. The program also includes a rudimentary compressor model and a representation of a suction line liquid line heat exchange. For this research, however, the suction line to liquid line heat exchange feature was not implemented. Thermodynamic properties of the refrigerants are calculated with the Carnahan-Starling-Desantis equation-of-state [2]. The program does not require or use refrigerant transport properties. In order to further understand the assumptions made for the simulation model used in this analysis, the authors invite the interested individual to read reference [1].

The simulation was used to give a reasonable idea about which of the considered refrigerant mixtures can replace $R 22$ as a heat pump working fluid. Therefore, it was sufficient to limit the number of simulation runs by assuming many parameters to be constant for all four considered operating conditions. These parameters are:

- compressor speed

- refrigerant pressure drops in the heat exchangers

- polytropic compressor efficiency

- refrigerant liquid subcooling (leaving the condenser)

- refrigerant vapor superheat (leaving the evaporator)

- compressor pressure drop and heat transfer parameters

The authors recognized that these parameters would not be constant in the test apparatus and therefore the comparability of test and simulation results would be limited. However, the purpose of the simulations was to screen and compare a large number of refrigerant mixtures on a consistent basis. This task was satisfied.

\subsection{Description of Input Data and Output Data}

The program input and output data consist of two parts:

- working fluid specification

- cycle specification

The working fluid specification includes identification of the refrigerants and their composition in the mixture.

The refrigerant cycle specifications are defined by the following eleven refrigerant states, which correspond to key locations in a real system (Fig. 1), and are calculated by the program:

- 1- Suction line outlet, inlet to the shell of the hermetic compressor 
Refrigerant state in the cylinder before the compression process

Refrigerant state in the cylinder after the compression process

Compressor shell outlet, condenser inlet

Saturated vapor refrigerant state in the condenser

Saturated liquid refrigerant state in the condenser
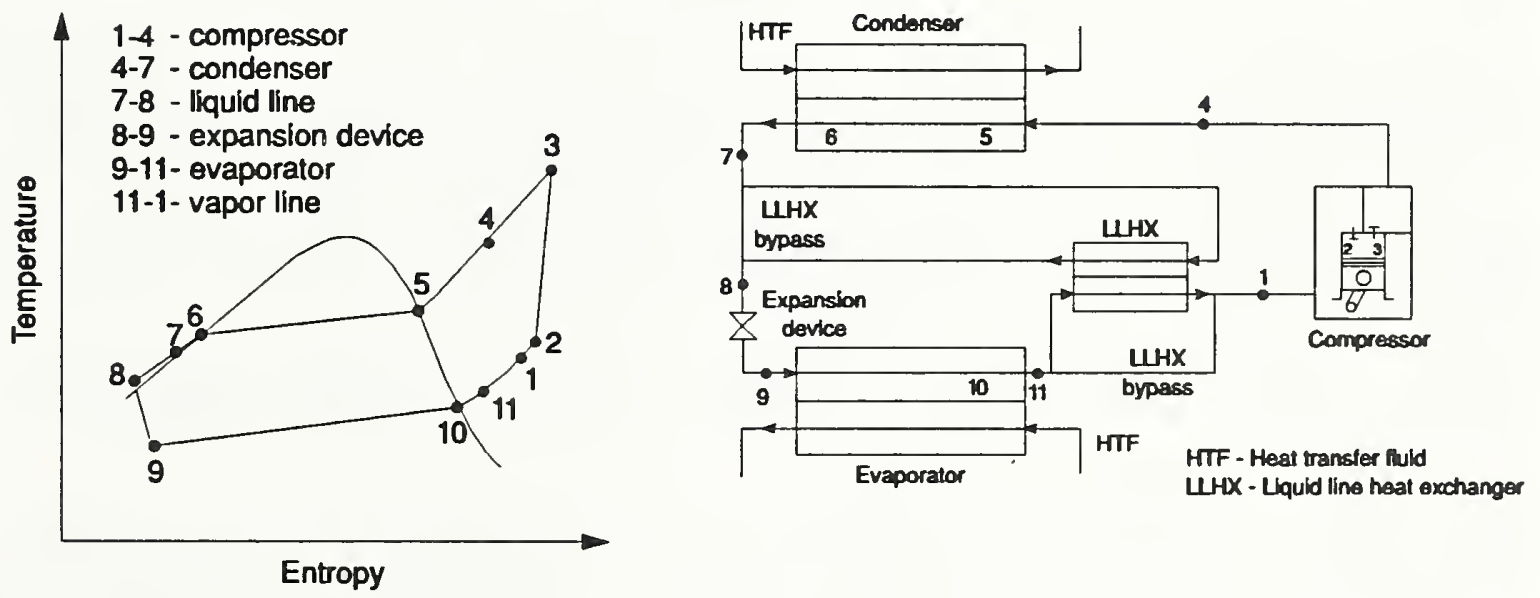

Fig. 1: Key Point Locations of the Simulation Program CYCLE11

The following list presents the input data that must be provided to the simulation program:

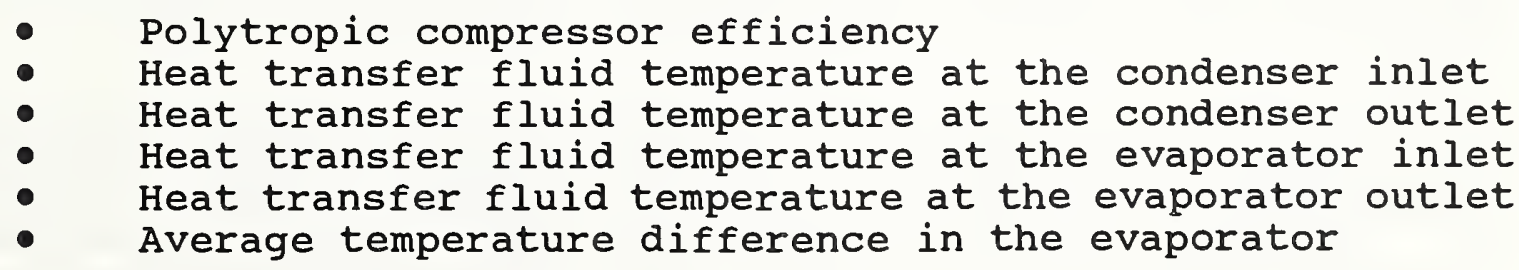




- Average temperature difference in the condenser
Pressure drop in the condenser
Pressure drop in the evaporator
- Refrigerant subcooling leaving the condenser
- Refrigerant superheat leaving the evaporator
- Refrigerant temperature at the compressor inlet
- Ratio of compressor RPM to reference RPM
- Heat transfer coefficient for process 1-2 (Fig. 1)
- Heat transfer coefficient for process 3-4 (Fig. 1)
Pressure drop coefficient for process 1-2 (Fig. 1)
- Pressure drop coefficient for process 3-4 (Fig. 1)

The specification of the refrigerant temperature at the compressor inlet is optional and defines the usage of the liquid line to suction line heat exchanger (the LLHX feature was not used for the simulation study).

\subsection{Approach to Choose the Input Variables}

The information given in section 2.1 shows system dependent parameters and operating condition dependent parameters. For the definition of these parameters, two different approaches have been used.

The system dependent parameters (section 2.2.1), which are mainly compressor specifications were determined in an empirical way.

The operating condition depending parameters (section 2.2.2) were specified by air-air heat pump specifications, although the actual tests were performed on the liquid-liquid MBHP.

\subsubsection{Input Variables Describing the Refrigeration system}

In order to specify the input variables for the compressor (e.g. the heat transfer coefficients, the pressure drop coefficients, and the polytropic compressor efficiency), the computer model was used to generate output data over a range of different compressor speeds at a certain operating condition using refrigerant R22. Then the same heat transfer fluid conditions were used to run laboratory tests with the MBHP, also using R22 as the working fluid. The results of these laboratory tests were then compared with the simulation results. By changing the above specified parameters in the simulation program, the model was adjusted to reflect the real system.

The goal of this procedure was to show the tendency of changes of the coefficient of performance (COP) and of the volumetric capacity with respect to different compressor speeds. It was not expected nor intended to actually achieve the same absolute values in the computer study as the measured data, since the simulation program 
employs several simplifications compared to a real system. This means that the results of the computer study had to be evaluated on a relative basis. They also had to be confirmed by laboratory tests on the same relative basis. Nevertheless, they reflect the relative system performance regarding the different refrigerants and mixtures accurately.

\subsubsection{Input Variables Describing the operation Conditions}

The ASHRAE Standard ANSI/ASHRAE 116-1983 [3], which is based on the DOE requirements, is used for the definition of the heat transfer fluid temperatures. These test standards specify wet bulb and dry bulb temperatures. Since the test rig is a water/glycol to water/glycol heat pump system, the external heat transfer fluid temperatures are specified by the temperature corresponding to the dry bulb temperature of the air-air standard. For the heating test conditions, the two steady state conditions for a single speed compressor were used. These temperatures are given in table 1. The outlet temperatures of the HTF appearing in that table are calculated according to the following assumptions :

$$
\begin{aligned}
& \text { - the evaporator airflow rate is } 187.90 \mathrm{~m}^{3} / \mathrm{kWh} \\
& \text { ( } 400 \mathrm{scfm} / \mathrm{ton}) \text { of refrigeration } \\
& \text { the condenser airflow rate is } 375.79 \mathrm{~m}^{3} / \mathrm{kWh} \\
& \text { ( } 800 \mathrm{scfm} / \mathrm{ton} \text { ) of refrigeration (i.e. per } 4.57197 \mathrm{~kW} \\
& \text { ( } 1.3 \text { tons) of rejected heat, assuming a cop of } 3.0 \text { for } \\
& \text { the cycle performance) }
\end{aligned}
$$

Applying these assumptions, the calculated temperature change for a $3.5169 \mathrm{~kW}$ ( 1 ton) evaporator load per $0.18878 \mathrm{~m}^{3} / \mathrm{s}$ (400 scfm) airflow rate, is about $12.3 \mathrm{~K}\left(22^{\circ} \mathrm{F}\right)$. For a condenser load of $4.57197 \mathrm{~kW}(15,600 \mathrm{Btu} / \mathrm{h})$ per $0.37756 \mathrm{~m}^{3}$ (800 scfm) airflow rate, 


\begin{tabular}{|c|c|c|c|c|}
\hline & Test $A^{1}$ & Test $\mathrm{B}^{2}$ & Test $c^{3}$ & Test $D^{4}$ \\
\hline & $\begin{array}{c}{ }^{\circ} \mathrm{C} \\
\left({ }^{\circ} \mathrm{F}\right) \\
\end{array}$ & $\begin{array}{l}{ }^{\circ} \mathrm{C} \\
\left({ }^{\circ} \mathrm{F}\right) \\
\end{array}$ & $\begin{array}{l}{ }^{\circ} \mathrm{C} \\
\left({ }^{\circ} \mathrm{F}\right) \\
\end{array}$ & $\begin{array}{l}{ }^{\circ} \mathrm{C} \\
\left({ }^{\circ} \mathrm{F}\right)\end{array}$ \\
\hline Condenser Inlet & $\begin{array}{l}35.0 \\
(95) \\
\end{array}$ & $\begin{array}{l}27.8 \\
(82) \\
\end{array}$ & $\begin{array}{l}21.1 \\
(70) \\
\end{array}$ & $\begin{array}{l}21.1 \\
(70) \\
\end{array}$ \\
\hline Condenser outlet & $\begin{array}{c}43.2 \\
(110)\end{array}$ & $\mathrm{VFRC}^{5}$ & $\mathrm{VFRE}^{6}$ & VFRE $^{6}$ \\
\hline Evaporator Inlet & $\begin{array}{l}26.7 \\
(80) \\
\end{array}$ & $\begin{array}{l}26.7 \\
(80) \\
\end{array}$ & $\begin{array}{l}8.3 \\
(47) \\
\end{array}$ & $\begin{array}{r}-8.3 \\
(17) \\
\end{array}$ \\
\hline Evaporator outlet & $\begin{array}{l}14.4 \\
(58)\end{array}$ & $\mathrm{VFRE}^{6}$ & VFRC $^{5}$ & $\mathrm{VFRC}^{5}$ \\
\hline
\end{tabular}

TABLE 1: Heat Transfer Fluid Temperatures by ANSI/ASHRAE Standard 116-1983 [3]

the temperature change is about $8.2^{\circ} \mathrm{C}\left(15^{\circ} \mathrm{F}\right)$. This method provides a set of inlet and outlet temperatures of the heat transfer fluid for the steady state air conditioning test at $35^{\circ} \mathrm{C}$ $\left(95^{\circ} \mathrm{F}\right.$ ) condenser inlet temperature (test $\mathrm{A}$ ). For the heating conditions (Table 1, Test $C$ \& D), it was assumed that the airflow rates (i.e. the liquid flow rates in the test rig) are not changed in the indoor and outdoor part of the unit. since any unit experiences a change in performance under such a constraint, it is not possible to accurately predetermine the outlet temperatures of the HTF. In order to use reasonable values for those temperatures, experimental tests with $\mathrm{R} 22$ were run at equivalent test $A$ conditions. The established liquid flow rates for test $A$ were then used to run experiments under the other three conditions. The heating mode tests were accomplished with reversed HTF flow rates: the evaporator flow rate of test $A$ is the condenser flow rate of tests $C$ and $D$; the condenser flow rate of test $A$ is the evaporator flow rate of tests $C$ and $D$. The resulting temperature differences could then be used for the computer simulation runs. Those results are reflected in table 2 .

\footnotetext{
1 high temperature cooling

2 low temperature cooling

3 high temperature heating

4 low temperature heating

5 volume flow rate condenser (heat transfer fluid)

6 volume flow rate evaporator (heat transfer fluid)
} 


\begin{tabular}{|c|c|c|c|c|}
\hline & Test $A^{1}$ & Test $\mathrm{B}^{1}$ & Test $c^{1}$ & Test $D^{1}$ \\
\hline & $\begin{array}{l}{ }^{\circ} \mathrm{C} \\
\left({ }^{\circ} \mathrm{F}\right) \\
\end{array}$ & $\begin{array}{l}{ }^{\circ} \mathrm{C} \\
\left({ }^{\circ} \mathrm{F}\right)\end{array}$ & $\begin{array}{l}{ }^{\circ} \mathrm{C} \\
\left({ }^{\circ} \mathrm{F}\right)\end{array}$ & $\begin{array}{c}{ }^{\circ} \mathrm{C} \\
\left({ }^{\circ} \mathrm{F}\right)\end{array}$ \\
\hline Condenser Inlet & $\begin{array}{l}35.0 \\
(95) \\
\end{array}$ & $\begin{array}{l}27.8 \\
(82) \\
\end{array}$ & $\begin{array}{l}21.1 \\
(70)\end{array}$ & $\begin{array}{l}21.1 \\
(70)\end{array}$ \\
\hline Condenser outlet & $\begin{array}{c}43.2 \\
(110) \\
\end{array}$ & $\begin{array}{c}37.4 \\
(99.3) \\
\end{array}$ & $\begin{array}{c}32.5 \\
(90.5) \\
\end{array}$ & $\begin{array}{c}28.1 \\
(82.6)\end{array}$ \\
\hline Evaporator Inlet & $\begin{array}{l}26.7 \\
(80) \\
\end{array}$ & $\begin{array}{l}26.7 \\
(80) \\
\end{array}$ & $\begin{array}{r}8.3 \\
(47) \\
\end{array}$ & $\begin{array}{r}-8.3 \\
(17) \\
\end{array}$ \\
\hline Evaporator outlet & $\begin{array}{l}14.4 \\
(58)\end{array}$ & $\begin{array}{c}13.8 \\
(56.8)\end{array}$ & $\begin{array}{c}2.7 \\
(36.9)\end{array}$ & $\begin{array}{c}-11.3 \\
(11.7)\end{array}$ \\
\hline
\end{tabular}

TABLE 2: Heat Transfer Fluid Temperatures Used for the Computer Simulations

\subsubsection{Processing the simulation Results}

For each of the selected operating conditions, all possible binary refrigerant mixtures were simulated for the chosen pure substances. Each test condition was evaluated at twenty-one different mixture compositions for each mixture. This is accomplished by changing the composition in steps of five percent from one pure substance to the other. The results of the simulation runs were then processed in a spread sheet fashion in order to provide a graphical presentation. Simulation data for $\mathrm{R} 22$ is providea as reference in the graphs. This allows further insight in the relative performance changes with respect to the different mixture components and the different mixture compositions. Additionally, a graphical presentation of the condenser pressures, discharge temperatures, and suction pressures of the various mixtures was generated.

\section{Selection of Mixture Components}

To decide which substances to use in the laboratory tests, the following criteria had to be considered:

- The compressor discharge pressure should not exceed $2600 \mathrm{kPa}$ (377 psia) under any operation condition

1 see footnotes for table 1 on previous page 
- The compressor suction pressure should always be above ambient pressure, i.e. above $100 \mathrm{kPa}$, in order to insure that no dirt as air or water vapor enter the system.

- The compressor discharge temperature should not exceed $150{ }^{\circ} \mathrm{C}\left(302^{\circ} \mathrm{F}\right)$ in order to prevent chemical breakdown of the lubricant.

- The ozone Depletion Potential of each substance has to be zero (i.e. chlorine and bromine free) which leads to HFC's (if only the methane and ethane series is chosen).

- The Greenhouse Warming Potential should be significantly lower than the values for the currently used refrigerants.

- Critical point values

- Toxicity

- Flammability

The issue of which lubricants are sufficiently soluble in chlorine-free refrigerants has not yet been determined. Thus, for this study, a mineral oil with $33 \mathrm{cst}$ at $37.7{ }^{\circ} \mathrm{C}$ (150 sus at $\left.100^{\circ} \mathrm{F}\right)$ viscosity was selected and used for all tests. This was satisfactory for the relatively few hours the compressor was actually run. Since the performances of all different working fluids were evaluated with the same lubricant, the impact on the relative performance is considered minimal.

\section{Pure Refrigerants}

\subsection{General Remarks}

Considering pure substances with respect to the criteria given in section 3, there are some statements that can be made to evaluate the possible usage of these refrigerants. The pure media are also compared to pure R22 in this section. It should be noted that R22 is the best of the pure refrigerants with respect to the combined performance in COP and volumetric capacity for the defined operating conditions. Refrigerants such as R23, R32, R125, and R143a have a higher volumetric capacity but a lower COP compared to R22. For R134a and R152a the opposite is true. The COP of these fluids is higher, but their volumetric capacity is too low to use these substances as a drop-in replacement for R22. This also describes the problem in finding a replacement for R22 since R22 appears to be an almost ideal working fluid for the heat pump applications, balancing equipment size with operating efficiency. 
The vapor pressure curves of the named refrigerants are presented in figure 2. This figure can be used to interpret the performance of the different refrigerants with respect to their volumetric capacity and their COP. As a rule of thumb, it can be stated that the further the refrigerant state line lies to the right (higher boiling point or lower pressure refrigerant), the higher the achievable COP. The further the line is to the left (lower boiling point or higher pressure refrigerant), the higher is the possible volumetric capacity.

The critical point and normal boiling point values given in sections 4.2 to 4.7 are obtained from reference [4].

The values for the ODP for the following pure refrigerants is zero, as required by the selection criteria in section 3 .

The values for the GWP are relative to RII (GWP=1.0).

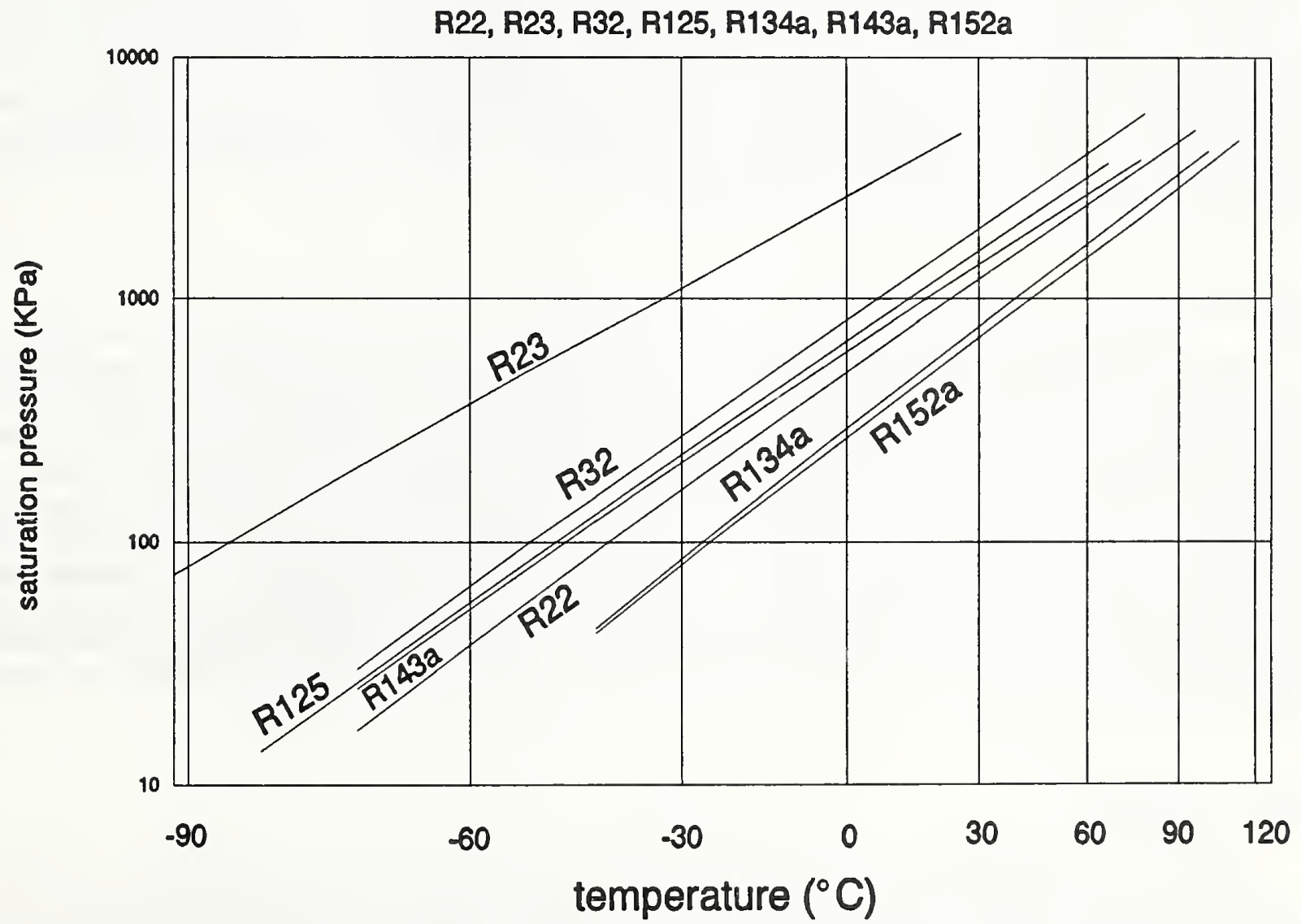

Fig. 2: Vapor Pressure Curves of Selected Refrigerants [ $\lg \mathrm{p} /(1 / \mathrm{T})$ scale] 
As a pure refrigerant R23 can only be considered in low temperature applications, since otherwise the high pressure criterion specified in section 3 would easily be violated. Its normal boiling point is $191.1 \mathrm{~K}$. The critical point lies at $298.98 \mathrm{~K}$ and $4820 \mathrm{kPa}$. Because of these constraints, it can only be used in heat pump applications as a mixture component. R23 has a high volumetric capacity, which makes it a potentially valuable mixture component, since it can be used to increase the capacity of low capacity -but high efficiency- refrigerants. R23 is nonflammable and the toxicity is considered to be low [5]. The GWP is about 21 [6] which may eventually rule out any use of R23 as a working fluid.

\section{$4.3 \quad R 32$}

R32 is flammable [7] as a pure substance. Its normal boiling point is $221.4 \mathrm{~K}$. The critical point values are $351.56 \mathrm{~K}$ and $5830 \mathrm{kPa}$. The computer calculations showed that the volumetric capacity of the pure refrigerant is significantly higher than that of R22. As a mixture, it may be a very valuable component if it is used together with a nonflammable refrigerant, so that the $\mathrm{R} 32$ concentration would be outside the flammability limits (controlled flammability in a mixture). The toxicity tests for R32 are not finished [8] but assumed to be low [7]. The GWP for this substance is 0.13 [9]. These attributes make this refrigerant a very attractive candidate for mixtures.

\subsection{R125}

The normal boiling point of $\mathrm{R} 125$ is $224.6 \mathrm{~K}$ and the critical point values are $339.4 \mathrm{~K}$ and $3631 \mathrm{kPa}$. The computer simulations show that R125 has about the same volumetric capacity but a lower COP than R22. In fact, the COP of R125 is lower than that of R32 which makes it an exception to the previously stated "rule of thumb". This is because the critical point is lower, which typically causes excessive flash gas in the vapor compression cycle. As a nonflammable refrigerant [7], R125 is a possible component for refrigerant mixtures. The toxicity tests for R125 are not finished [8] but assumed to be low [7]. The value for the GWP is 0.58 [9].

\section{$4.5 \quad R 143 a$}

Again, by looking at the $\log p-(1 / T)$ diagram (Fig. 2), it can be concluded that R143a has to be very close in its performance to R22. The normal boiling point is $225.8 \mathrm{~K}$ and the critical point values are $346.25 \mathrm{~K}$ and $3811 \mathrm{kPa}$. With respect to the GWP, R143a 
has a relatively high value of 0.74 [9]. R143a is flammable [7] and -relying on preliminary data- is probably at least moderately toxic. With this in mind, R143a does not appear to be a good choice as a part of any refrigerant mixture. Due to the lack of information with respect to the toxicological data at this time, the researchers chose not to perform laboratory tests at NIST with this refrigerant until further information is available.

\subsection{R134a}

This is the most readily available alternative refrigerant of the ones considered here. The toxicity tests for this substance are not finished, but the limited results indicate a low toxicity [8]. Since R134a is also not flammable [7] and its GWP is 0.26 [9], it is one of the prime candidates of any future refrigerant mixture in this study. The critical point values are $374.21 \mathrm{~K}$ and $4056 \mathrm{kPa}$. The normal boiling point is $247.0 \mathrm{~K}$. It turns out to be the only one out of the six refrigerants in this study that is nonflammable and has a normal boiling temperature that is higher than that of R22. This is an important fact with respect to the mixture flammability, since any mixture that could exceed R22 in volumetric capacity and in COP would probably be composed of a higher and a lower boiling substance (compared to R22).

On the lower boiling temperature side of R22, there are two refrigerants that are non-flammable: $R 23$ and $R 125$.

\subsection{R152a}

This refrigerant is flammable in the range of 5.1 to 17.1 volume percentage in air [8] and has a low toxicity [7]. The critical pressure is $4520 \mathrm{kPa}$ and the critical temperature is $386.44 \mathrm{~K}$. The normal boiling point is $249.0 \mathrm{~K}$. The simulation runs show that R152a has a slightly higher COP and a significantly lower volumetric capacity than that of R22. The fact of the flammability of this refrigerant and the lower capacity makes it difficult to propose its use as a single component refrigerant. However, in mixtures together with a nonflammable component, R152a could become a valuable refrigerant if a well-performing nonflammable mixture can be found. Another reason to consider $\mathrm{R} 152 \mathrm{a}$ is the low GWP of 0.03 [9]. 


\section{Results of the simulation study}

\subsection{General Remarks}

This section is intended to give the reader the comprehensive results of the computer simulations.

The best results in the computer study are achieved with the R152a/R32 refrigerant mixture. Figures A1 to A8 in Appendix A show the calculated results of $C O P$ and volumetric capacity change with respect to $\mathrm{R} 22$ versus the mass fraction of $\mathrm{R} 32$.

Both refrigerants, $\mathrm{R} 32$ and $\mathrm{R} 152 \mathrm{a}$, are flammable, which may be a drawback of this zeotropic mixture. It should be noted here that this mixture consists of the two refrigerants with the lowest GWPs of the considered substances. Depending on the composition of the mixture, the GWP can range from 0.03 for pure R152a to 0.13 for pure R32. Compared to R22 (GWP $=0.34$; relative to $\mathrm{R} 11$ ) this means a significant decrease in GWP.

The second best performing mixture is R32/R134a. For better comparison, their performance is presented in the same figures as R32/R152a.

The R32/R134a mixture contains only one flammable component: R32. Flammability tests regarding this controllable-flammable mixture should be conducted in order to find the best performing nonflammable composition. The GWP of this mixture can range between 0.13 (R32) and 0.26 (R134a) which is higher than that of the R32/R152a working pair but still significantly lower than the GWP of R22.

The mixture of R125 and R134a is the third best performer. It is a nonflammable binary blend in all concentrations. As a substitute for R22, however, it does not seem to be a good choice. The COP is slightly lower than that of R2 2 and the volumetric capacity is also generally lower for R125 contents of less than 80 \%-mass. For high R125 concentrations though, the discharge pressure increases to unacceptable levels (greater than $2600 \mathrm{kPa}$ (377 psia), see section 3). The GWP values of this mixture range from 0.26 (R134a) to 0.58 (R125). This states another reason not to consider this mixture as a replacement since its use would probably result in a mixture with a higher GWP than R22.

\subsection{The Mixtures and their Projected Performance}

This section presents the results of the computer study with respect to each mixture. Emphasis is given to the point that a suitable mixture should meet or exceed both the COP and the volumetric capacity of $\mathrm{R} 22$ as the compared refrigerant. Some of 
the graphs showing the COP or the volumetric capacity versus the mixture composition are presented in Appendix A. Due to the large number of graphs generated by this study, the authors refrained from appending all diagrams and restricted themselves to the best performing mixtures: R32/R152a and R32/R134a.

The computer tests did not consider liquid line to suction line heat exchange (LLHX). For the initial comparison of the mixtures to the pure R22, it seemed to be appropriate to start with no LLHX.

It should be emphasized again that none of the mixtures containing R23 would be acceptable because of their high GWP. Even small amounts of R23 for example $5 \%$-mass would already create a refrigerant mixture with a GWP of greater than 1.0. On top of that, the contribution of the other mixture component would have to be added. The GWP consideration is mentioned here in order not to repeat it in the sections 5.2.1 to 5.2.5. For all these mixtures, the GWP would result in unacceptably high GWP's.

Many of the refrigerant mixtures that were investigated in this study were not considered to be good alternatives for R22. The discharge pressure criterion of section 3 was often violated for one or more of the four operating conditions in the composition range of interest (i.e. cop improvement and/or volumetric capacity improvement). Thus, these mixtures were rejected as possible R22 replacements under the here considered operating condition. However, under different operating conditions (i.e. different applications) other mixtures might perform better than the two mixtures that were concluded to be best for the here investigated application in household heat pumps.

\section{$5.2 .1 \quad R 23 / R 32$}

This mixture contains two refrigerants that are both low boilers compared to R22. This translates to high condenser pressures which exceed the allowable limits in most calculated cases. For test conditions $A$ and $B$, there is not a single composition that does not violate the pressure criterion set for this study in section 3 (maximum discharge pressure of $2600 \mathrm{kPa}$ (377 psia)).

\section{$5.2 .2 R 23 / R 125$}

Although R125 is generally lower in its vapor pressure than R32 (Fig. 2), this mixture also exceeds the pressure limit set for this study. 
The higher boiling pressures of both components compared to R22 make this mixture unattractive considering the criteria of section 3. Especially in the cooling mode the discharge pressure limit is exceeded easily.

\section{$5.2 .4 R 23 / R 134 a$}

This mixture would eventually be suitable with very low R23 content with respect to its projected COP. The calculations show a maximum in COP at about 10 \%-mass of R23 which exceeds the COP of R22 for test conditions $A, B$, and $C$ by up to nine percent in the case of test $B$. For test $D$, the mixture cop is about three percent less than that of pure R22. The volumetric capacity increases almost proportionally with the R23 content. The capacity of R2 2 is met between $15 \%$-mass and $30 \%$-mass of R23 depending on the test conditions. Considering the fact that the test conditions reflect normal operating conditions rather than extreme conditions, the mixture would have to contain $30 \%$-mass R23 in order to achieve the same heating capacities as R22 under all operating conditions. That concentration of R23, however, would result in lower COP's and too high head pressures. Together with the remarks about the GWP of R23 in section 5.2, this leads to the conclusion that this mixture is not the desired working fluid for the considered operating conditions.

\section{$5.2 .5 R 23 / R 152 a$}

The refrigerant $\mathrm{R} 23$ again curtails the usefulness of this mixture for the investigated heat pump application. For low R23 amounts (under $20 \%$-mass R23), a distinct maximum in COP can be observed, which exceeds the R22 COP in the cases of tests $A, B$, and $C$ by five to fifteen percent. In the test case $D$, the COP of the mixture is slightly lower than that of the pure refrigerant. The cop maxima all occur between zero and fifteen $\%$-mass of R23. But in this composition range, the volumetric capacity of this mixture does not meet the requirement to be as high as that of R22. At R23 amounts that ensure a sufficiently high volumetric capacity of the mixture, the condenser side pressures, as well as a lower cop's make this mixture unsuitable under the chosen restrictions for these operating conditions.

\section{$5.2 .6 \quad R 32 / R 125$}

This mixture forms a positive azeotrope (i.e. the vapor pressure of the azeotropic composition is higher than either one of the vapor pressures of the pure components). The investigated operating conditions would already create high discharge pressures 
for the two pure refrigerants and thus violate the pressure criterion of section 3. Since the azeotropic saturation pressures for this mixture are higher than for both pure components (compared at the same temperatures), it was concluded that this mixture does not represent the desired working fluid.

\section{$5.2 .7 \quad R 32 / R 143 a$}

Although the pressures are generally lower than those of the R23/R143a mixture, the margin of safety with respect to the discharge pressures seems to be too small, considering extreme cooling applications.

Another interesting observation can be made by observing the fact that no maximum in COP appears for this mixture. The higher the R32 content, the higher the COP (at least for the four test conditions as long as the pressure limit is not exceeded). This phenomenon can be explained using figure 2: the property curves of the pure substances are close together and therefore the temperature glide during evaporation or condensation due to the zeotropic effect is small. This, in turn, means that the positive effect due to temperature glide is very small. Hence, the change in performance due to composition shift is approximately a Iinear change between the pure substances. The same observation can be made for the mixtures of R32/R125, R125/R143a and R134a/R152a.

\section{$5.2 .8 R 32 / R 134 a$}

This combination generally shows good performance as long as the amount of R32 is kept under $60 \%$-mass. The highest cop for this mixture is calculated at $50 \%$-mass R32 for the cooling conditions and at 70 and $80 \%$-mass R32 for the heating conditions (Fig. A1, $\mathrm{A} 3, \mathrm{A5} \& \mathrm{~A} 7)$. The values are $10 \%$ to $12 \%$ higher than for $\mathrm{R} 22$ in the cooling mode and six to eight percent higher in the heating mode. The heating tests show a shallow maxima, which is explained by the characteristic double maxima of zeotropic mixtures. The benefit of this broad high COP in this case is that these high R32 contents are not necessary to achieve a good performance. At these R32 mass fractions the condenser pressure would easily exceed the pressure limits in extreme operating conditions. Even mass fractions of $40 \%$-mass R32 still show four to seven percent COP improvement in the heating mode.

The volumetric capacity increases with the content of the high pressure refrigerant R32 (Fig. A2, A4, A6 \& A8). Since R134a has a lower volumetric capacity and pure $\mathrm{R} 32$ a higher volumetric capacity than R22, it is again of interest at which composition the volumetric capacity of the mixture is higher than that of R22. This R32 content is $26 \%$-mass to $27 \%$-mass for the cooling tests and $31 \%$-mass to $35 \%$-mass for the heating conditions. This 
implies that for all four test conditions mixtures with at least 35 s-mass of R32 will meet or exceed the volumetric capacity of R22. At the same time, the COP of R22 will be exceeded.

The flammability aspect of this mixture should again be emphasized. R134a as a nonflammable refrigerant would definitely lower the flammability of the R32/R134a. It has not yet been established if these compositions are flammable.

As one of the two predicted best performing zeotropic mixtures, R32/R134a is tested in the MBHP. The results are presented in section 8 and Appendix B.

\section{$5.2 .9 R 32 / R 152 a$}

The highest values for the COP are reached between $40:-$ mass and 55 - 5 -mass R32 depending on the operating condition (Fig. A1, $A 3, A 5, A 7)$. An increase in COP of $16 \%$ to $18 \%$ in the cooling mode and seven to eleven percent in the heating mode is calculated.

The same volumetric capacity as for $\mathrm{R} 22$ is reached at $37 \%$-mass and 38 -mass R32 for the cooling conditions and 44 -mass and 48 \%-mass $\mathrm{R} 32$ for the heating conditions (Fig. A2, A4, A6, A8). In order to assure the same volumetric capacity and the same CoP of this mixture compared to R22, this mixture should contain about $50 \%$-mass R32.

In the heating tests (Fig. A5 \& Fig. A7) R32/R152a shows the characteristic double maximum for zeotropic mixtures. Due to the temperature glide during evaporation and condensation, the COP increases with the R32 mass fraction. The first maximum is reached at the point of best glide matching. The further increase in R32 content in the mixture causes too much temperature glide on the refrigerant side. This overglide causes the cop to drop until a local minimum is reached. That is the composition of worst overglide. By going to mixtures with even higher R32 mass fractions, the temperature glide of the refrigerant drops again, i.e., the temperature glide matching gets better. This way a second local maximum can be observed at a point of good glide matching. With a further reduction in refrigerant temperature glide, the COP goes further down and approaches the value for the pure refrigerant. This effect can only be observed if at least one of the refrigerant temperature glides in the evaporator or the condenser is bigger than the HTF temperature glide. Table 2 shows the evaporator temperature glide of the HTF for the heating conditions to be the smallest of the four test series. Test condition D (low temperature heating) also shows the lowest condenser HTF glide of the four test conditions. This test condition shows the two most distinct double maxima in figure $\mathrm{A} 7$. 
Unfortunately, both mixture components are flammable and therefore have questionable use as replacement refrigerants for R22. On the other hand, this is the mixture with the lowest GWP out of the fifteen considered mixtures.

R32/R152a is the second mixture that has been tested in the test rig. The results are compared to test data of $R 22$ and of the R32/R134a mixture in the later section 8 of this report. The graphical presentation of the test results can be found in Appendix B.

\section{$5.2 .10 R 125 / R 143 a$}

Referring to the remarks about the R32/R143a mixture, the calculations show that no composition exceeds the highest cop or the highest volumetric capacity of the two pure substances. At the same time, both pure refrigerants show a lower COP and a higher volumetric capacity than R22. Again, the log $p-1 / T$ diagram (Fig. 2) indicates that the gliding temperature difference for any mixture composition will be very small. The result is that the mixture shows performance results between the performance of the pure substances. But since neither of the pure refrigerants exceeds the R22 performance, the mixture also does not exceed the R22 results.

\section{$5.2 .11 R 125 / R 134 a$}

The performance of this mixture generally does not exceed the R22 performance. Its COP comes close to or even meets that of R22 depending on the composition and test condition. At the same time, it is, however, not delivering the required volumetric capacity and therefore does not appear to be a good candidate to replace R22.

\section{$5.2 .12 R 125 / R 152 a$}

This mixture shows good results with respect to the COP, since it surpasses that of R22 for tests $A, B$, and $C$ and is almost equal for test $D$ (in a certain composition range). But the volumetric capacity is lower than that of R22 for R125 contents of less than 80 \%-mass. In that range though, the COP is decreasing with increasing $\mathrm{R} 125$ amount. The calculated results do not indicate a mixture composition where both the COP and the volumetric capacity are acceptable as a replacement for $\mathrm{R} 22$. 
The COP of this mixture is about equal to that of $\mathrm{R} 22$ for a 50 \%-mass to 60 \%-mass R134a content. However, in this composition region of interest, the volumetric capacity is about 30\% lower than that of R22. Therefore, this mixture is not considered a suitable working fluid for heat pump units.

\section{2 .14 R143a/R152a}

Again, the fact that only one of the two major criteria is satisfactory curtails the usefulness of this mixture. The COP is calculated greater than that of R22 for a variety of compositions, but the volumetric capacity of the mixtures is too small to be considered as a replacement for $\mathrm{R} 22$.

\subsubsection{R134a/R152a}

The property lines of the two pure components that form this mixture are again very close (Fig. 2). That translates to low temperature glides during the evaporation and condensation. Since those glides are the basic reason for a performance maximum of a zeotropic mixture, this characteristic maximum cannot be seen here. The graphs show almost straight lines for the change in COP and volumetric capacity with respect to composition change. Since the volumetric capacity of both single components is about $40 \%$ lower than that of R22, any composition of these two does not deviate much from that capacity. Hence, this mixture is not considered suitable for the desired purpose.

\section{Discussion of the simulation Results}

The results of this computer study are consistent with the expectations suggested by the refrigerant component properties. There are two binary mixtures that indicate a better performance than the currently used R22. By name, these are R32/R152a and R32/R134a. Although the pure components of these mixtures show either lower COPs and higher volumetric capacities or higher COPs and lower capacities, wide ranges of mixture compositions perform better in COP and show a higher volumetric capacity.

The mixture of R32/R152a (Section 5.2.9) is definitely flammable since both pure substances are flammable. Both pure refrigerants appear to have low toxicities. The GWP of this mixture is the lowest of all possible binary combinations. The engineering aspects discussed in section 3 are found to be within acceptable limits for the investigated composition range.

The calculations for R32/R134a (Section 5.2.7) show a smaller performance improvement than for R32/R152a but still a significant 
increase compared to R22. Both of these refrigerants are in the class of low toxicity and only R32 is flammable. If flammability tests show that a nonflammable refrigerant mixture exists within the composition range of performance improvement (compared to R22), this mixture would clearly be the substance of choice with respect to safety considerations. The GWP of R32/R134a is higher than that of R32/R152a. However, it is still significantly lower than that of R22. Again the engineering aspects from section 3 do not appear to pose any problems.

Given the results of the computer study, the researchers chose to conduct tests with these two refrigerant mixtures within certain composition ranges. The ranges of the tested mixtures are largely determined by the attempt to find a mixture that achieves at least the same volumetric capacity and the same COP as R22. This should be the case for all operating conditions. At the same time, excessive amounts of $R 32$ should not be used in order to provide for acceptable discharge pressures even under extreme operating conditions. The researchers chose to run tests for both refrigerant mixtures in a range between $15 \%$-mass and $40 \%$-mass $\mathrm{R} 32$. For all these compositions, the pressures are expected to be well within the acceptable range. 


\section{The Mini-Breadboard Heat Pump}

\subsection{General Remarks}

The term Mini-Breadboard Heat Pump (MBHP) originates from the fact that the charge for the test system is about $0.5 \mathrm{~kg}$ ( 1.1 lb) of refrigerant. A small required refrigerant charge was a major design criterion of the test rig since the desired refrigerants are expensive and/or not readily available.

The test apparatus is designed for a $3.5 \mathrm{~kW}$ ( 1 ton) refrigeration capacity.

other design criteria were:

- counterflow heat exchangers (condenser, evaporator and LLHX)

- liquid heat transfer fluid

- variable speed compressor

- system usable with and without LLHX

- accessibility of refrigerant and heat transfer fluid in order to create condenser and evaporator temperature profiles

\section{2 system Design}

The system emulates the basic refrigeration cycle. The refrigerant side consists of the compressor, the condenser, the liquid line heat exchanger, the expansion device and the evaporator, as can be seen in figure 3. The system does not include an oil separator or an accumulator in order to satisfy the low charge design criteria.

The refrigerant is compressed in a two cylinder reciprocating compressor and discharged into the condenser. The condenser is a counterflow heat exchanger; the refrigerant flows in the inner tube and a water-ethylene glycol mixture is pumped through the annulus. In order to increase the heat transfer coefficient, the refrigerant and the HTF side are modified. The inner tube is equipped with turbulators ${ }^{1}$ and the heat transfer on the water-glycol side is enhanced by using a spine-fin tube. This ensures a turbulent flow

\footnotetext{
1 twisted tape that was inserted in the inner tube before assembly of the heat exchanger units
} 
on both sides and a large heat transfer area. The resulting increase in flow pressure drops, especially on the water/glycol side, was not considered as important as the compactness of the system design since that allowed for a small refrigerant charge. After leaving the condenser, the refrigerant flows either through the LLHX and then to the expansion device or directly to the expansion device. The liquid line heat exchanger is used to further subcool the condensed liquid refrigerant. The subcooling is accomplished with the low pressure refrigerant vapor leaving the evaporator. The LLHX, as well as the evaporator and the condenser, is working in pure counterflow.

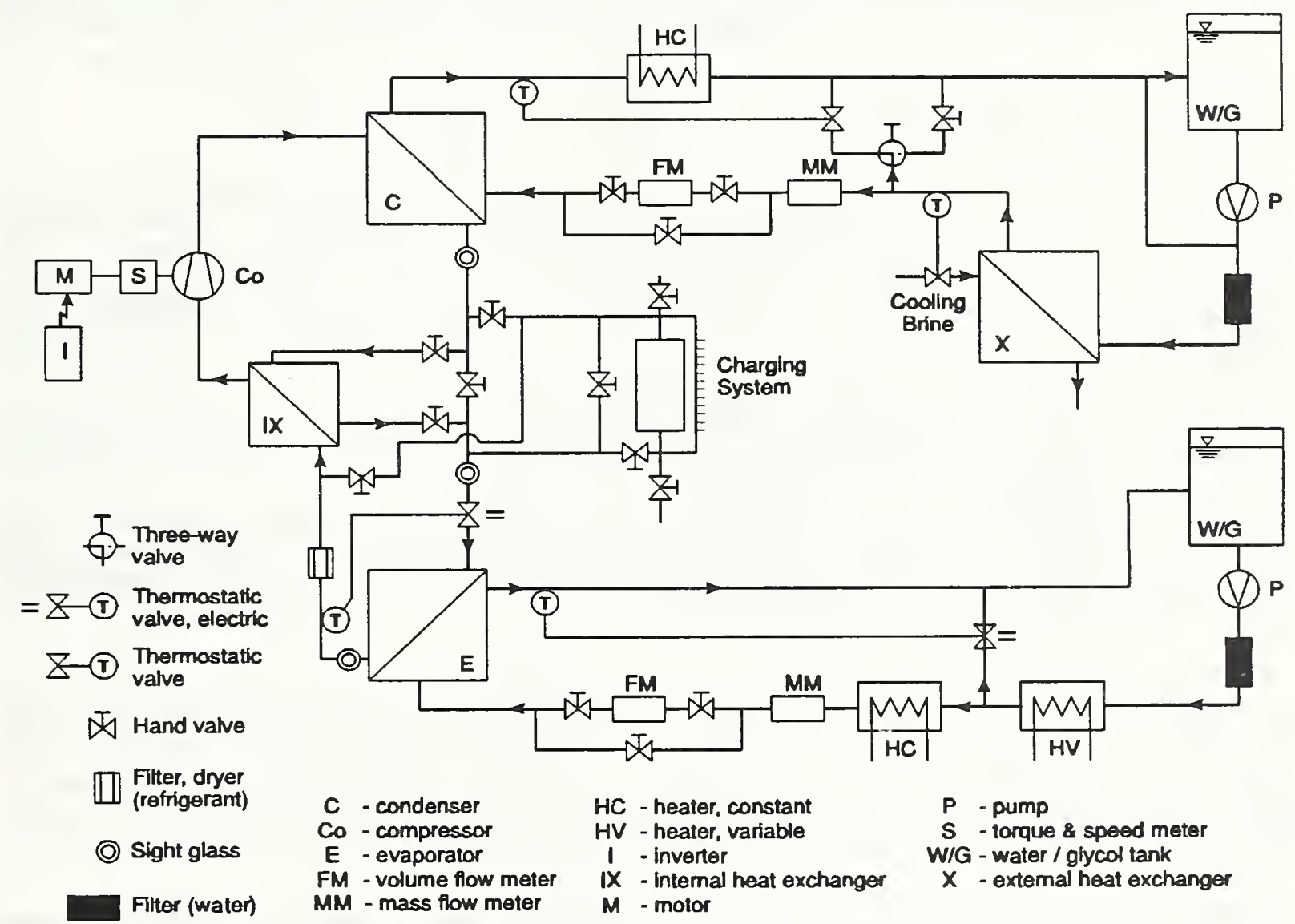

Fig. 3: System Setup of the Mini-Breadboard Heat Pump

The refrigerant enters the evaporator after its expansion in a manually controlled expansion device. The evaporator is a duplication of the condenser - the refrigerant again flows in the inner tube and the water/ethylene glycol mixture in the annulus. After leaving the evaporator, the refrigerant can be superheated in the LLHX, as explained before. The refrigeration loop is closed when the refrigerant vapor enters the compressor again. 
The heat transfer fluid is, in both cases, a mixture of $60 \%$-wt water and 40 \%-wt ethylene glycol. This mixture ensures a frostproof temperature down to $-20^{\circ} \mathrm{C}\left(-4^{\circ} \mathrm{F}\right)$, which makes it possible to run low outdoor temperature heating tests (Test $\mathrm{D}$ in Table 1). The same HTF is used in the condenser in order to have similar (i.e. better comparable) fluid properties in both heat exchangers. This is desirable because the heating and cooling conditions are simulated by changing the mass flow rates and operating temperatures of the HTF and not by reversing the refrigerant flow.

The oil problem mentioned in section 3. was more or less ignored. The system design provided for a good oil return to the compressor and there have been no problems encountered during the test period.

\section{3 system Instrumentation}

A data acquisition system is used to measure the engineering data that are needed for a detailed analyses of the tests. This system is also used to control the machine during its operation. All parts of the MBHP such as compressor, heaters, and pumps can be switched interactively via the computer in connection with the data acquisition.

During the test period, data are read every minute and can be compared to the desired set points of the heat transfer fluids.

For a successful test, the data for the set points have to be constant within reasonable deviations for at least 30 minutes. The data are then averaged over the time period of the test and used for the performance evaluation.

The collected data consist of 97 temperatures, 18 voltages, and 2 frequencies. Figure 4 shows the location of the thermocouples, pressure transducers, flow meters, and all other measuring devices used to determine the performance of the different refrigerants. The temperature measurements are conducted with type $T$ thermocouples (copper-constantan).

Appendix C contains an uncertainty analysis for the COP and mass fraction measurements. 


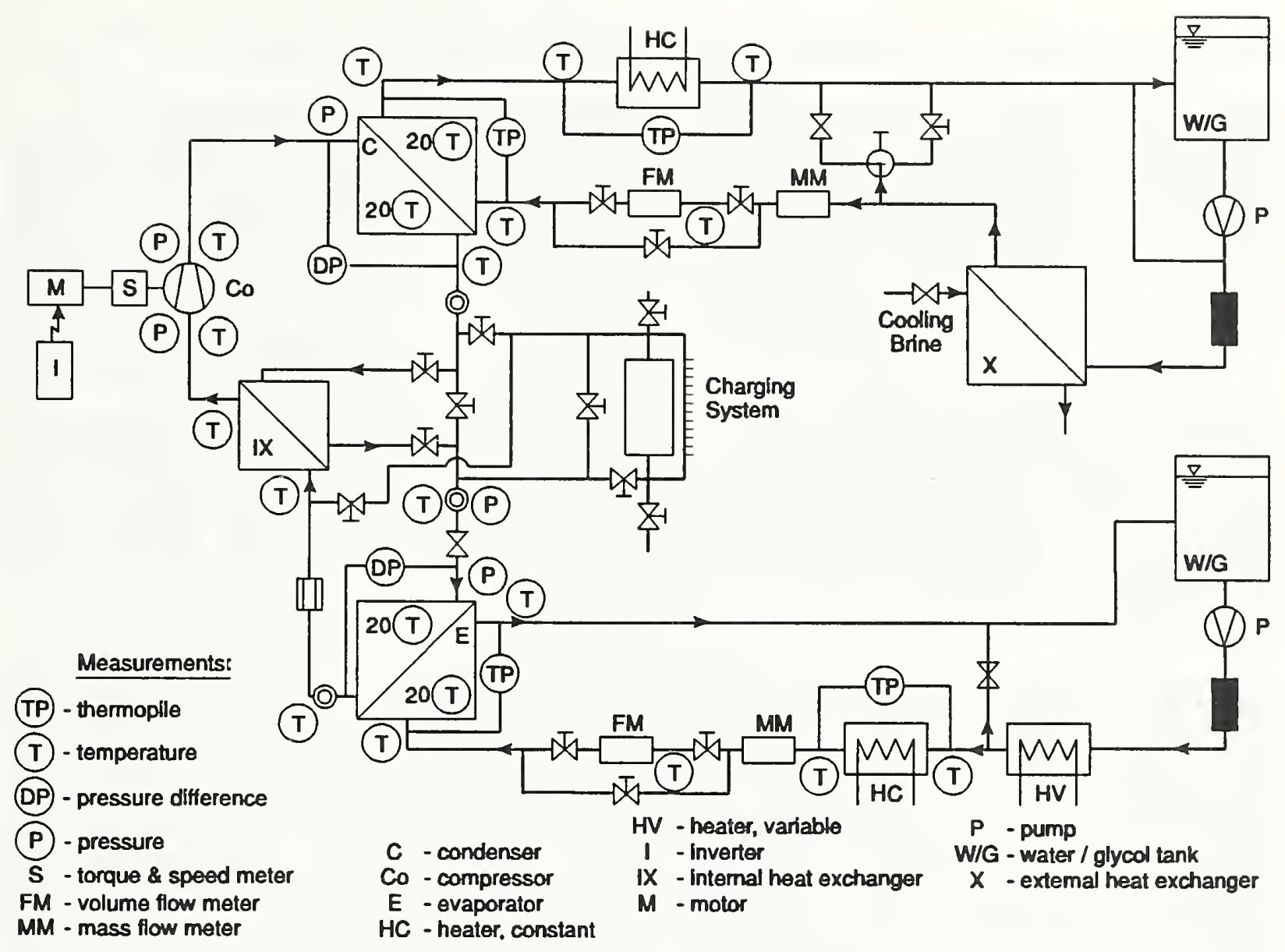

Fig. 4: Instrumentation of the Mini-Breadboard Heat Pump

\subsection{Test criteria}

The criteria for the tests of the different refrigerant mixtures are derived from section 2.2 .2 and the approach of testing the substances at a constant $\frac{\dot{Q}}{U * A_{\text {total }}}$ value as suggested by McLinden and Radermacher [10].

McLinden and Radermacher concluded that an appropriate method of comparing pure refrigerants with zeotropic refrigerant mixtures is

\footnotetext{
$1 U$ : heat transfer coefficient $\left(W /\left(m^{2} \star K\right)\right)$

$A_{\text {toal }}$ : total heat transfer area $\left(\mathrm{m}^{2}\right)$

$\dot{Q}:$ capacity $(W)$
} 
to specify the HTF temperatures and to keep the ratio of $\frac{U * A_{\text {total }}}{\dot{Q}}$

constant. This approach is slightly modified in the study in order to make it more practical. Using the calculated HTF temperatures in table 2 and R22 as working fluid in the MBHP, the values for the capacities are experimentally established. For each test condition, the capacity is measured with R22 and held constant for all mixture tests of the same operating condition. The heat exchanger areas are also held constant throughout the test series. This implies that the compressor speed has to be changed from test to test. A drawback of this method is that the values of the heat transfer coefficients, $U$, are not necessarily constant for all tests. Since the prediction of the heat transfer coefficients for the different working fluids would be very difficult to accomplish, the authors decided to accept this deviation from the proposed test criterion. McLinden and Radermacher mentioned in their paper that such concessions may have to be made for the actual testing of mixtures.

In order to get comparable test results, the tests have to be further restricted with respect to condenser subcooling and evaporator superheat. The researchers chose to run the tests with as little subcooling as possible (effectively not greater than $2 \mathrm{~K}$ ) and that the superheating region should start at $80 \%$ ( \pm five percent) of the evaporator length. The superheat criterion is necessary in order to ensure that no two-phase refrigerant is leaving the evaporator, since that would affect the performance rating of the system. The subcooling and superheat criteria are held constant for all operating conditions. Both criteria require the adjustment of the refrigerant charge during the test procedure. The charging system design (Fig. 3) is crucial in accomplishing that task. The capacity defining tests are conducted at compressor speeds of 1500 RPM to 1620 RPM.

For the composition measurements, a small vapor sample is taken from the discharge line during the steady state phase of the test and then evaluated with the gas chromatograph. 


\section{Test Results}

In this section, the test results which are graphically presented in Appendix B are discussed. The compressor speeds, coPs, suction temperatures, discharge temperatures, suction pressures, and discharge pressures are reported versus the mass fraction of $\mathrm{R} 32$. The suitable R22 data are displayed as a reference line in those graphs.

\subsection{General Remarks}

Again, it should be noted that the tests are obtained under the criterion of constant capacity for all tests in one test series. This has the effect that different compressor speeds (Fig. B1.1 to B1.5) are used for different refrigerant compositions since the volumetric capacity of a mixture varies with its composition (see simulation results in Appendix A). Different compressor speeds, as well as different refrigerant densities and transport properties, affect the compressor performance and the pressure drop within the heat exchangers. But, these changes are system specific rather than refrigerant specific. Considering a proper system layout for each refrigerant mixture, it should be possible to reach the same compressor efficiency, as well as the same pressure drops independent of the working fluid. This suggests that a correction of the test data with respect to the named non-idealities would give some more insight in the differences of pure and mixed refrigerants. However, for this study, these thoughts are not reflected in the results since the process of how to correct the test data has yet to be determined.

\subsection{High Temperature cooling Test (test condition 1A)}

The cooling capacity, which is kept constant for these tests, is $3,510 \mathrm{~W}(11,976 \mathrm{BTU} / \mathrm{h})$. The compressor speed is shown in figure B1.1. As one point of interest, the refrigerant mixture R32/R134a containing $24 \%$-mass $R 32$ should be pointed out because for that composition the speed and capacity are equal to that of R22. For the mixture of R32/R152a, that is true at about $31 \%$ mass of R32.

The COP of the R32/R134a mixture (Fig. B2.1 \& B3.1) shows a steady increase in the measured composition range with increasing R32 amount. For R32 mass fraction below 0.22 in the R32/R134a mixture, the COP is lower than that of R22. The maximum is reached at an improvement of $19 \%$ over R22 at $40 \%$-mass of R32. For R32/R152a, the COP is higher than that of R32/R134a for mass fractions lower than about 0.37 . The tests indicate that the COP levels out for this mixture at that composition. The maximum measured increase in COP is $17 \%$ to $18 \%$ over that of R22 at the same 
capacity. At the composition that shows the same speed and capacity as R22, the COP is $14 \%$ higher for R32/R152a and four percent higher for R32/R134a.

The suction pressures (Fig. B4.1) are proportional to the R32 content of the mixture. They vary in the tested range $\pm 20 \%$ compared to R22. The lower pressures at lower R32 content also mean low volumetric capacities (i.e. higher compressor speed, since the tests were conducted at a constant capacity). The same suction pressure as for R22 is reached at about $28 \%$-mass R32. The R152a mixture generally shows lower pressures than R134a at the same R32 content. Its mixture pressures are lower by about 10\% (with respect to $\mathrm{R} 22$ ). At a mass fraction of $36 \%$ the suction pressure of $\mathrm{R} 152 \mathrm{a}$ is equal to that of $\mathrm{R} 22$.

For the discharge pressure (Fig. B5.1), a similar statement as for the suction pressure can be made, although the differences are not as big on a relative basis. For R32/R134a, the discharge pressure varies from $-12 \%$ to $+8 \%$ (with respect to R22) in the mass fraction range of 0.17 to 0.4 . For the R32/R152a binary, the discharge pressure varies from $-24 \%$ to $-6 \%$ in the measured range.

The figures for the suction and discharge pressures show that both refrigerant mixtures lie well within acceptable pressure limits (section 3), which was anticipated for this test condition.

With respect to the suction and discharge temperatures (Fig. B6.1 \& B 7.1) observed in this test series, it can be noticed that the suction temperature is constant (within $1 \mathrm{~K}$ ) for all tests independent of the working fluid. The discharge temperature, however, is not constant. For both mixtures, the discharge temperature is lower than that of the comparable R22. The R32/R152a mixture shows a decrease of $3 \mathrm{~K}$ to $5 \mathrm{~K}$ (with increasing R32 content) and the R32/R134a mixture shows a decrease of $5 \mathrm{~K}$ to almost $10 \mathrm{~K}$ compared to R22. The difference in the discharge temperatures can be explained with the different specific heats of the working fluids.

\subsection{Low Temperature cooling Test (test condition 1B)}

The cooling capacity at which the test results for this test condition are obtained is $3,685 \mathrm{~W}(12,574 \mathrm{Btu} / \mathrm{h})$. The obtained change in compressor speed is shown in figure B1.2. The mixture composition that is run at the same speed as R22 contains $23 \%-m a s s$ of R32 for the R32/R134a mixture and $29 \%$-mass R32 for the R32/R152a test series.

The COP of all tested refrigerant mixtures is higher compared to test condition $1 \mathrm{~A}$ since the temperature lift is smaller. The relative and absolute change of COP with respect to $\mathrm{R} 22$ is presented in figure B2.2 \& B3.2. The mixture of R32/R152a shows a 
measured improvement of over $20 \%$ for $\mathrm{R} 32$ contents higher than $35 \%$-mass. At about $17 \%$-mass the COP is equal to that of R22, and below that the COP is also lower. The mixture of R32/R134a shows a lower COP compared to R32/R152a in the range of up to $30 \%$-mass of R32. Above a mass fraction of $0.35 \mathrm{R} 32$ the COP appears to be higher than that of R32/R152a. The largest increase in COP for this mixture is about $22 \%$ at $38 \%$-mass R32.

The suction and discharge pressures (Fig. B4.2, B5.2) are again well within acceptable limits. With respect to $\mathrm{R} 22$, the suction pressures of the R32/R134a mixture are 10\% to $15 \%$ higher than those of the R32/R152a mixture (Fig. B5.2). In absolute numbers, this means a higher pressure of about $100 \mathrm{kPa}$ (14.5 psi) on the suction side (Fig. 4.2). However, this does not translate into the same difference on the discharge side. Here, figure B5.2 shows an absolute pressure difference of about $200 \mathrm{kPa}(29 \mathrm{psi})$. At the same time, the discharge pressures for R32/R134a are lower than those of R22 for R32 contents of less than $30 \%$-mass. For R32/R152a, all measured discharge pressures are below the obtained R22 value.

The suction and discharge temperatures (Fig. $6.2 \& 7.2$ ) show a similar results as for test condition $1 \mathrm{~A}$. The suction temperature is within $\pm 1 \mathrm{~K}$ (except one data point). The discharge temperatures are generally lower than the corresponding R22 temperature. For the R152a mixture, the difference in discharge temperature varies from $3 \mathrm{~K}$ lower at about $20 \%$-mass to $5 \mathrm{~K}$ lower at $\mathrm{R} 32$ mass percentages higher than 30. As for the R32/R134a mixture, the decrease compared to the R22 discharge temperature is higher and amounts to about $10 \mathrm{~K}$ for mixtures with more than $30 \%$-mass $\mathrm{R} 32$.

\subsection{High Temperature Heating Test (test condition 1C)}

For this test condition the reference heating capacity is $3,140 \mathrm{~W}$ $(10,714 \mathrm{Btu} / \mathrm{h})$. Figure B1.3 shows the compressor speed variation versus the composition change of the mixtures. For R32/R134a, the speed equivalence with the R22 test is obtained at $28 \%$-mass R32, and for the R32/R152a mixtures this point is reached at $37 \%-$ mass R32.

In the heating mode, the heating coPs of the R32/R134a mixture are higher than those of the R32/R152a mixture (Fig. B2.3 \& B3.3). This observation is different from the cooling mode where the cooling coPs of R32/R134a are lower compared to R32/R152a. The increase in COP of R32/R134a is about two percent based on the R22 COP. For R32 contents of more than $20 \%$-mass, the COP is higher than that of R22 for the R134a binary. The R32/R152a mixture also shows an COP improvement against R22 above $20 \%$-mass R32. At the mixture compositions of same speed and same capacity, however, R32/R134a shows four percent improvement over R22 and R32/R152a shows eight percent. 
The suction and discharge pressures at this operating condition appear lower than the R22 tests for less than 32 R32/R134a mixture (Fig. B4.3, B5.3). The R32/R152a mixture again shows generally lower pressures and never reaches the R2 2 discharge pressure in the tested range.

The suction temperatures in figure B6.3 appear to be slightly lower (about $1.5 \mathrm{~K}$ ) than in the $\mathrm{R} 22$ reference test. However, for the two mixtures, the suction temperature is almost constant over the complete tested composition range.

The discharge temperatures (Fig. B7.3) prove to be about $5 \mathrm{~K}$ higher for the R32/R152a mixture than the R32/R134a binary. For both test series the discharge temperature is lower than the reference temperature. The difference is from 3 to $5 \mathrm{~K}$ for the R152a binary. For the R134a mixture tests, the temperatures are 10 to $8 \mathrm{~K}$ lower for the test over $23 \%$-mass R32.

\subsection{Low Temperature Heating Test (test condition 1D)}

These tests are conducted at a condenser capacity of $1,970 \mathrm{~W}$ $(6,722 \mathrm{Btu} / \mathrm{h})$. In figure B1.4, the speed variation is shown with respect to the measured compositions of the mixtures. For R32/R134a the point of same speed and same capacity can be identified at about $35 \%$-mass R32. The R152a binary fulfills this criterion at $45 \%$-mass $\mathrm{R} 32$.

Similar to the high temperature heating tests, it appears that the R32/R134a mixture performs better in the heating mode than the other binary mixture at the same $\mathrm{R} 32$ content. With respect to $\mathrm{R} 22$, the R134a binary is about five to ten percent better than the R152a binary (Fig. B2.4 \& B3.4). The same COP as for R22 is reached at about $30 \%$-mass R32 for the R32/R134a mixture. The R152a binary needs about $40 \%$-mass $R 32$ to reach the COP of $R 22$. In the tested composition range, only R32/R134a shows an improvement in COP of five percent over R22 at $40 \%$-mass R32. At the composition of equal speed and capacity with the R22 reference test, both mixtures show the same COP as R22 for this test condition.

The measured pressures in figure B4.4 and B5.4 again show R32/R152a to be the low pressure mixture (compared at the same R32 content). It never reaches the same suction or discharge pressure as R22. The R32/R134a mixture pressures are relatively close to the R2 2 pressures and range between $\pm 10 \%$ for the discharge pressure in the measured composition range. The suction pressures are lower than the ones for $\mathrm{R} 22$ in the range of less than $30 \%$-mass R32.

For the suction and discharge temperatures shown in figure B6.4 and B7.4, a slightly different behavior than before can be observed. The discharge temperatures exceed the reference temperature of R22 for certain mixture compositions. The discharge 
temperature of the R152a binary generally exceeds the R22 temperature by $13 \mathrm{~K}$ to $3 \mathrm{~K}$ in the range of $20 \%$-mass to $43 \%$-mass R32. For R32/R134a, a higher discharge temperature than for the R22 reference test is measured for R32 mass fraction of less than 0.23 . For mass fraction above $0.23 \mathrm{R} 32$, a lower discharge temperature is measured $(5 \mathrm{~K}$ to $8 \mathrm{~K})$. The suction temperatures are again relatively constant for each mixture series (within $2 \mathrm{~K}$ ) but the R134a mixture tests show a lower temperature ( $2 \mathrm{~K}$ to $3 \mathrm{~K}$ below R22 reference and $1 \mathrm{~K}$ to $2 \mathrm{~K}$ below the R152a series).

\subsection{Iiquid Iine Heat Exchange (test condition 1A-LLHX)}

This test series has been conducted to find eventual benefits associated with the use of the LLHX. The tests are taken at the same operating conditions as test series $1 \mathrm{~A}$ (high temperature cooling). This also means that the same evaporator capacity of $3,520 \mathrm{~W}(12,011 \mathrm{Btu} / \mathrm{h})$ is used. The reference values for R22 referring to this section are also obtained with a LLHX.

Figure B1.5 shows the compressor speed variation for both mixtures. The point of equal speed and capacity is reached at 24 -mass R32 for the R32/R134a mixture and at $32 \%$-mass R32 for the R152a binary.

The COP in figures B2.5\& B3.5 increases for both mixtures with the addition of R32. The tests show an almost linear increase of COP for the R134a mixture matching the COP of R22 at 20 \%-mass R32. At 40 \%-mass R32, this mixture shows a $17 \%$ higher COP than R22. For R32/R152a, the slope of increase in COP appears to be smaller. Although the COP is higher for R32, mass fractions below 0.3 , a lower COP than for R32/R134a can be observed for mass fractions over $0.35 \mathrm{R} 32$. The absolute values for the COP reach 4.4 for R32/R152a and 4.55 for R32/R134a. For the test without LLHX, the highest COP values for this operating condition are 4.23 for $\mathrm{R} 32 / \mathrm{R} 152 \mathrm{a}$ and 4.3 for $\mathrm{R} 32 / \mathrm{R} 134 \mathrm{a}$. The results are, in both cases (R32/R134a \& R32/R152a), obtained for capacities of $3520 \mathrm{~W}$ ( $\pm 1 \%$ ). Compared to the tests without the LLHX, a significant performance improvement was measured using the LLHX (+4\% in COP for R32/R152a and $+5.8 \%$ in COP for R32/R134a). However, it should be noted again that part of the performance improvement with the LLHX has to be attributed to the lower compressor speeds that are needed to run at the same capacity. By using the LLHX, the latent heat available during evaporation increases, thus requiring a lower refrigerant mass flow rate if the capacity is held constant. Although the suction gas density drops due to the superheat created by using the LLHX, a lower compressor speed was measured for tests using the LLHX (comparing tests with the same refrigerant composition at the same capacity) (see figure B1.1 \& B1.5). The latent heat effect also appears to be the reason why the COP of the R22 tests with LLHX increases compared to the R22 tests without LLHX. In order to 
give an accurate assessment of the influence of the LLHX, it will be necessary to analyze the obtained data further.

At the composition of equal speed and capacity with R22, the COP improvement of the R32/R134a mixture is three percent and of the R32/R152a mixture is eleven percent.

One interesting aspect of the liquid line heat exchange should be noted here. When the LLHX is incorporated within the system, the performance advantage of the R32/R152a mixture over the R32/R134a mixture in the composition region below $35 \%$-mass R32 (Fig. B2.1) shrinks to almost zero. In fact, it seems that in the range above $30 \%$-mass $\mathrm{R} 32$, the mixture of $\mathrm{R} 32 / \mathrm{R} 134 \mathrm{a}$ performs better in the cooling mode. If the phenomenon of a higher increase in performance for the R134a mixtures with the usage of a LLHX is true in the heating mode, then R32/R134a would probably be the refrigerant mixture of choice.

The suction pressures (Fig. B4.5) for the R134a mixtures are lower than the ones for $\mathrm{R} 22$ in the composition range below $17 \%$-mass R32. Above that composition, they exceed the reference pressure by up to $20 \%$ at the highest measured composition of 40 \%-mass R32. The R152a mixtures are again generally lower than the ones of $\mathrm{R} 134 \mathrm{a}$ and reach the suction pressure of $\mathrm{R} 22$ at about $38 \%$-mass R32. Below that composition, the pressure falls up to $20 \%$ below the value of R22. The use of the LLHX increases the absolute suction pressures for this test series which is expected from the theory of the liquid line heat exchange with zeotropic mixtures.

The discharge pressures (Fig. 5.5) are almost identical to the ones measured for the tests without the LLHX. R32/R134a reaches the R22 pressure at $29 \%$-mass R32. R32/R152a is about $300 \mathrm{kPa}$ (43.5 psi) lower in its condenser pressures at the same R32 content.

Compared to the tests without LLHX (Fig. B6.1) the suction temperatures are about $10 \mathrm{~K}$ higher for the tests with LLHX (Fig. B6.5). The start of the superheat region in the evaporator is kept the same as for the tests without the LLHX. Comparing the temperatures to the R22 reference test, both mixture series show a $2 \mathrm{~K}$ to $3 \mathrm{~K}$ lower suction temperature.

The discharge temperatures in figure B7.5 are naturally also higher with the use of the LLHX. The R134a mixtures show the lowest temperature difference with about $10 \mathrm{~K}$ less than R22. The R152a test shows about $5 \mathrm{~K}$ less than R22. All discharge temperatures are well within acceptable limits. 


\subsection{Test Conclusions}

From the graphical presentation of the results, it can be concluded that both refrigerant mixtures are suitable replacements for R22 if the appropriate mixture composition is chosen and counterflow heat exchange with the heat transfer fluid is possible.

For R32/R152a, the mixture should have a R32 content of at least 40 - 8 -mass R32. This high fraction of R32 is necessary to ensure a heating capacity that meets the $R 22$ capacity for all operating conditions (limiting is test condition 1D). At all other operating conditions, a significant increase in COP can be expected given counterflow heat exchange. The operating pressures and temperatures indicate no problem in the usage of this mixture. This mixture has the lowest GWP possible of the tested mixtures which is about one-fourth of the R22 value. However, this zeotropic mixture is flammable in the whole composition range.

The other zeotropic mixture investigated has been found to perform not as well as R32/R152a in the region of lower R32 content if used without LLHX. But, for mixtures consisting of at least 35 \%-mass of R32, this R32/R134a zeotrope shows better or equivalent performance than R32/R152a. There are two definite advantages of this mixture. The performance in the heating mode is better than that of R32/R152a since, in general, this mixture has a higher volumetric capacity at the same $R 32$ concentration. This is important since it affects the need for supplementary heat (resistance heating) during the heating period. The second reason, and this might be even more important, is the flammability aspect. Since $\mathrm{R} 134 \mathrm{a}$ is not flammable, this is a 'controllable-flammable' mixture, meaning that a certain range exists in which the mixture is nonflammable. Flammability tests with this mixture are being conducted at the current time at NIST. Interesting to note is that the computer simulations indicated a better performance for the R32/R152a mixture over the whole composition range. This was not found to be the case for the test results. This deviation from the computer prediction can probably be attributed to the differences in operating parameters as discussed in section 2 .

The tests with LLHX favor the mixture of R32/R134a since, compared to R32/R152a, they show a higher increase in the COP with respect to the tests without the LLHX. The possible benefits of the liquid-line heat exchange are remarkable with respect to another aspect. These performance increases are not dependent on the kind of heat exchange used in the evaporator or condenser. As a separate counterflow unit in the refrigeration cycle, the LLHX impact on performance is independent of the kind of evaporator or condenser used. If these increases in COP with the usage of the LLHX can be validated for other test conditions, then there are two new aspects. One is that with the same R32 content higher cops can be achieved. The other aspect is that, if the flammability is an important issue, the R32 content can be lowered to a point where 
the volumetric capacity is still satisfactory and the mixture is nonflammable. For this decision, however, it is necessary to know the flammability region of the mixture.

The increases in COP over R22 that were measured with both mixtures amount to up to $20 \%$ (test condition B; about 40 \%-mass R32, no LLHX). With cross or parallel flow heat exchangers and with a design resulting in the same pressure drops than for R22, these high increases can not be expected. However, the significant improvements that were measured offer enough potential that even cross or parallel flow heat exchange (as used in household heat pump units) should benefit from the usage of these mixtures.

Considering the use of a LLHX for the mixture of R32/R134a, it is very likely that a significant increase in COP remains even with heat exchangers that do not use the temperature glide of the mixtures (i.e., cross flow and parallel flow heat exchangers). This is the case, since a LLHX can always be incorporated in a system in counterflow. The benefits that are due to the internal heat exchange persist independently of the kind of evaporator or condenser that is used. The advantage due to the implementation of the LLHX in a system is estimated to be about five percent for the R32/R134a mixture (comparing at the same mixture composition with and without LLHX).

The test results for all mixtures and compositions were obtained using the same test apparatus. There was no optimization of the test equipment with respect to pressure drop, compressor efficiency,heat exchanger surface area, etc. for any specific working fluid. This is important because it turns out that the pressure drop in the heat exchangers for the R32/R134a mixture is significantly higher than that of the R32/R152a mixture (compared at the same R32 mass fraction). This pressure drop is system dependent, not refrigerant dependent. The compressor, however, does not differentiate operating pressures that are created due to pressure drops or due to the fluid properties. Thus, the pressure difference that the compressor has to overcome is increased due to the pressure drops in condenser and evaporator. These pressure drops were significantly higher for the R32/R134a mixtures than for the R32/R152a mixtures (at the same R32 content) thus creating a disadvantage for the R32/R134a mixtures. Exactly how big a disadvantage has not yet been determined. For a real system the pressure drop is a design criterion, therefore, for both mixtures the same pressure drops can be expected.

\section{Comparability of computer study and Test Results}

The chosen path of using computer simulations to find a wellperforming refrigerant mixture to suit heat pumping needs turned out to be efficient and accurate within the expected limits of the computer model. The two chosen mixtures were predicted to perform 
better than R22 assuming the same speed, pressure drops, and compressor efficiencies. In general, this performance increase has been found to be true. If the predicted relative changes are compared with the relative changes of test results taken at the same compressor speed (the R22 test speed), it can be found that the simulated improvements in COP are very close to the ones measured. This further establishes the confidence in the NIST simulation model.

If the predicted relative changes are compared with the measured relative changes at compressor speeds deviating from the R2 2 test speed, large discrepancies can be noticed (see also section 2). These discrepancies can be explained by changing compressor efficiencies and significantly different pressure drops for the different tests. For higher compressor speeds (i.e., lower volumetric capacity mixtures), the average fluid velocity in the system is higher. That causes higher pressure drops for the same operating condition. As a result, the compressor has to pump the refrigerant over a larger pressure difference: $i . e .$, for the same tests at constant capacity the cop decreases. The opposite scenario is true if mixtures with higher volumetric capacities are used.

It should be clear to the reader that neither a constant speed nor a constant capacity test will satisfy the restrictions used in the computer simulation and that it was not intended to be that way. By choosing either test criterion, the comparability of the actual test results is limited. This is the case, since in both tests the pressure drop in the heat exchangers changes with the changing working fluids due to compressor speed variations and/or refrigerant density variations. For the constant speed test, a change in capacity (i.e., in the heat exchanger effective temperature difference and/or in the heat transfer coefficient) further misrepresents the performance changes in the refrigeration system due to the different working fluids. However, if the test data are corrected with respect to changes in compressor efficiency and system pressure drops, the comparability can be regained. Since the simulation does not account for transport properties and the test apparatus is not redesigned for each mixture, such differences have to be expected. This constitutes the difficulty with the chosen approach, since the differences of the theoretical input data and the actually measured data are the reason for a substantial deviation in the performance of the considered refrigerant mixtures. This is specifically true for the pressure drops in the heat exchangers which are assumed to be constant for the simulation runs. However, knowing those limitations, the results are still very powerful and provide the basis for the conclusions drawn in this analysis. 


\section{Conclusions}

This study shows that the two zeotropic refrigerant mixtures, R32/R134a and R32/R152a, may be considered as replacements for R22 if the appropriate mixture compositions are chosen. Data indicate that multiple tradeoffs exist in mixture performance for different system compressor speed and mixture compositions.

If results for $\mathrm{R} 32 / \mathrm{R} 152 \mathrm{a}$ are compared at the same compressor speed and capacity at which the R22 results were obtained, the predicted improvements in COP are very close to the measured COP'S. These improvements over R22 range from 14 percent for the high temperature cooling mode to two percent for low temperature heating mode. operating pressures and temperatures of this mixture are well within acceptable limits. The Global Warming Potential of the tested mixture is about one-fourth the value of R22. However, this zeotropic mixture is flammable in the whole composition range.

The other mixture, R32/R134a, is not predicted to perform as well as the R32/R152a mixture. However, the test results indicate, that for mixtures containing more than 35 mass percent of $R 32$, the performance is very similar to that of the R32/R152a mixture. In the heating mode, slightly higher cop's were obtained and in the cooling mode, slightly lower cop's were measured (compared to the R32/R152a mixture at the same R32 mass fractions). The performance improvement over that of $\mathrm{R} 22$ at the speed and capacity equivalent to the R22 tests ranges from five percent in the high temperature mode to two percent in the low temperature heating mode. Since R134a is not flammable, the R32/R134a mixture exists in a certain range as a non-flammable mixture. Flammability tests will be conducted to determine this range. The test results for the R32/R134a mixture show no problems with respect to extreme pressures or temperatures in the tested composition range.

The achieved COP increases for both mixtures offer enough potential that even cross flow heat exchange systems (as currently used in household heat pumps) should benefit from the usage of these mixtures. This is espacially true for the R32/R134a mixture considering the use of a LLHX.

It should be stated that the test results of the mixtures were compared with those of R22 at the same heating/cooling capacity. The test results for the different working fluids were achieved with the same test apparatus, meaning there is no optimization with respect to system pressure drops, compressor efficiency, etc. 


\section{Further Research}

As reported in this study, both refrigerant mixtures are composed of at least one flammable component. For the R32/R134a mixture it seems to be a logical step to find the flammability region. Those results will provide the information up to which R32 content the mixture is nonflammable. If this range includes the $35 \%$-mass or even 40 \%-mass R32 composition, then this mixture has all the features needed for a wide acceptance.

In this report the approach of:

$$
\frac{\dot{Q}}{U * A_{\text {total }}}=\Delta T_{\text {eff }}=\text { const } \text {. }
$$

is chosen (see section 7.4 for more information on the test criterion). In the tests, this is not accomplished in a strict sense since only $\dot{Q}^{1}$ and $A_{\text {lotal }}$ are kept constant. The need to define test conditions for such studies more closely and to describe a way of interpreting test data is apparent in this study and deserves a closer look in future work.

The changes in compressor speed with changing mixture compositions affect the performance of different refrigerant mixtures due to changing pressure drops in the heat exchangers and due to changing compressor efficiencies. These effects should be extracted from the results in further examination of the test data in order to get a result based on the performance of the different working fluids and not on their performance in a certain system.

\footnotetext{
$1 \mathrm{U}$ : heat transfer coefficient $\left(\mathrm{W} /\left(\mathrm{m}^{2} \star \mathrm{K}\right)\right)$

$A_{\text {loal }}$ : total heat transfer area $\left(\mathrm{m}^{2}\right)$

$\dot{Q}:$ capacity $(W)$

$\Delta T_{\text {cff }}$ : effective mean temperature difference in the heat exchanger
} 


\section{References}

[1] Domanski P.A., and McLinden M.O., A Simplified Cycle simulation Model for the Performance Rating of Refrigerants and Refrigerant Mixtures, ASHRAE Purdue CFC Conference, 1990, July $17-20$

[2] Morrison, G., and McLinden, M.O., Application of a Hard Sphere Equation of state to Refrigerants and Refrigerant Mixtures, Nat. Bur. Stand. (U.S.) Tech. Note 1226, 1986141 p.

[3] ASHRAE STANDARD ANSI/ASHRAE 116-1983, American Society of Heating, Refrigerating and Air-Conditioning Engineers, Inc., pg. 17, 1983

[4] MCLinden M.O., Thermodynamic Properties of CFC Alternatives : A Survey of Available Data, International Journal of Refrigeration, Vol. 13, p.149-162, 1990 May

[5] ASHRAE Thermodynamic Properties of Refrigerants, American Society of Heating, Refrigerating and Air-conditioning Engineers, Inc., p. 170 and p. 191, 1969

[6] Hampson, R., Personal conversation, National Institute of standards and Technology, Gaithersburg, MD, 1991 April

[7] MCLinden M.O., and Didion D.A., CFC's - Quest for Alternative Refrigerants - A Molecular Approach, ASHRAE Journal, V.29, No.12, pp.32 - 42,1987 December

[8] Hoffman J.S., Replacing CFCs: The Search for Alternatives, AMBIO, Vol. 19, No.6-7, 1990 October

[9] Kurylo M.J., Atmospheric Characteristics of $\mathrm{HFC}-32\left(\mathrm{CH}_{2} \mathrm{~F}_{2}\right)$, Symposium to Evaluate $\mathrm{R}-32$ and $\mathrm{R}-32$ mixtures in Refrigeration Applications, EPA, 1991 March 19

[10] McLinden, Mark O., and Radermacher, R., Methods for Comparing the Performance of Pure and Mixed Refrigerants in the Vapor Compression Cycle, International Journal of Refrigeration, $V$. 10 , No. 6, pp. 318-325, 1987 November

[11] Doeblin, E. O., Measurement Systems, revised edition, McGrawHill, p. 38-68, New York, 1975 


\section{APPENDIX A}

\section{SIMULATION DATA}

The data presented in this appendix show simulation results obtained with the program CYCLE11. 


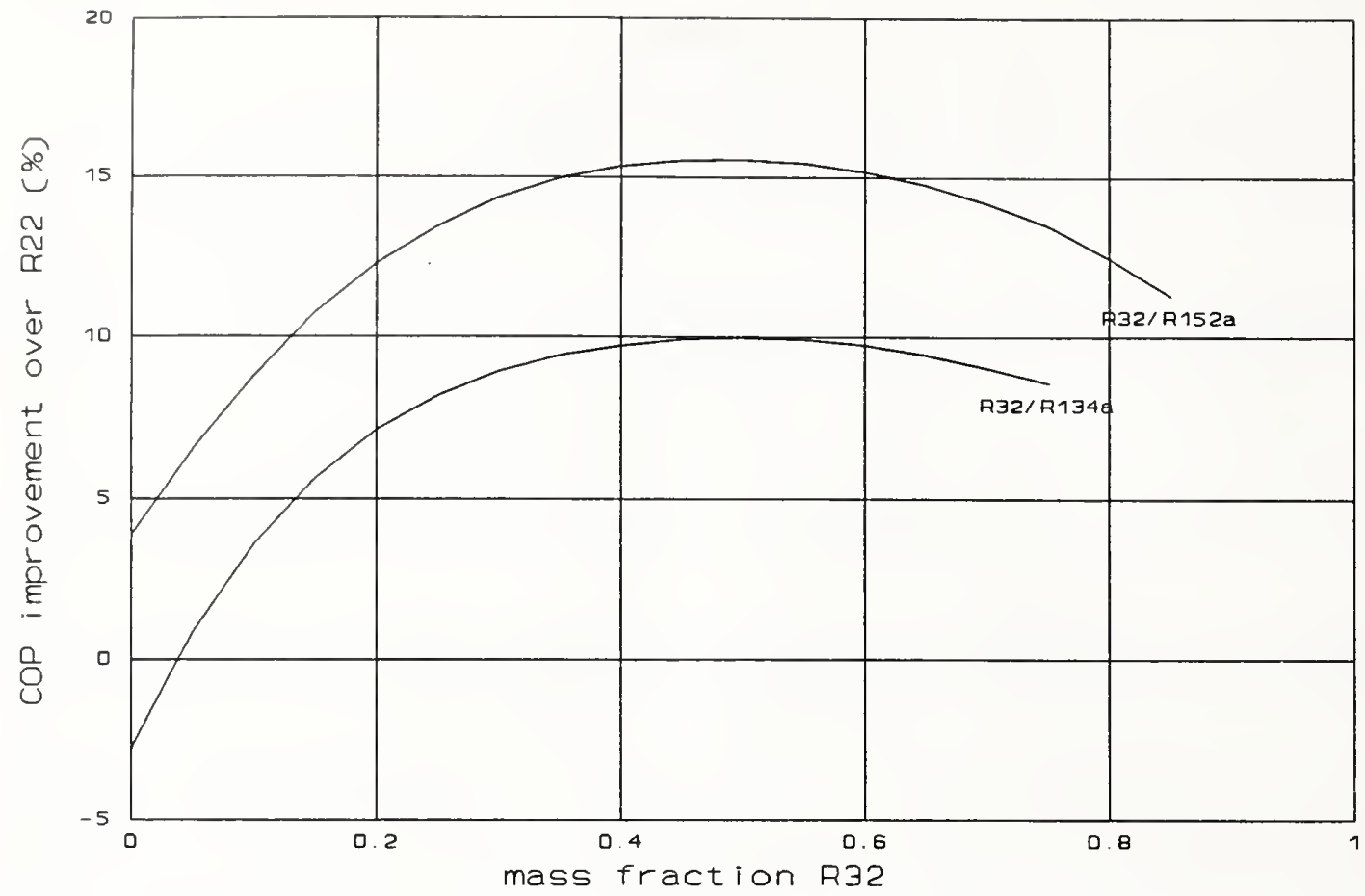

Fig. A1: Relative COP of R32/R134a \& R32/R152a vs. R32 content; high temperature cooling conditions

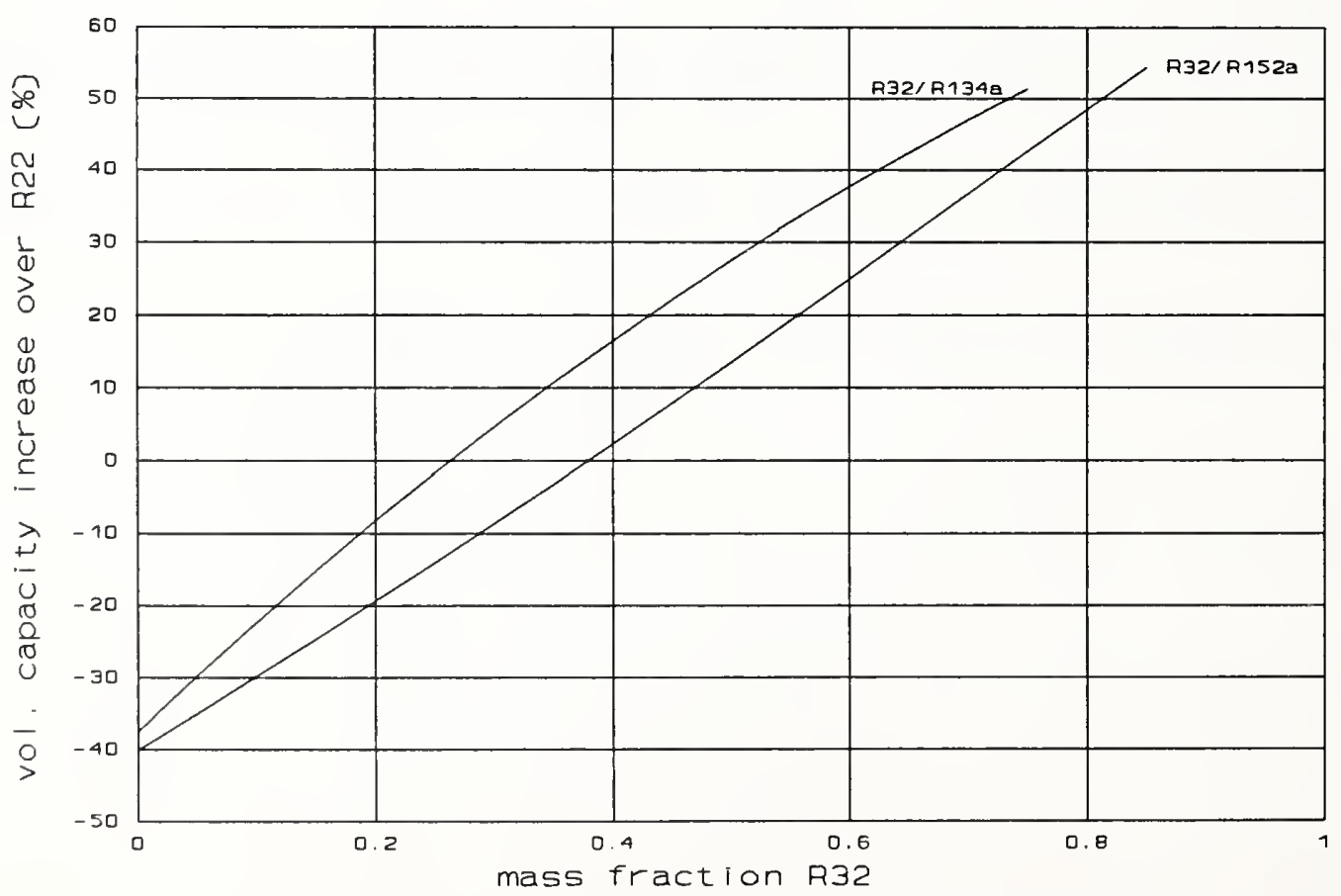

Fig. A2: Relative vol. capacity of R32/R134a \& R32/R152a vs. R32 content; high temperature cooling condition 


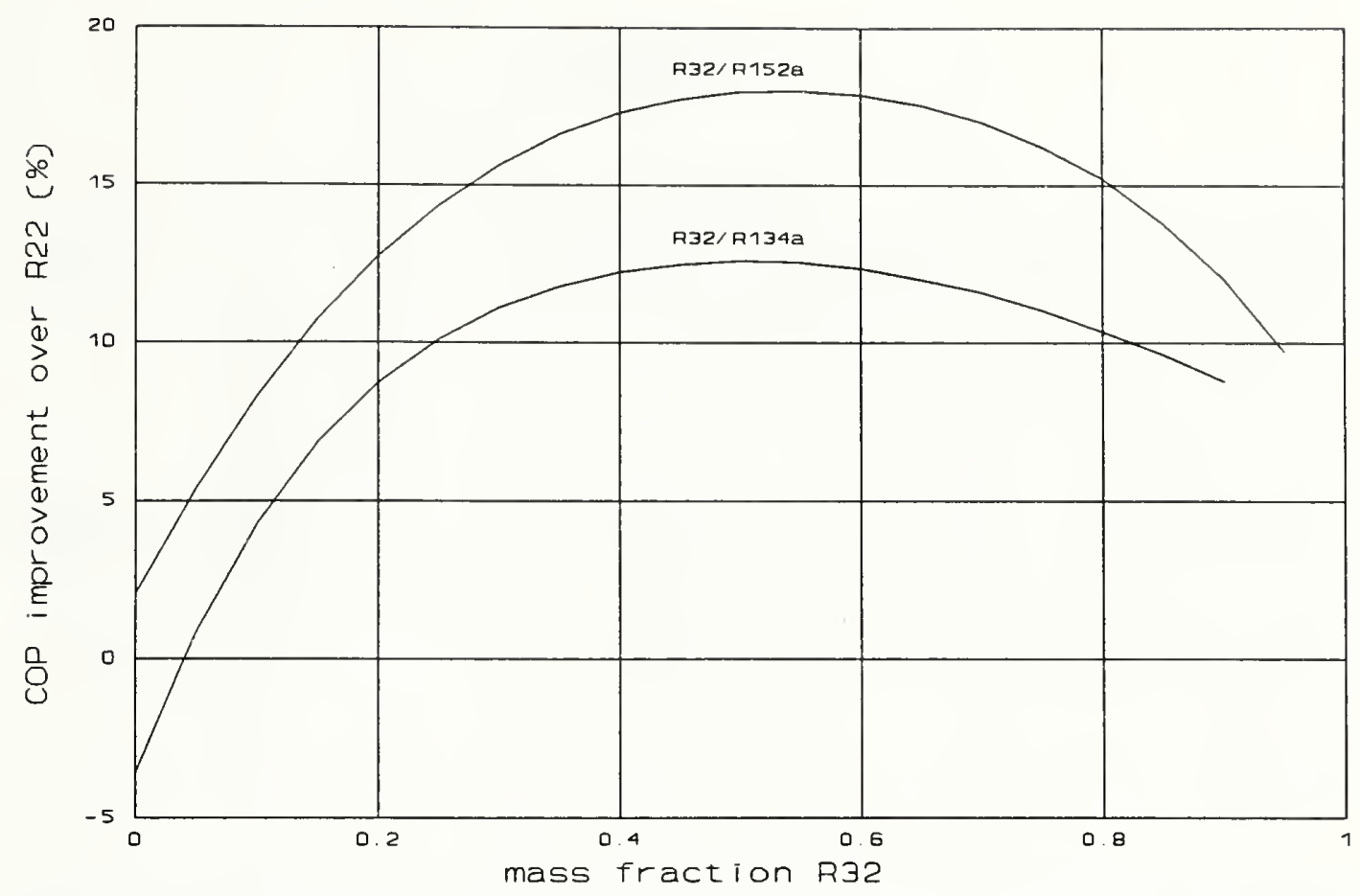

Fig. A3: Relative COP of R32/R134a \& R32/R152a vs. R32 content; low temperature cooling conditions

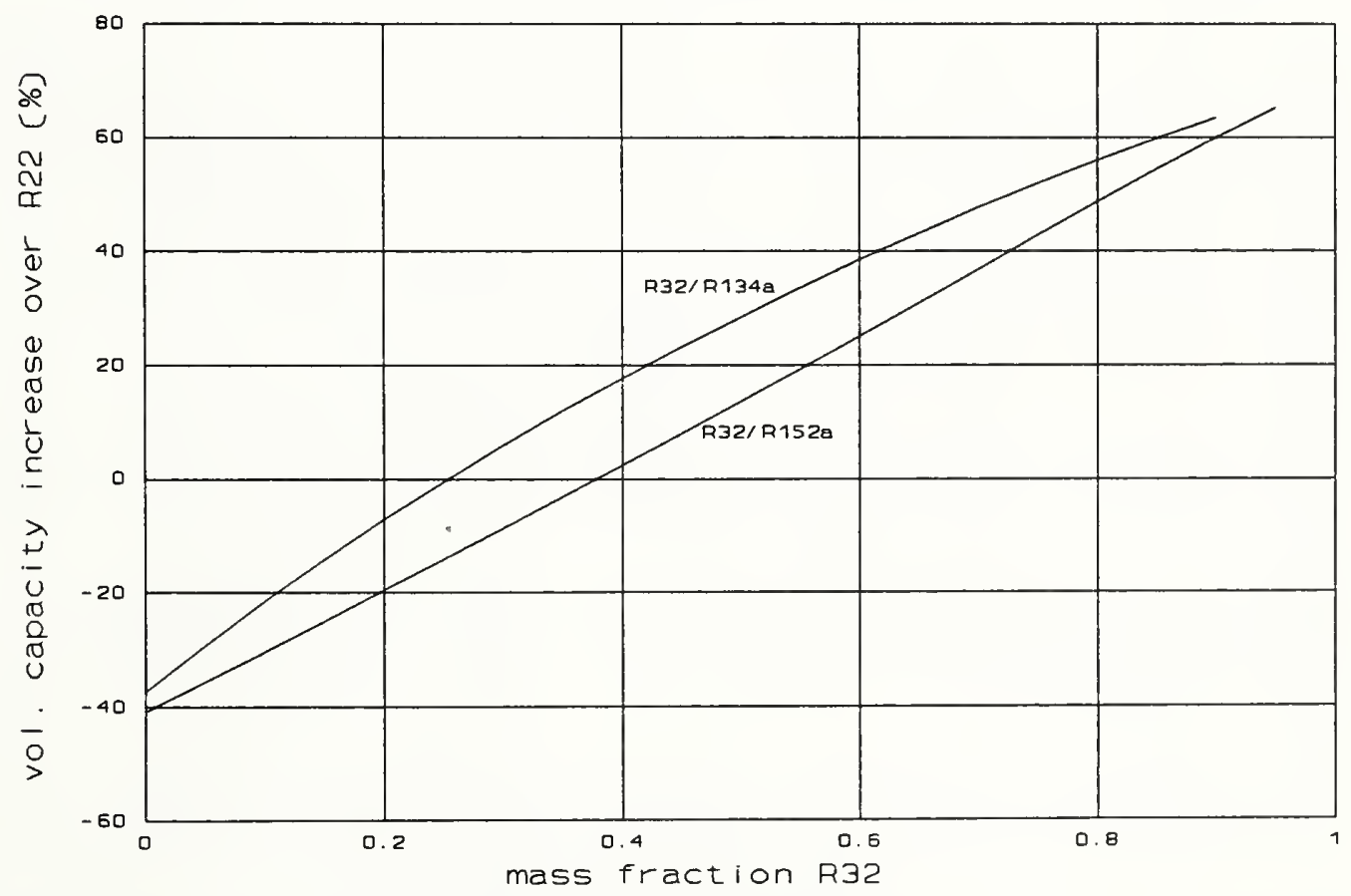

Fig. A4: Relative vol. capacity of R32/R134a \& R32/R152a vs. R32 content; low temperature cooling condition 


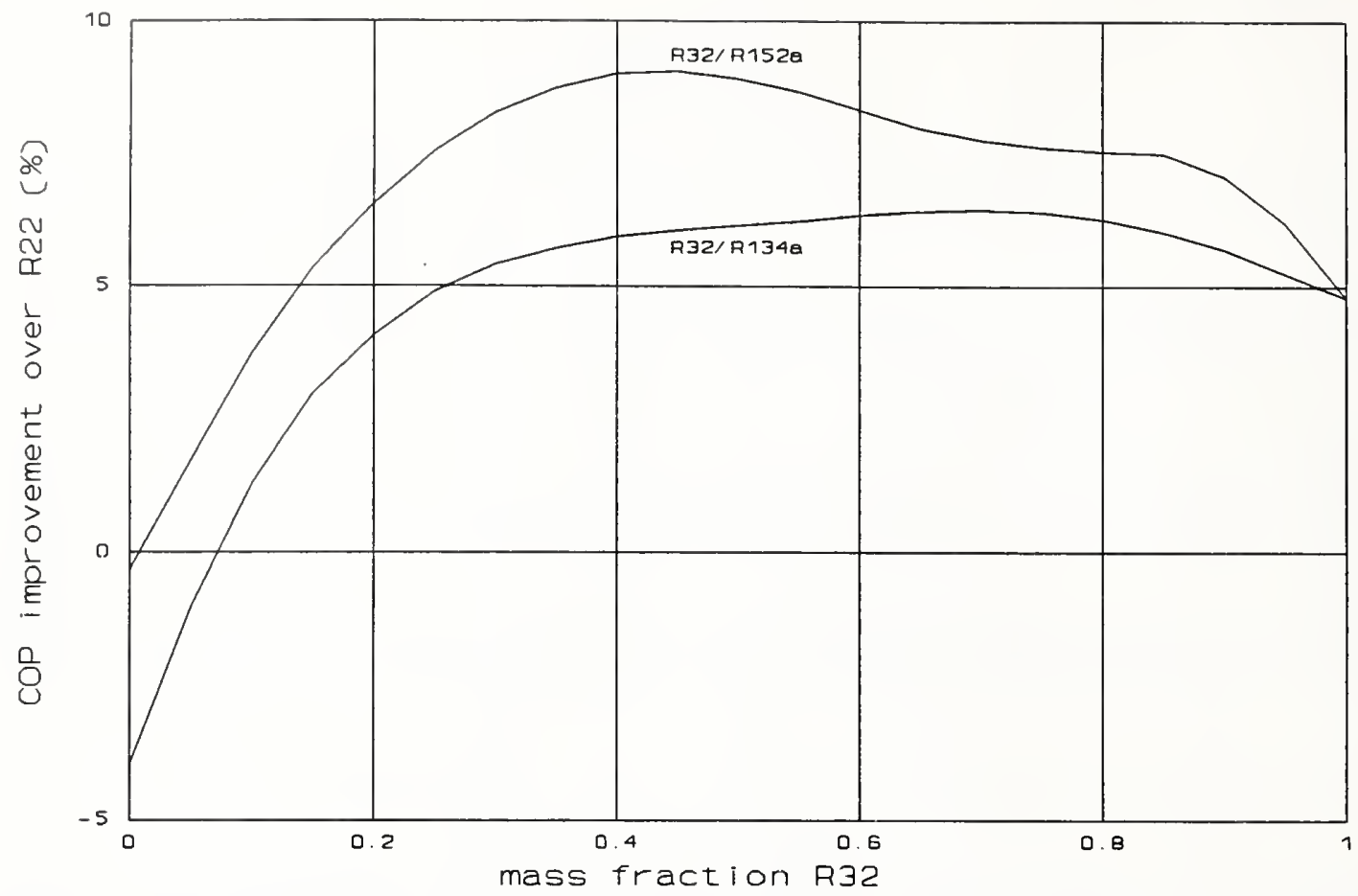

Fig. A5: Relative COP of R32/R134a \& R32/R152a vs. R32 content; high temperature heating conditions

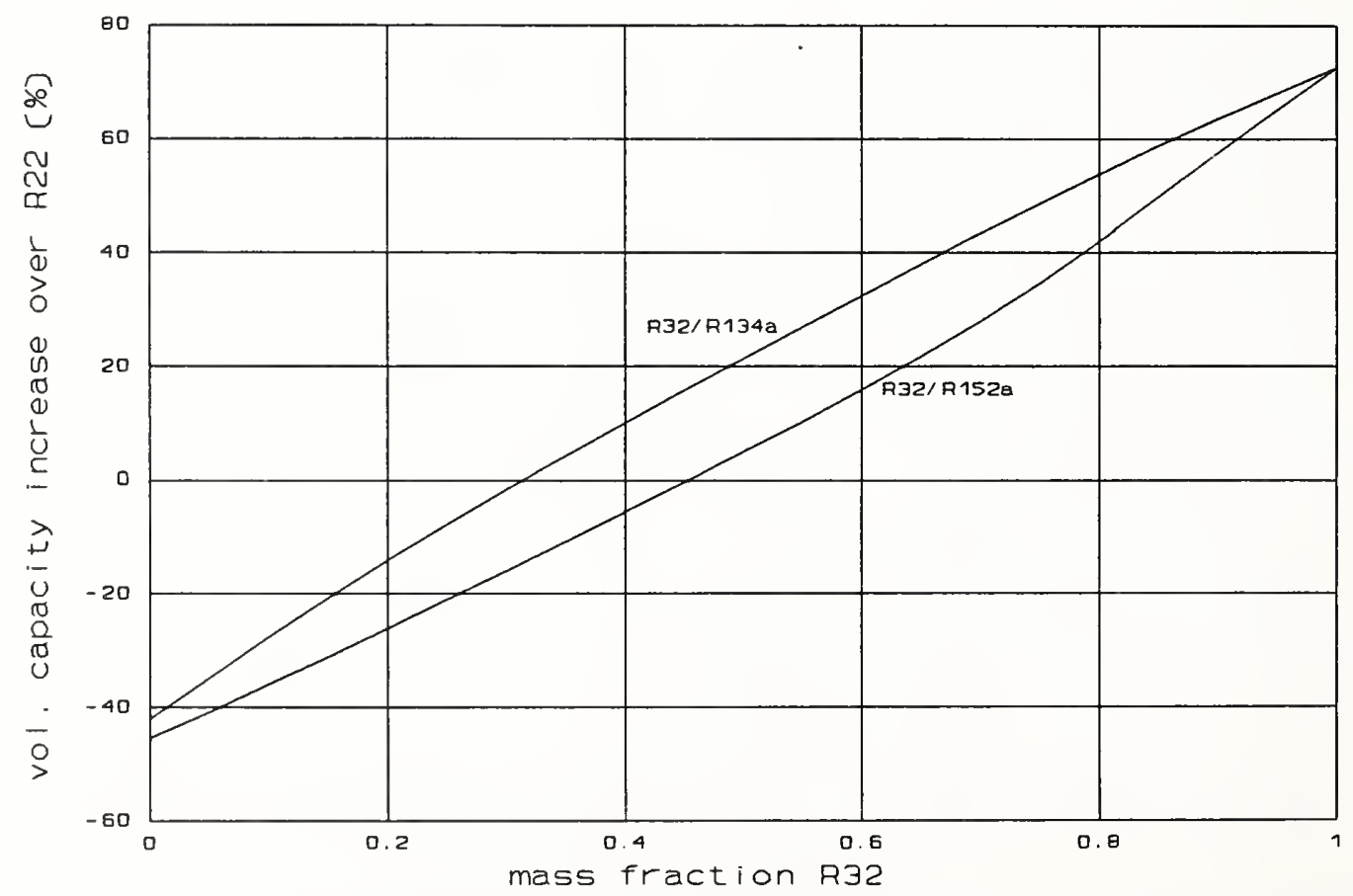

Fig. A6: Relative vol. capacity of R32/R134a \& R32/R152a vs. R32 content; high temperature heating condition 


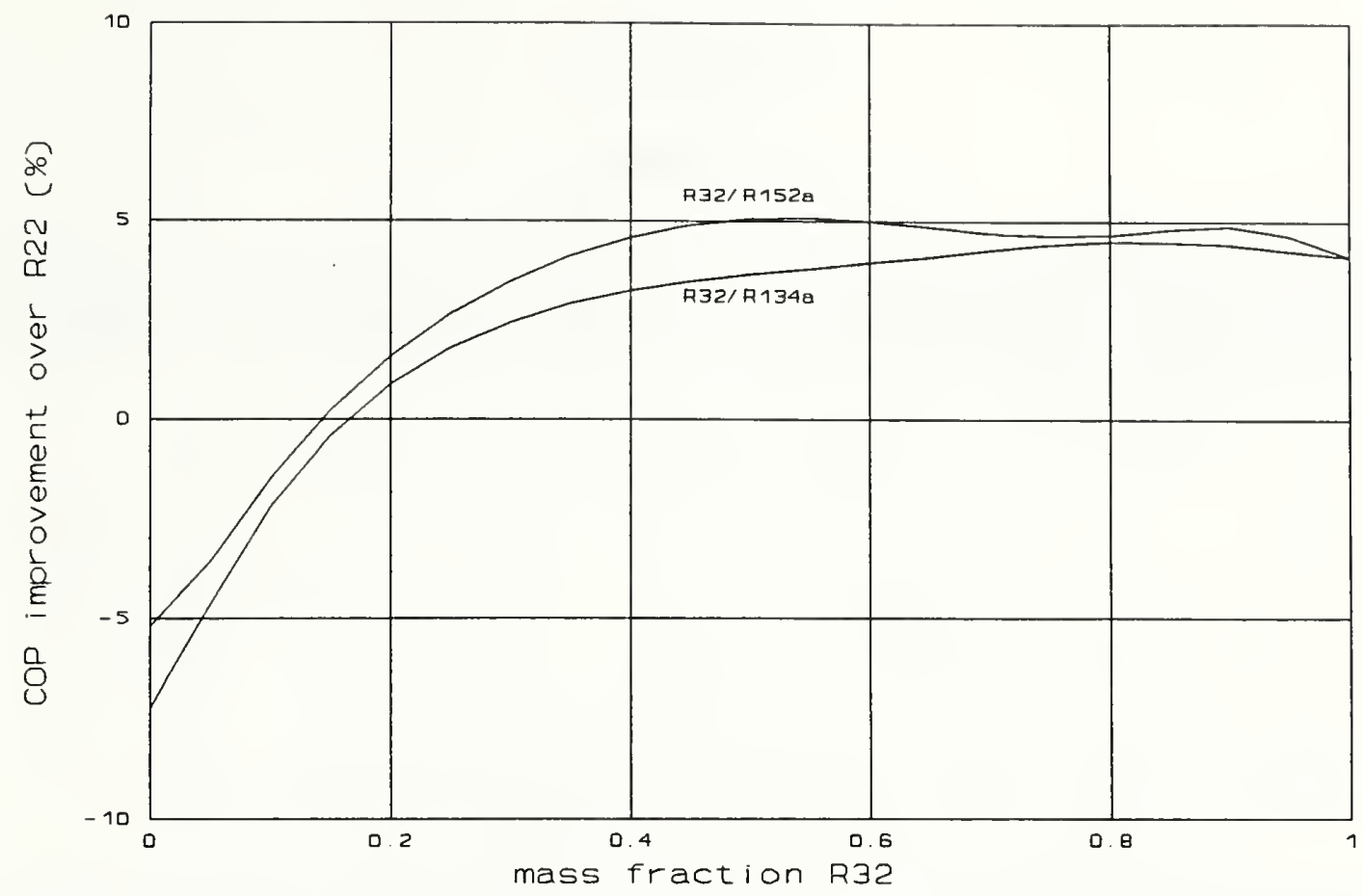

Fig. A7: Relative COP of R32/R134a \& R32/R152a vs. R32 content; low temperature heating conditions

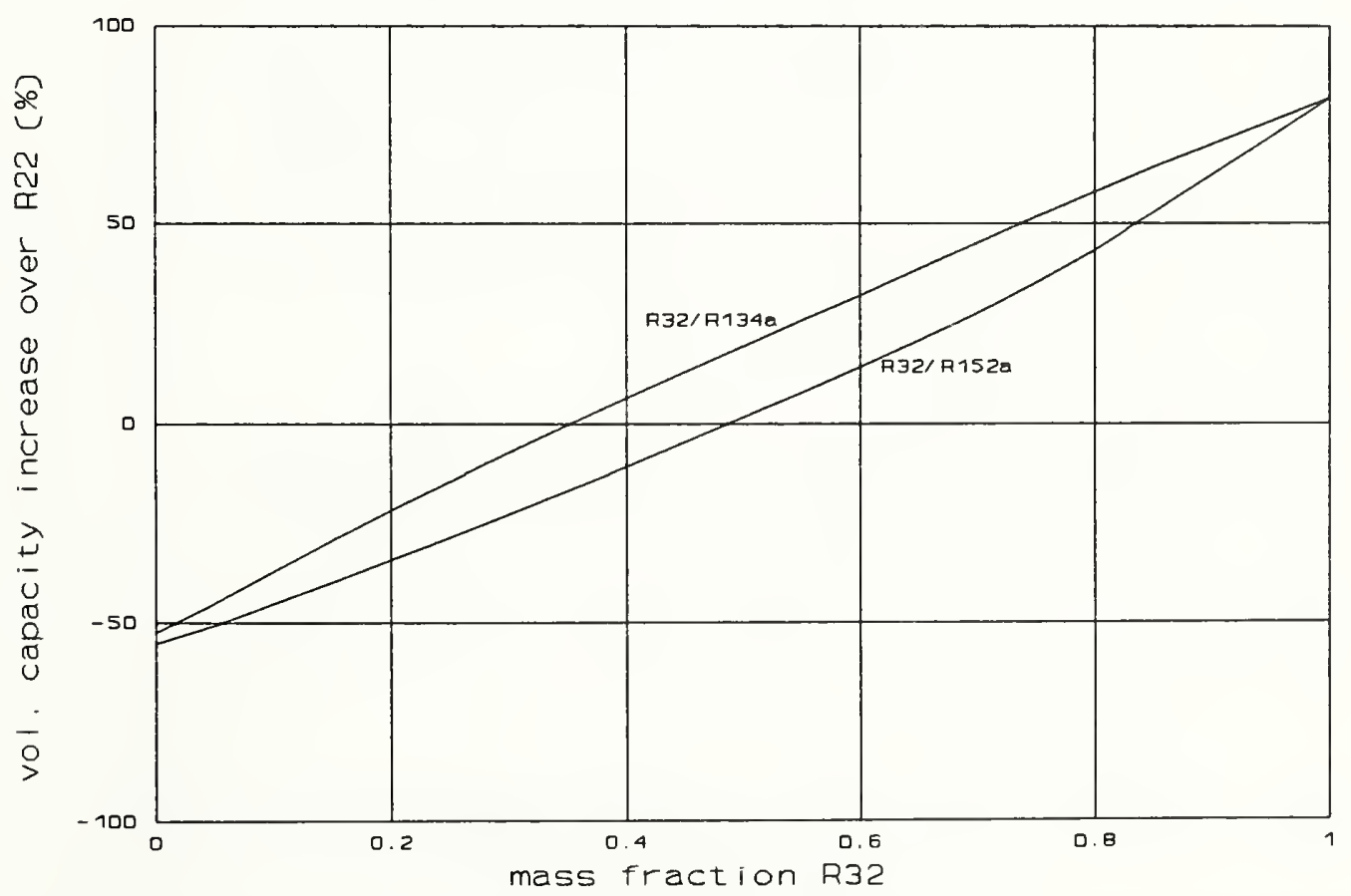

Fig. A8: Relative vol. capacity of R32/R134a \& R32/R152a vs. R32 content; low temperature heating condition 


\section{APPENDIX B}

\section{TEST DATA}

The data presented in appendix $\mathrm{B}$ is data obtained in test using the refrigerant mixtures $\mathrm{R} 32 / \mathrm{R} 134 \mathrm{a}$ and $\mathrm{R} 32 / \mathrm{R} 152 \mathrm{a}$ as well as the pure refrigerant R22. 


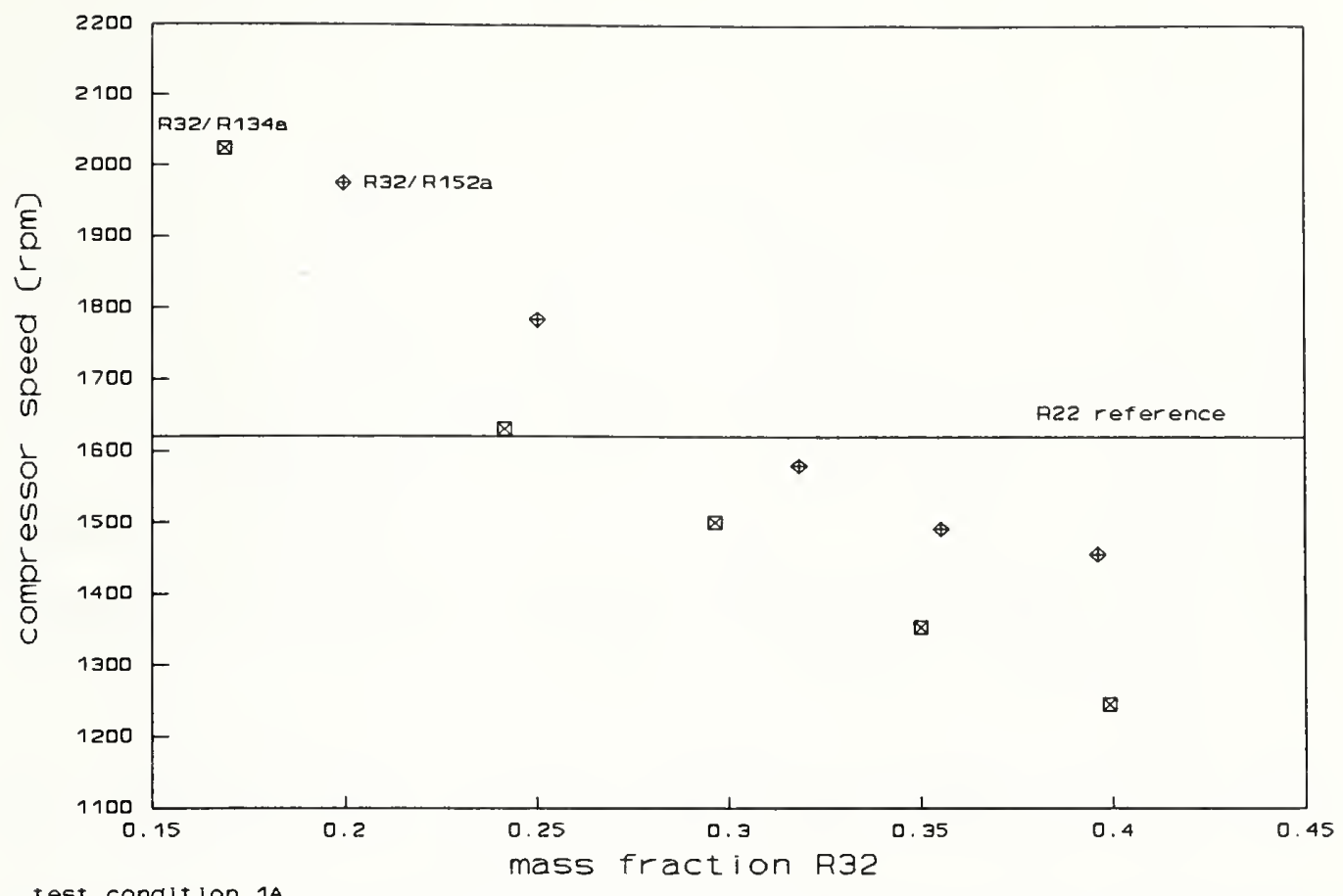

test condition 1A

Fig. B1.1: Compressor speed vs. R32 mass fraction; high temperature cooling condition (1A)

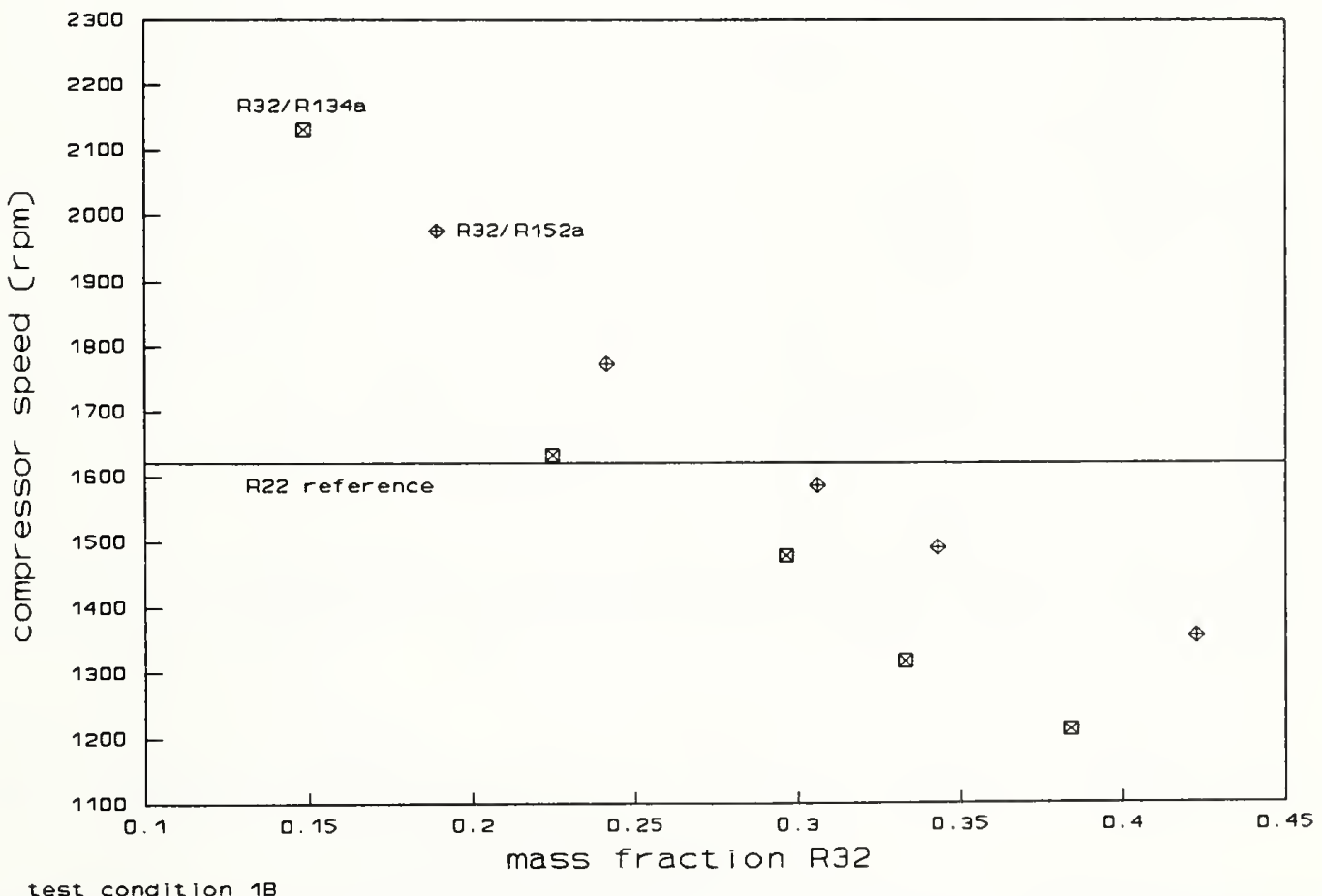

Fig. B1.2:

Compressor speed vs. R32 mass fraction; low temperature cooling condition (1B) 


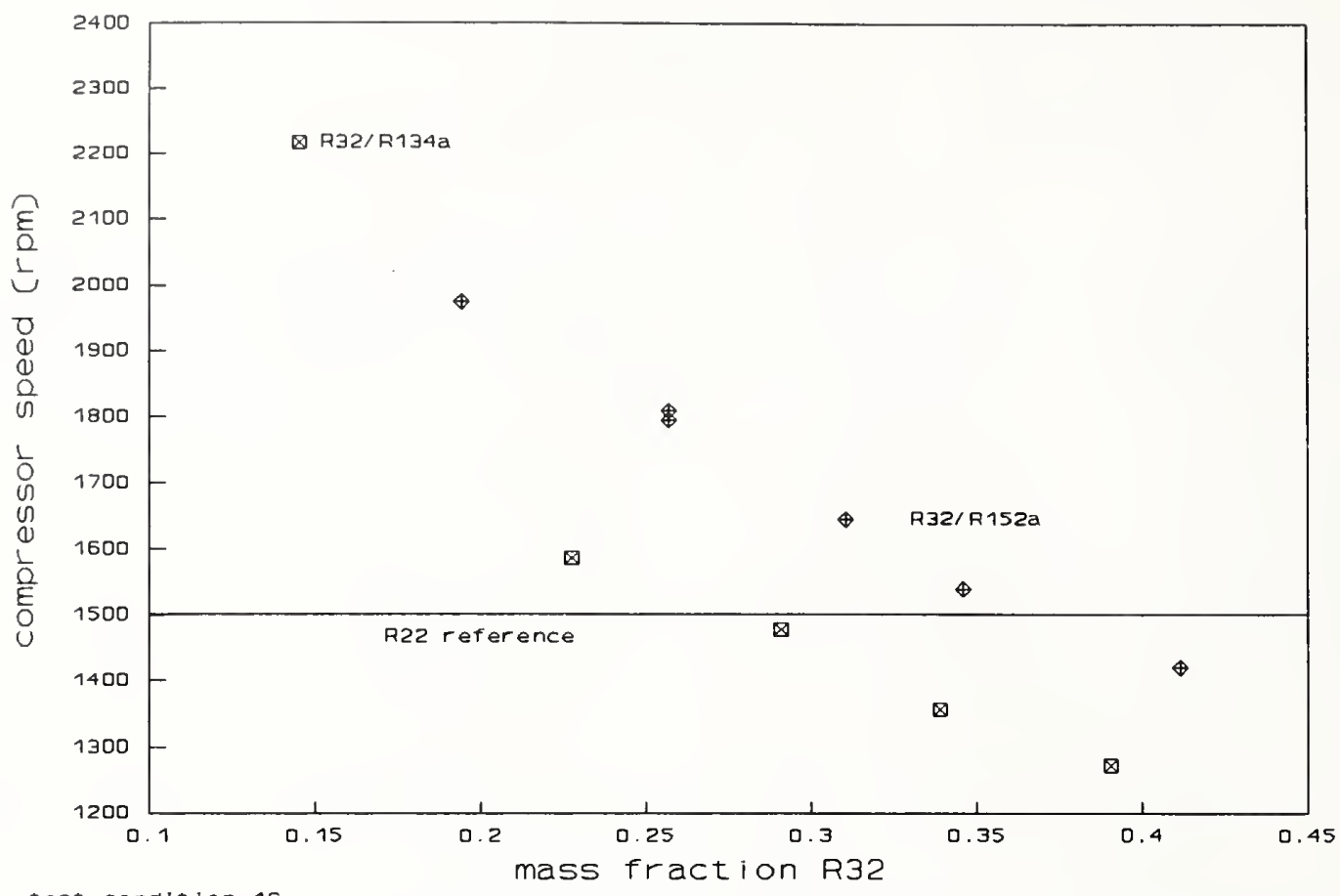

test condition $1 \mathrm{C}$

Fig. B1.3: Compressor speed vs. R32 mass fraction; high temperature heating condition (1C)

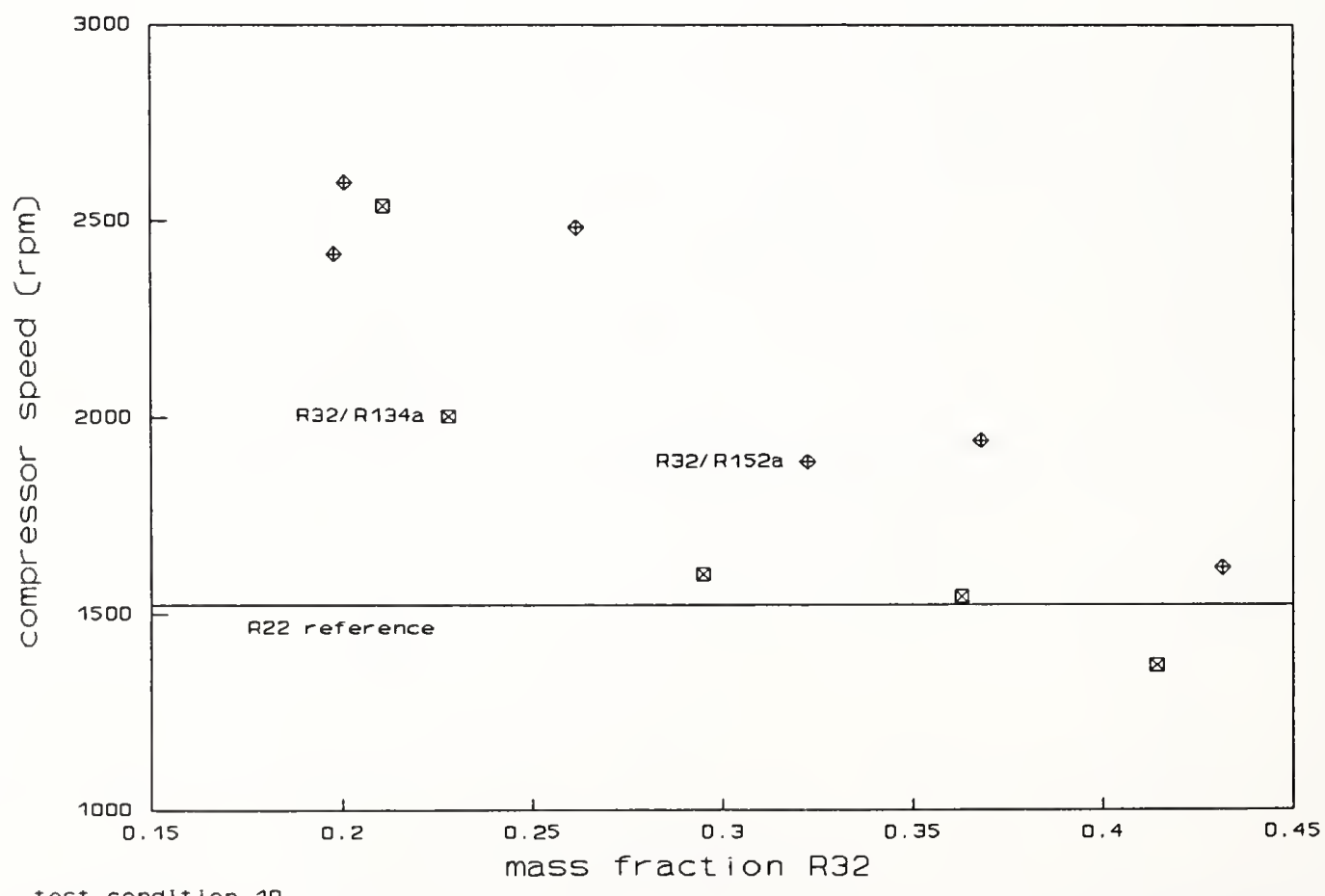

Fig. B1.4: Compressor speed vs. R32 mass fraction; low temperature heating condition (ID) 


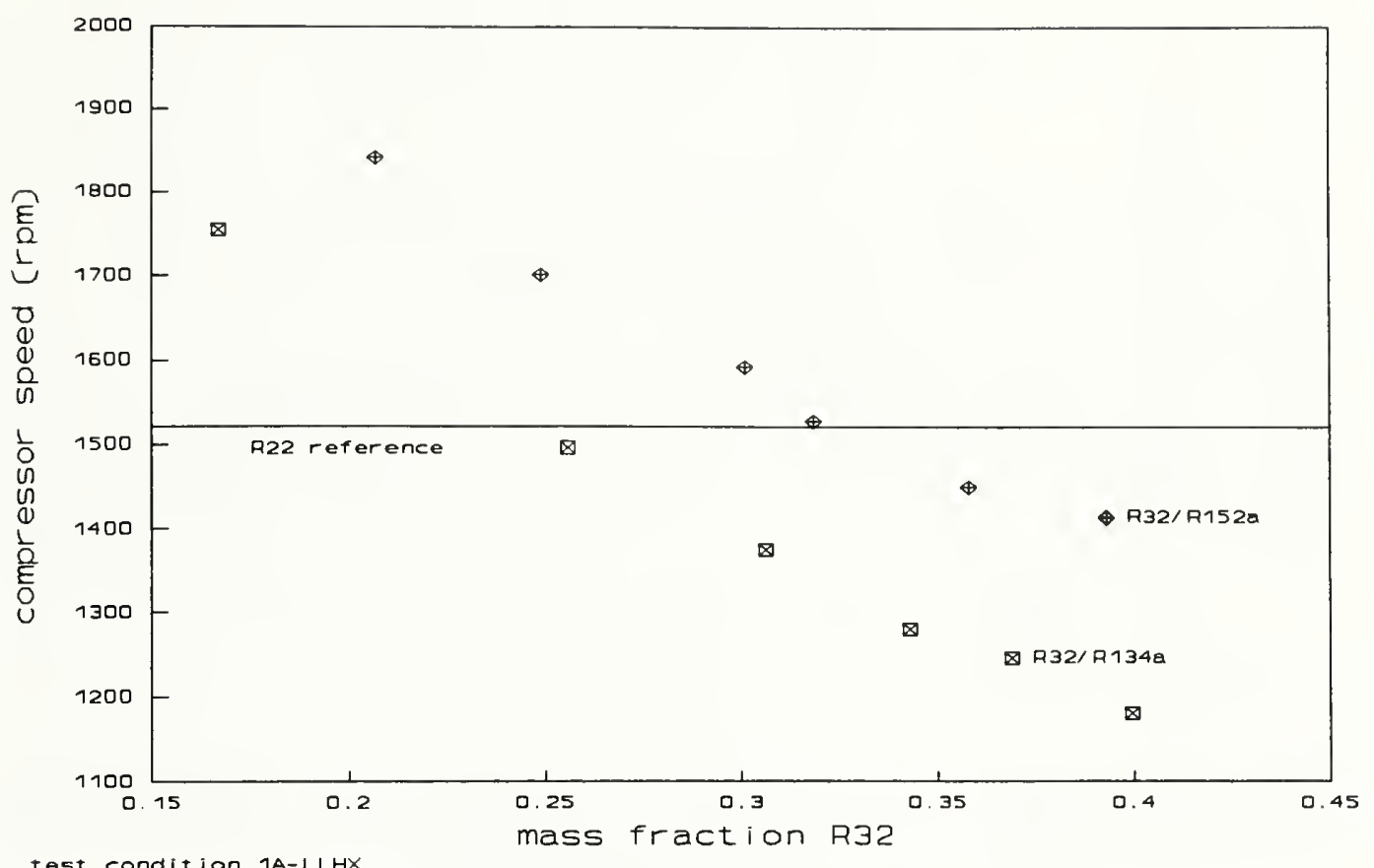

Fig. B1.5: Compressor speed vs. R32 mass fraction; high temperature cooling condition with LLHX (1A-LLHX)

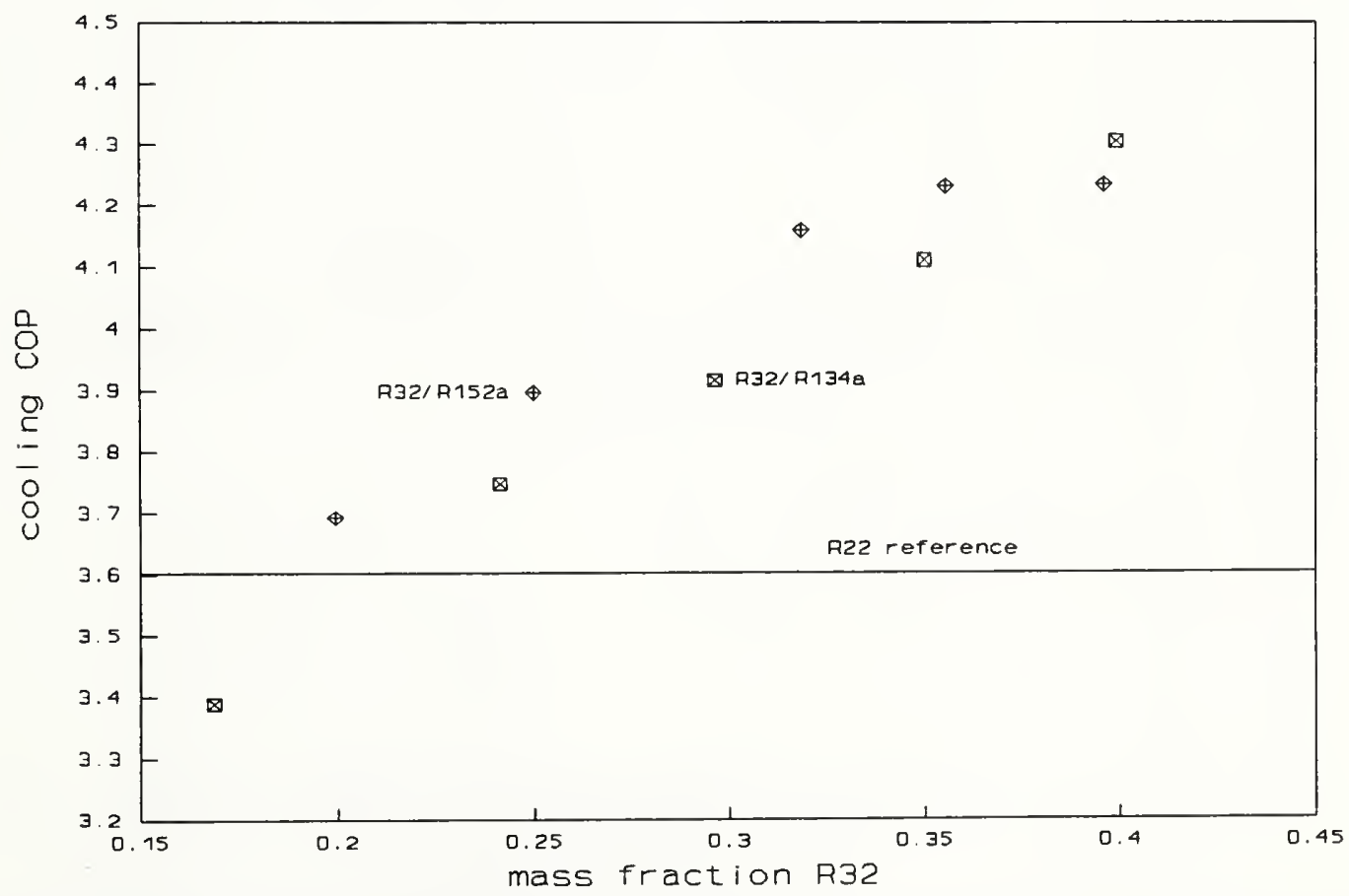

Fig. B2.1:

Cooling COP vs. R32 mass fraction; high temperature cooling condition (1A) 


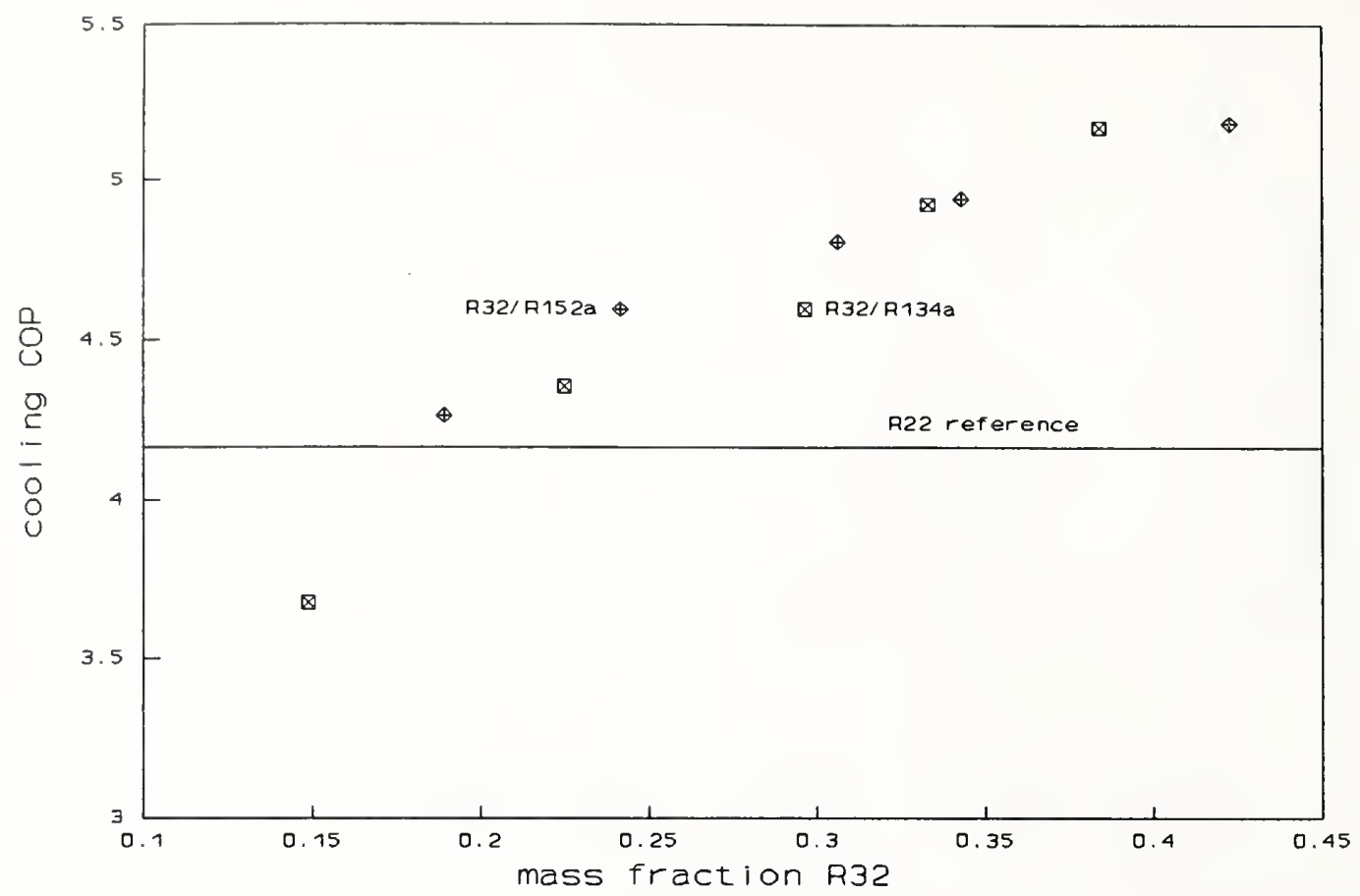

test condition 18

Fig. B2.2: Cooling COP vs. R32 mass fraction; low temperature cooling condition (1B)

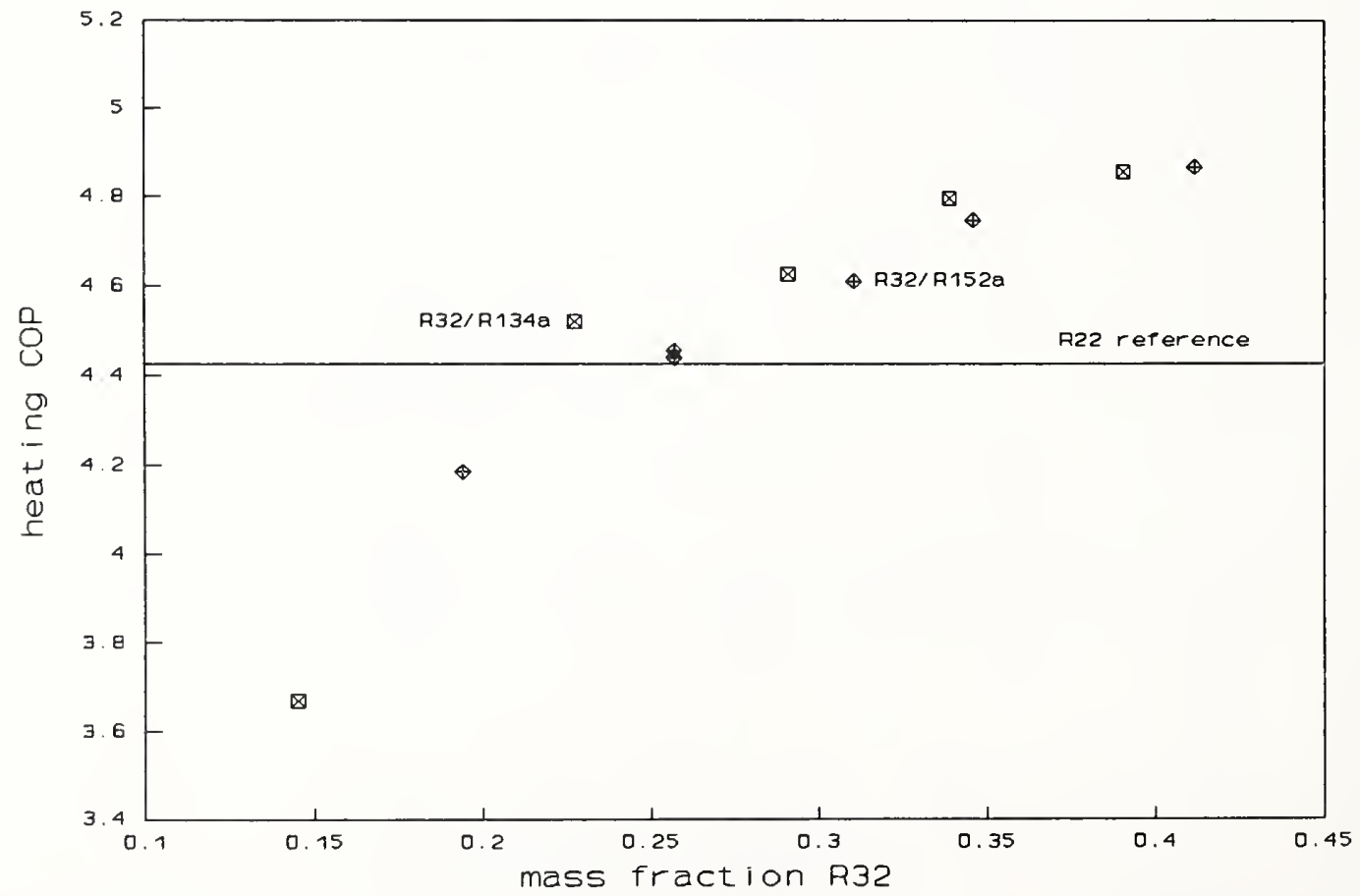

test condition $1 \mathrm{C}$

Fig. B2.3: Heating $C O P$ vs. R32 mass fraction; high temperature heating condition (1C) 


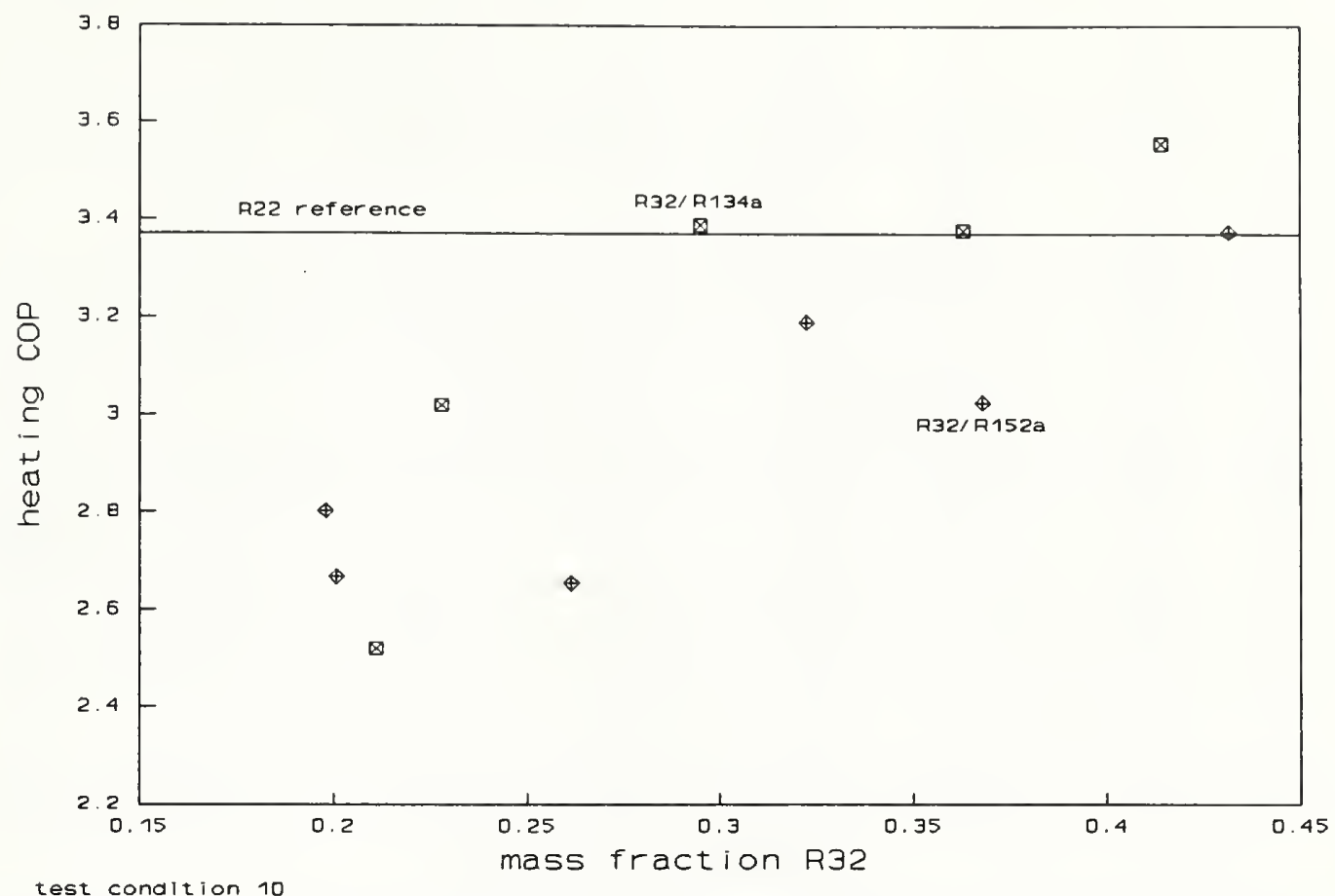

Fig. B2.4: Heating COP vs. R32 mass fraction; low temperature heating condition (1D)

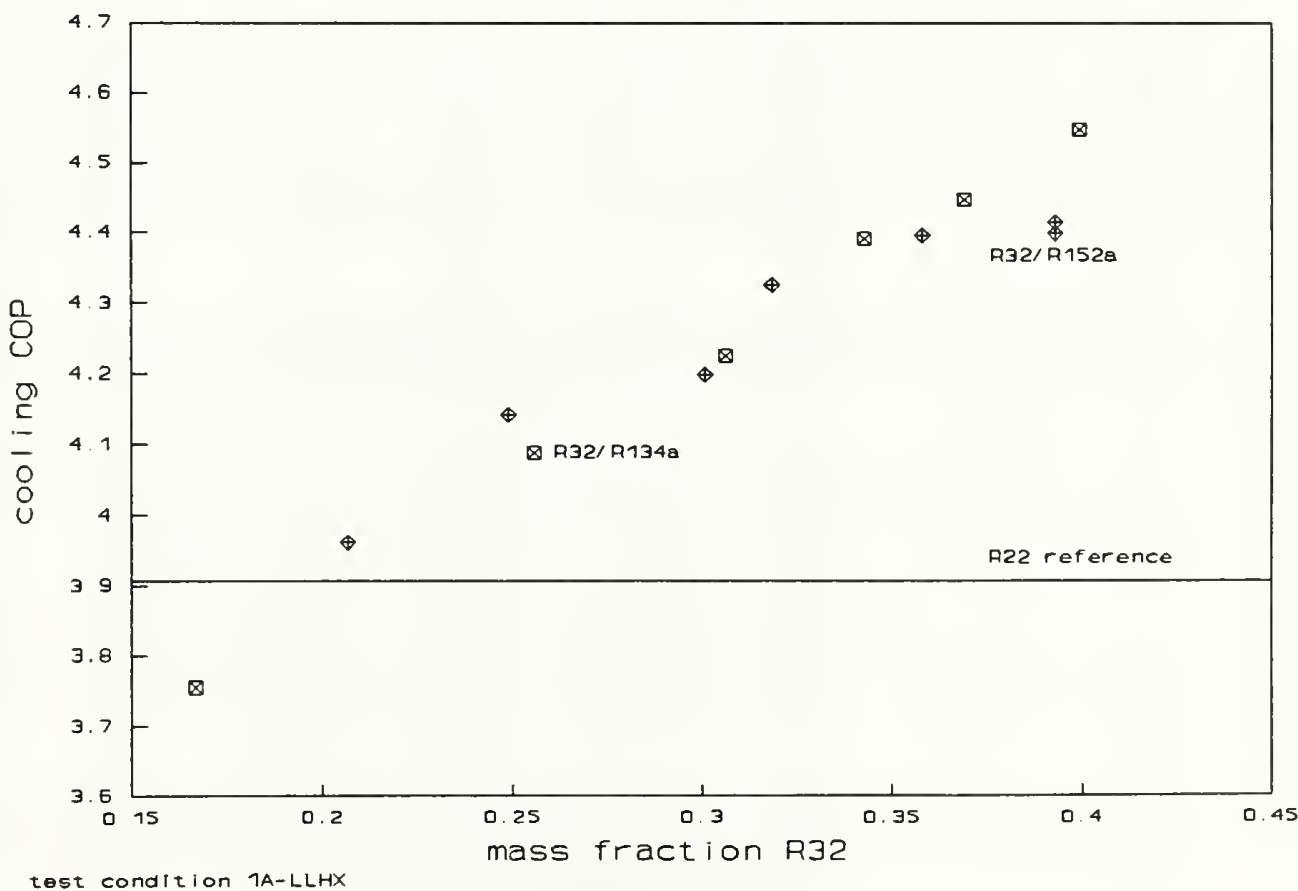

Fig. B2.5

Cooling COP vs. R32 mass fraction; high temperature cooling condition with LLHX $(1 A-L L H X)$ 


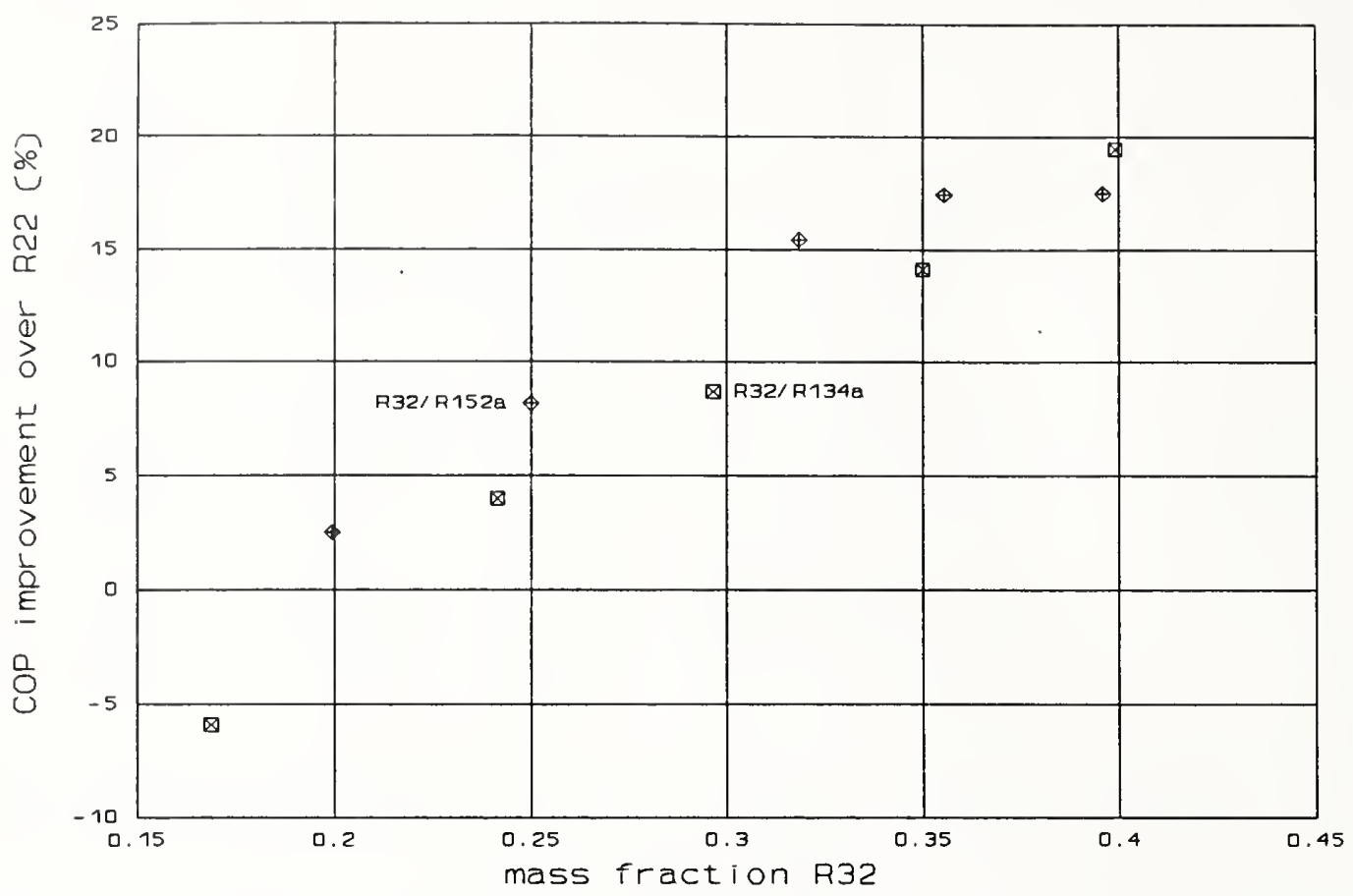

test condition TA

Fig. B3.1: Relative cooling COP vs. R32 mass fraction; high temperature cooling condition (1A)

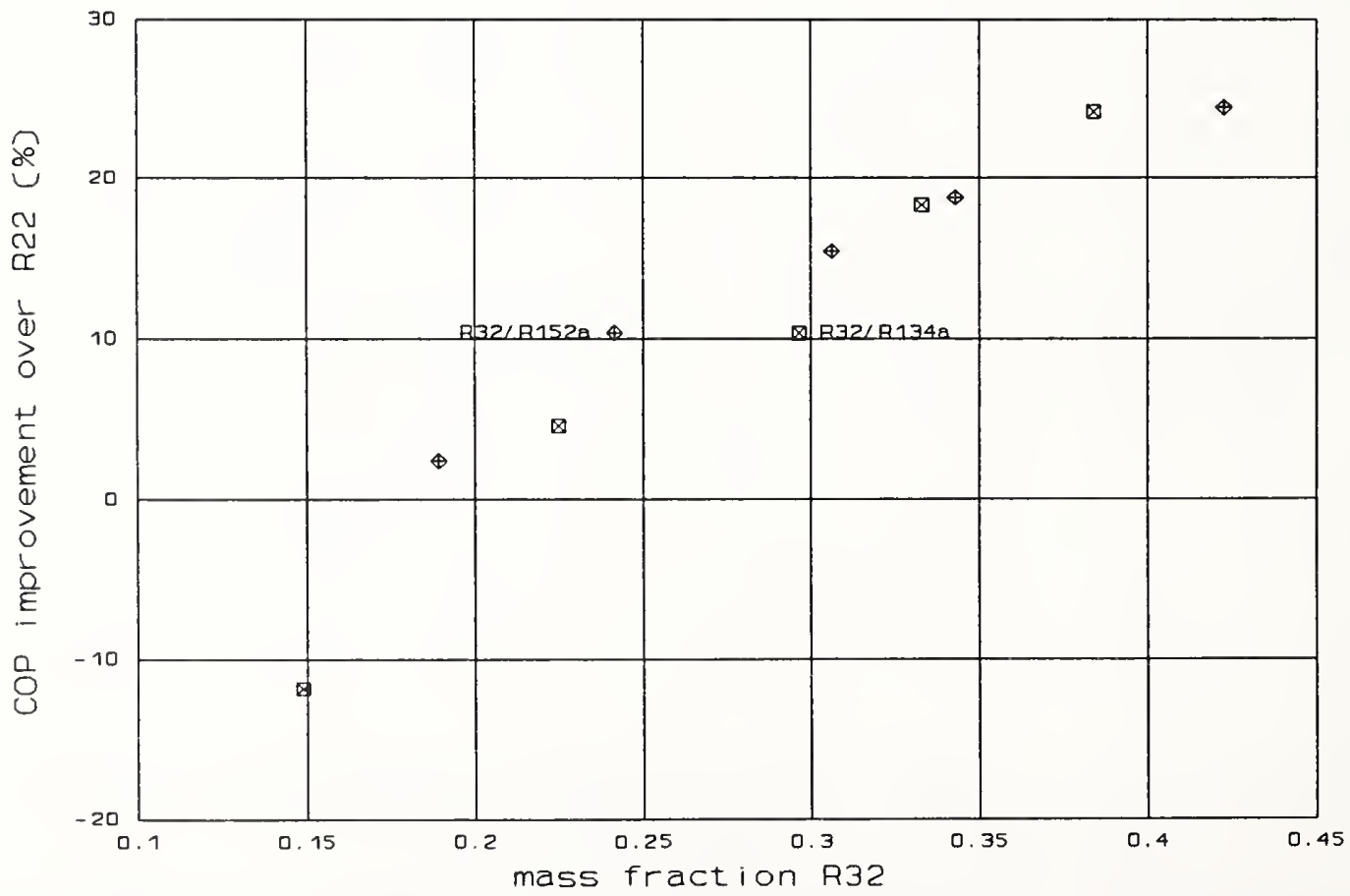

test condition 18

Fig. B3.2: Relative cooling COP vs. R32 mass fraction; low temperature cooling condition (1B) 


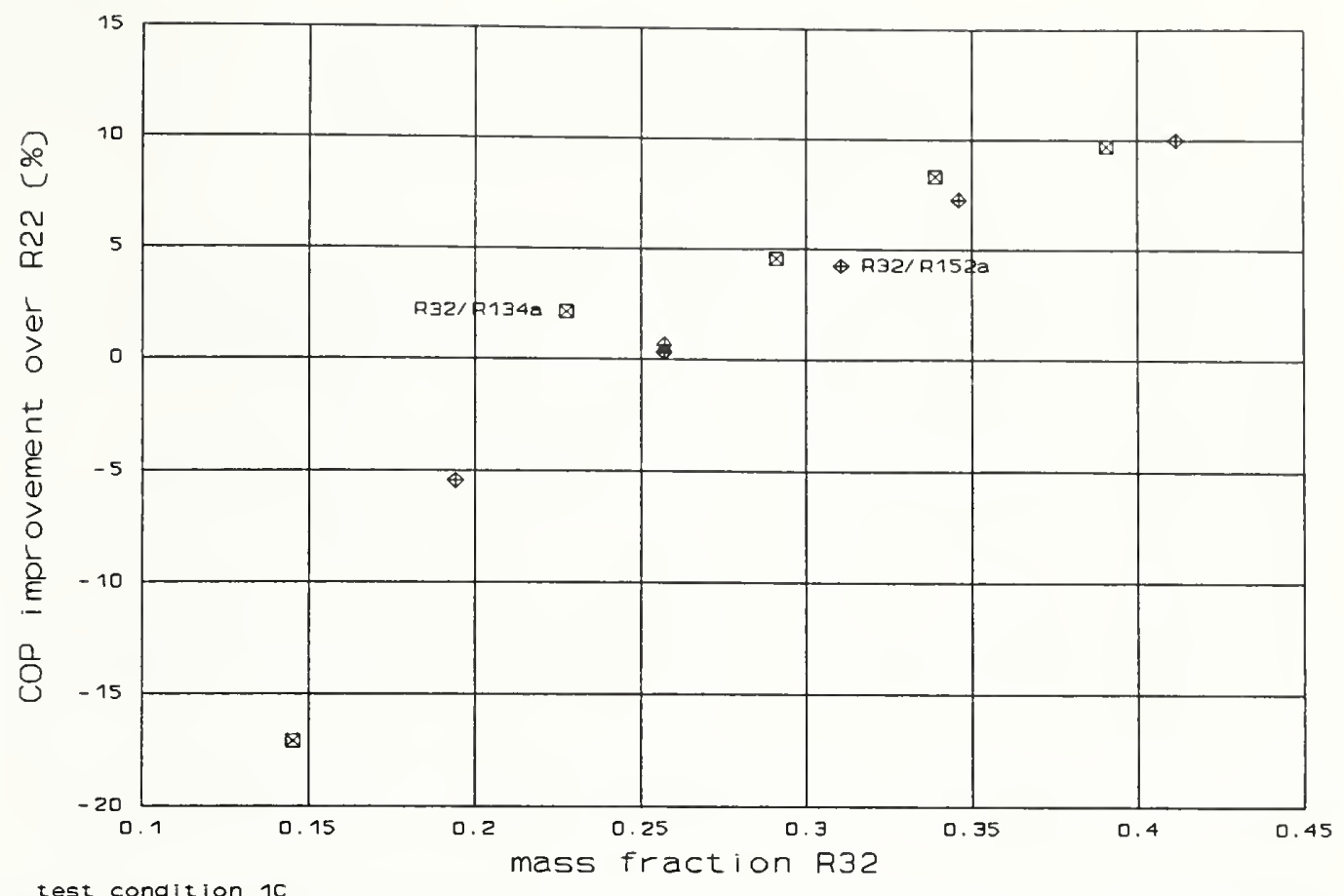

Fig. B3.3:

Relative heating COP vs. R32 mass fraction; high temperature heating condition (1C)

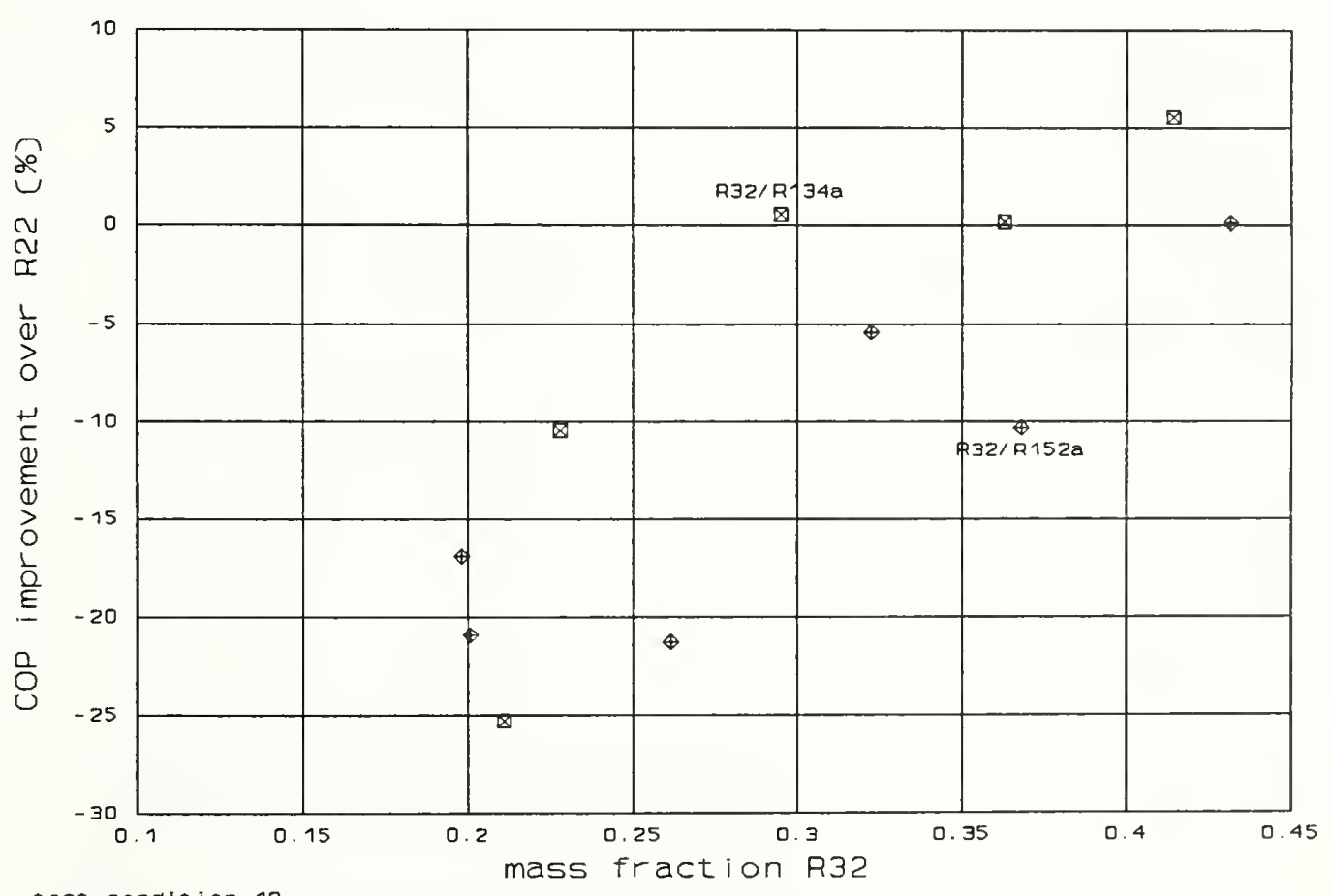

test condition 10

Fig. B3.4: Relative heating COP vs. R32 mass fraction; low temperature heating condition (1D) 


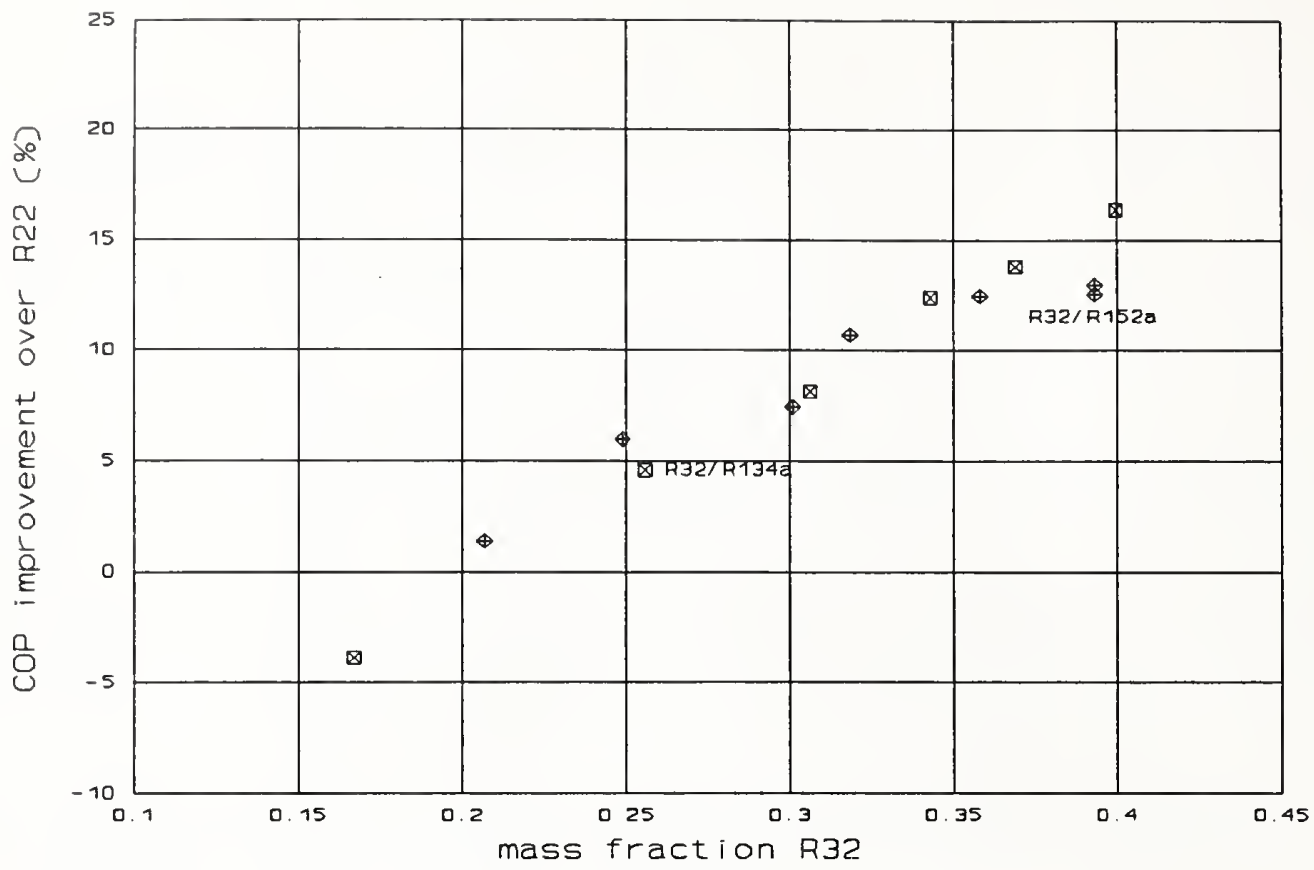

test condition 1A-LLHX

Fig. B3.5: Relative cooling COP vs. R32 mass fraction; high temperature cooling condition with LLHX (1A-LLHX)

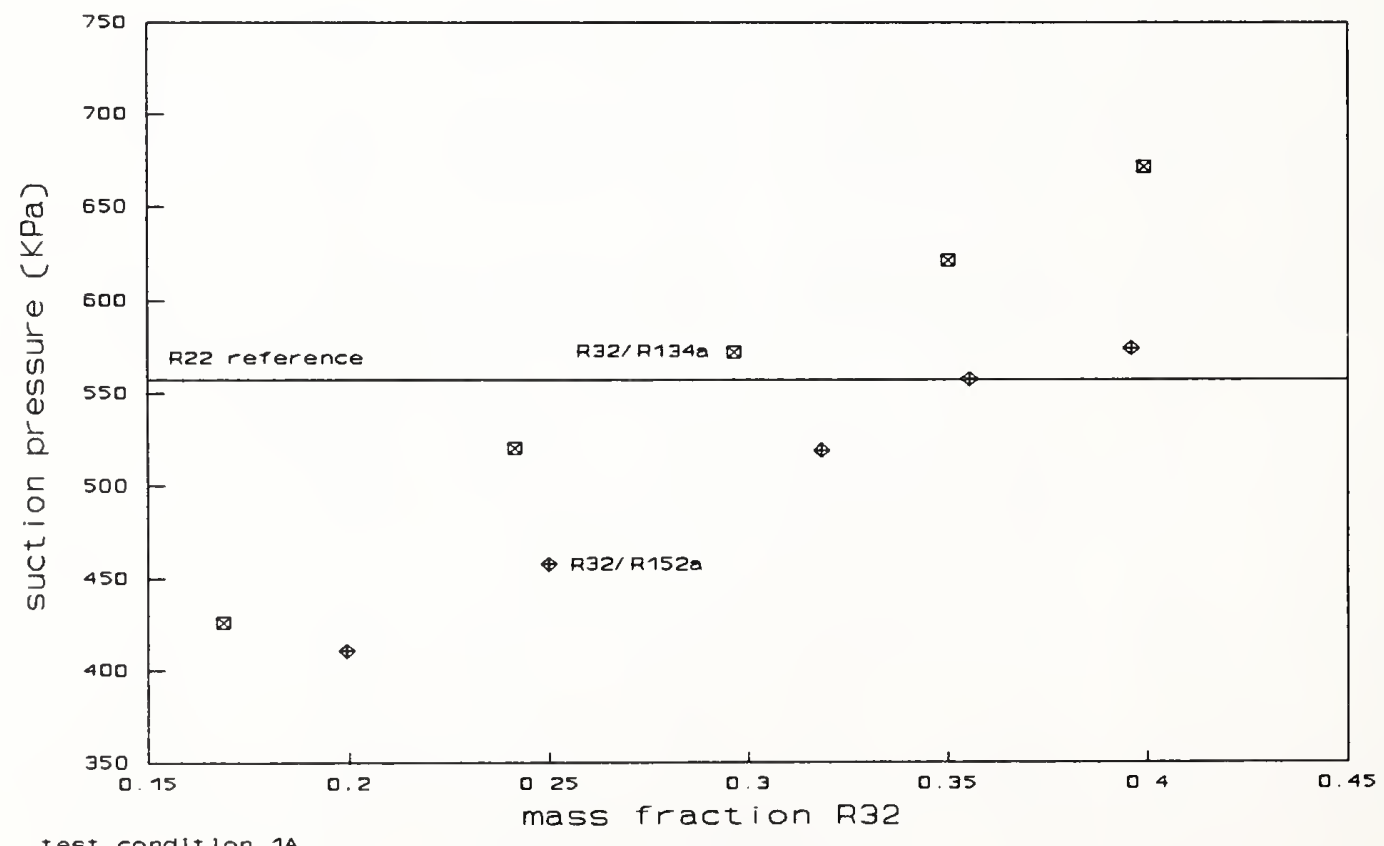

Fig. B4.1:

Suction pressure vs. R32 mass fraction; high temperature cooling condition (1A) 


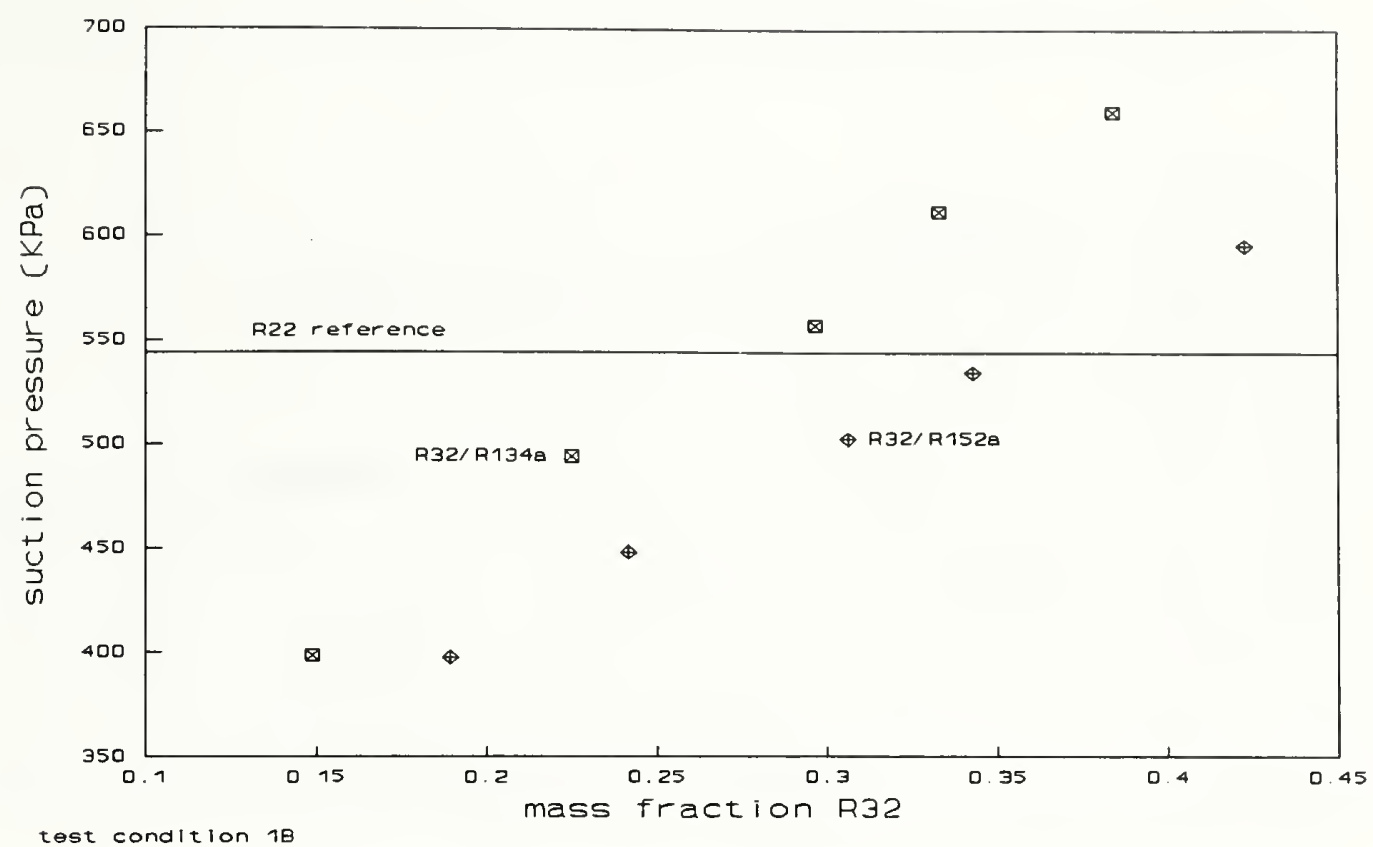

Fig. B4.2: Suction pressure vs. R32 mass fraction; low temperature cooling condition (1B)

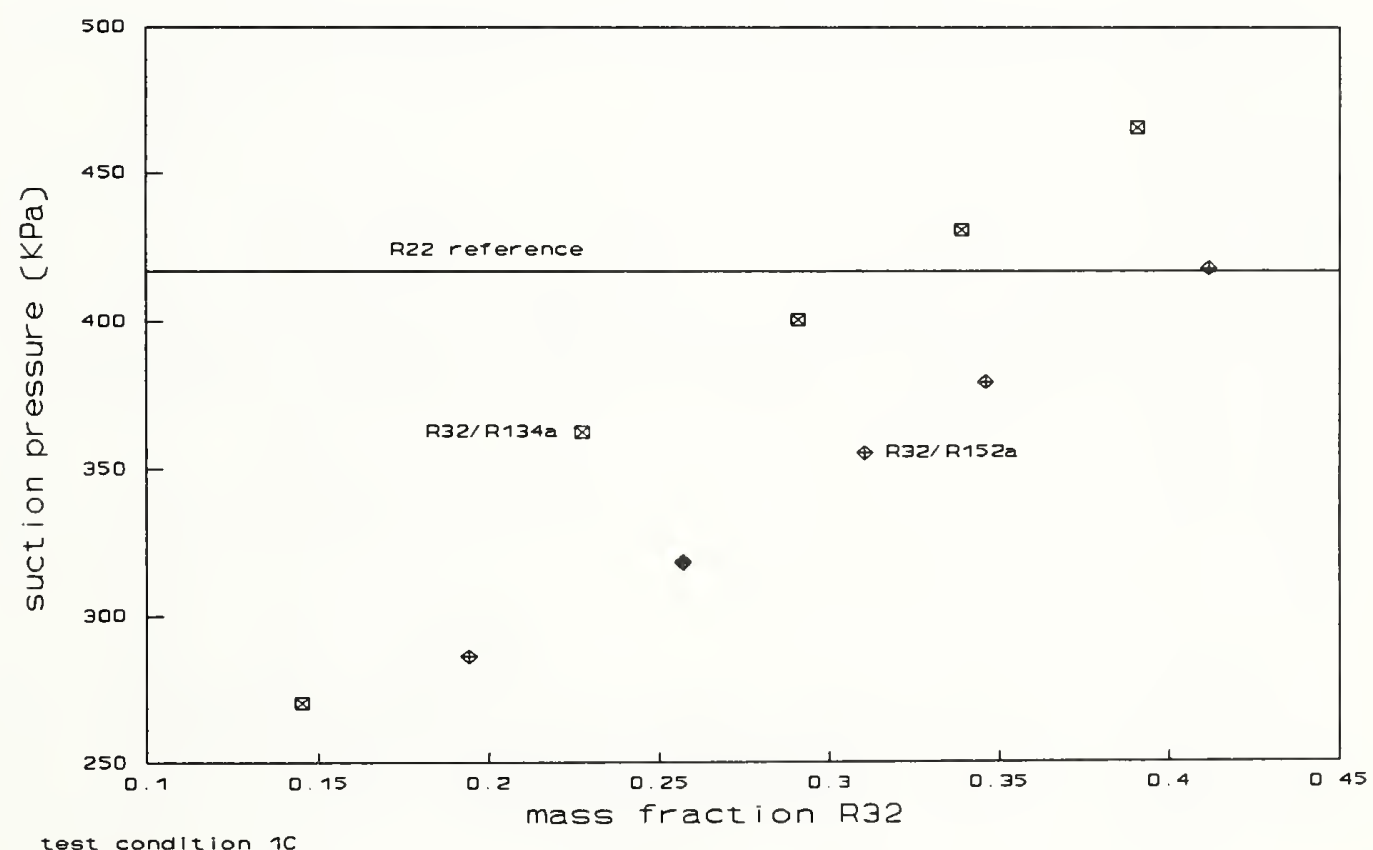

Fig. B4.3:

Suction pressure vs. R32 mass fraction; high temperature heating condition (1C) 


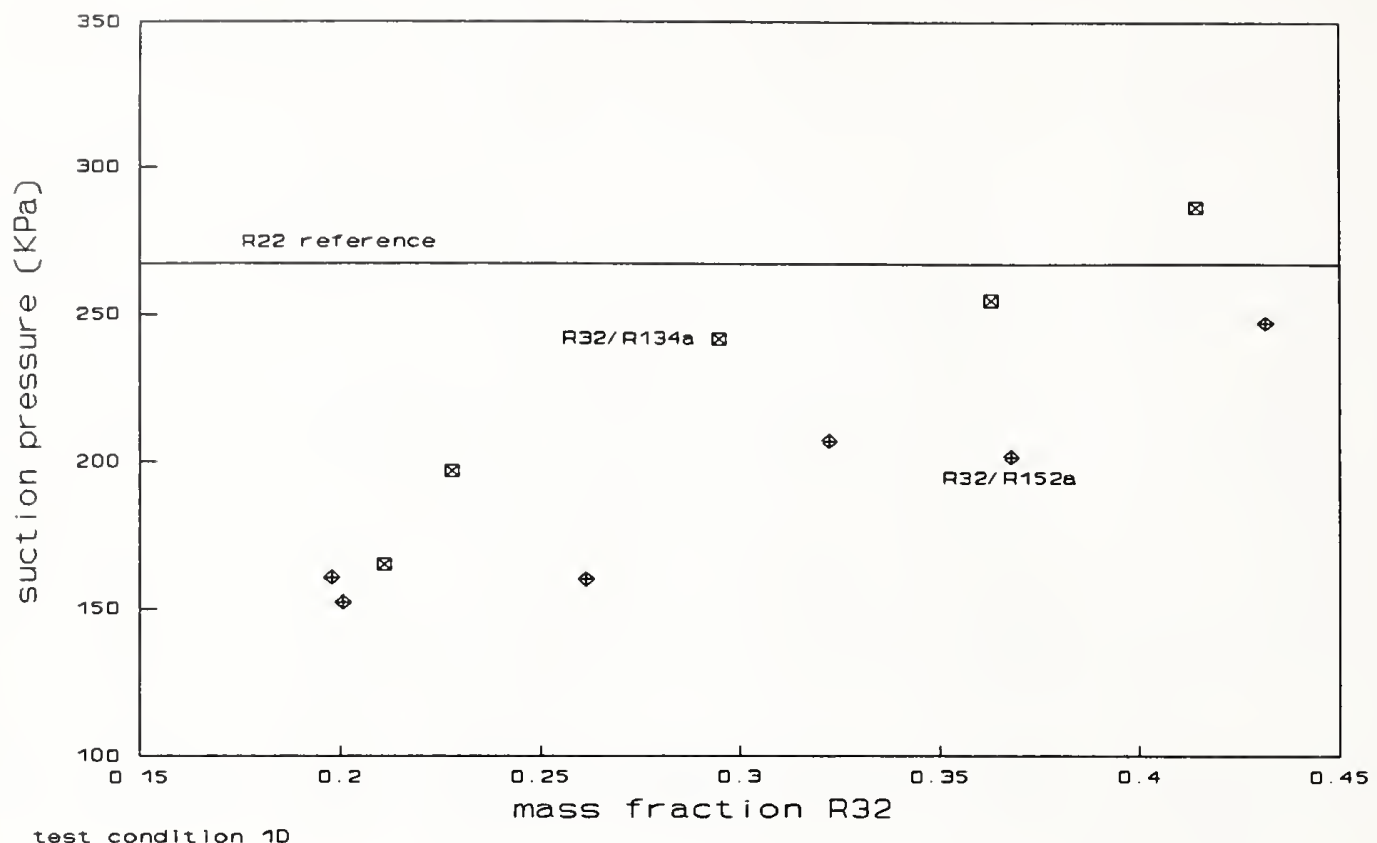

Fig. B4.4: Suction pressure vs. R32 mass fraction; low temperature heating condition (1D)

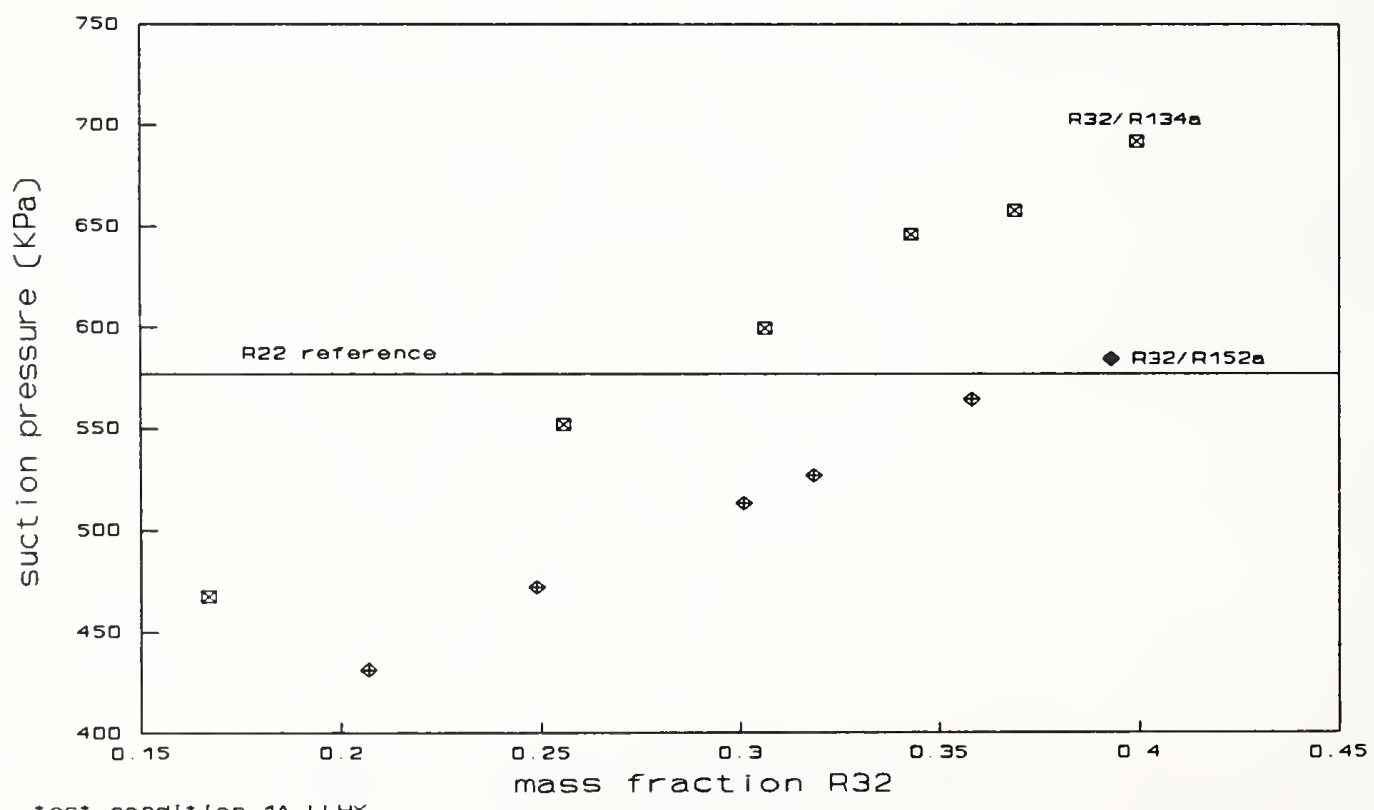

Fig. B4.5:

Suction pressure vs. R32 mass fraction; high temperature cooling condition with LLHX (1A-LLHX) 


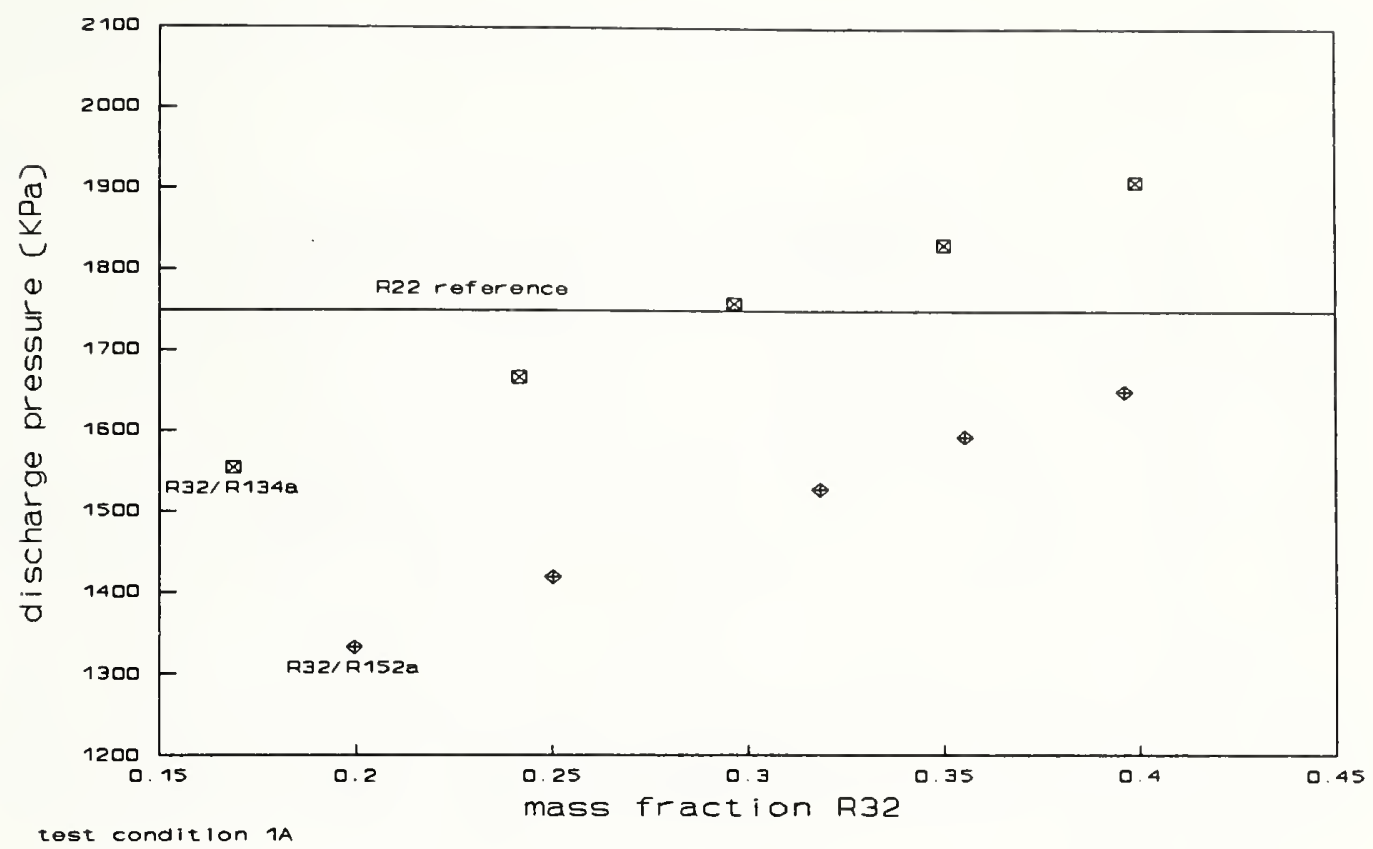

Fig. B5.1: Discharge pressure vs. R32 mass fraction; high temperature cooling condition (1A)

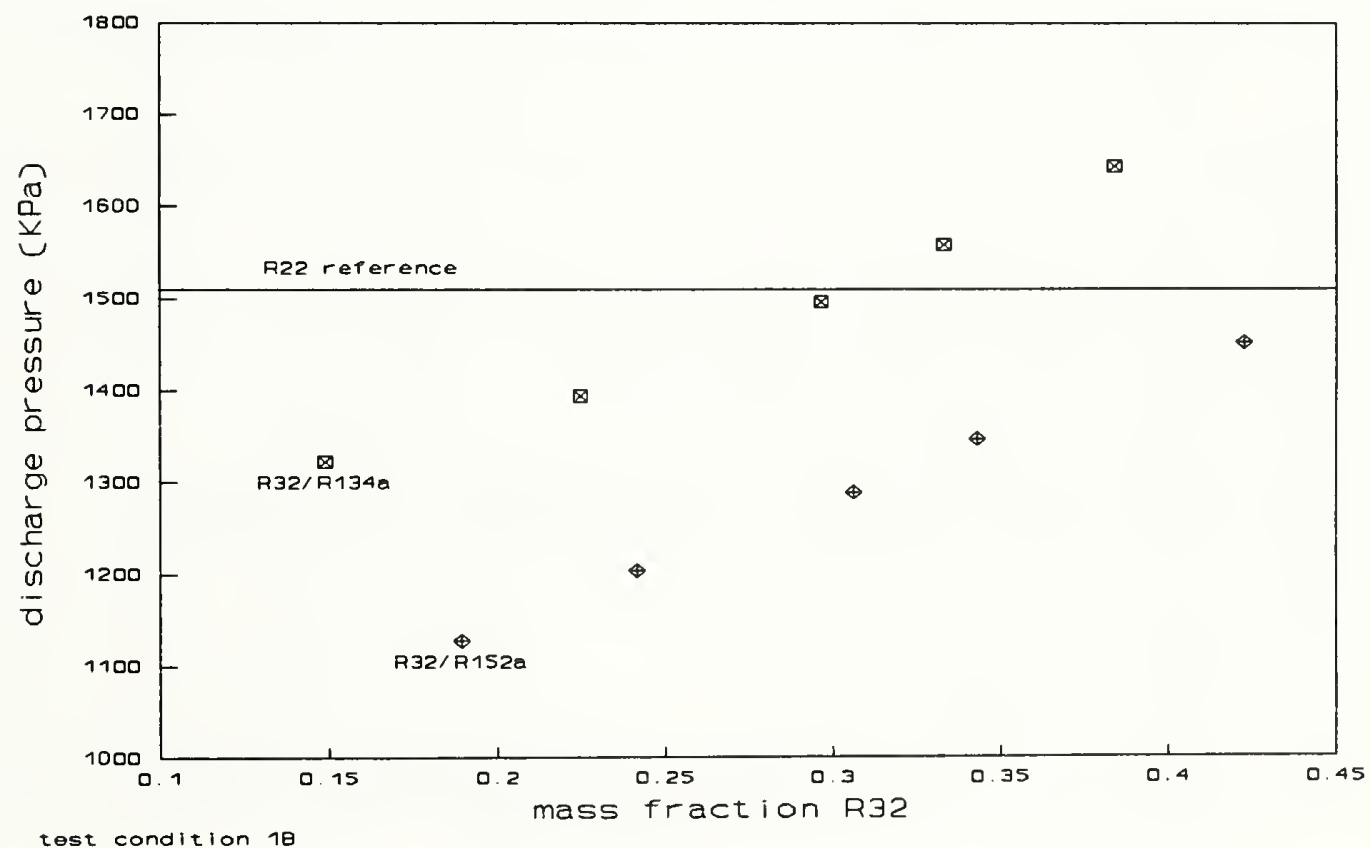

Fig. B5.2: Discharge pressure vs. R32 mass fraction; low temperature cooling condition (1B) 


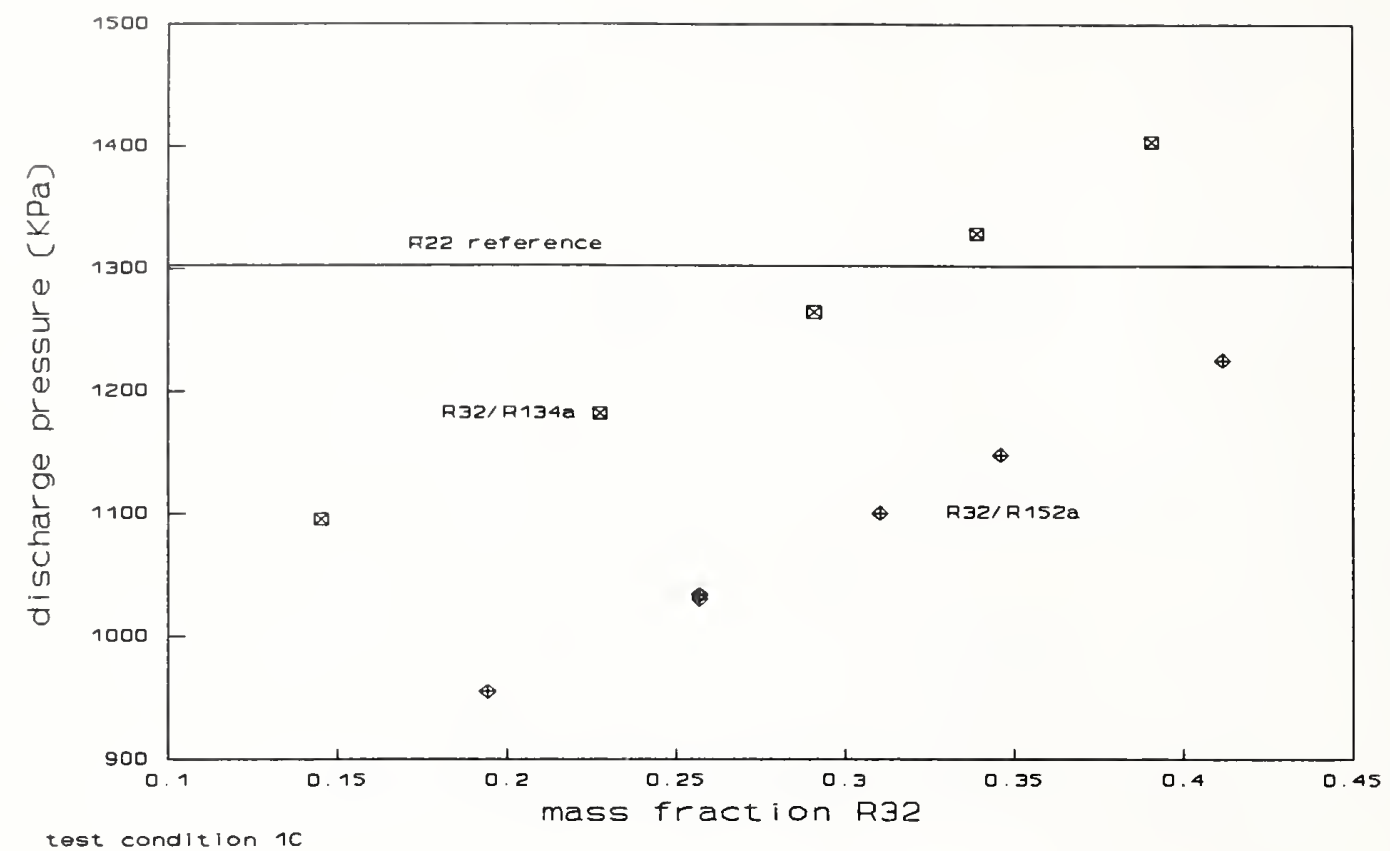

Fig. B5.3: Discharge pressure vs. R32 mass fraction; high temperature heating condition (1C)

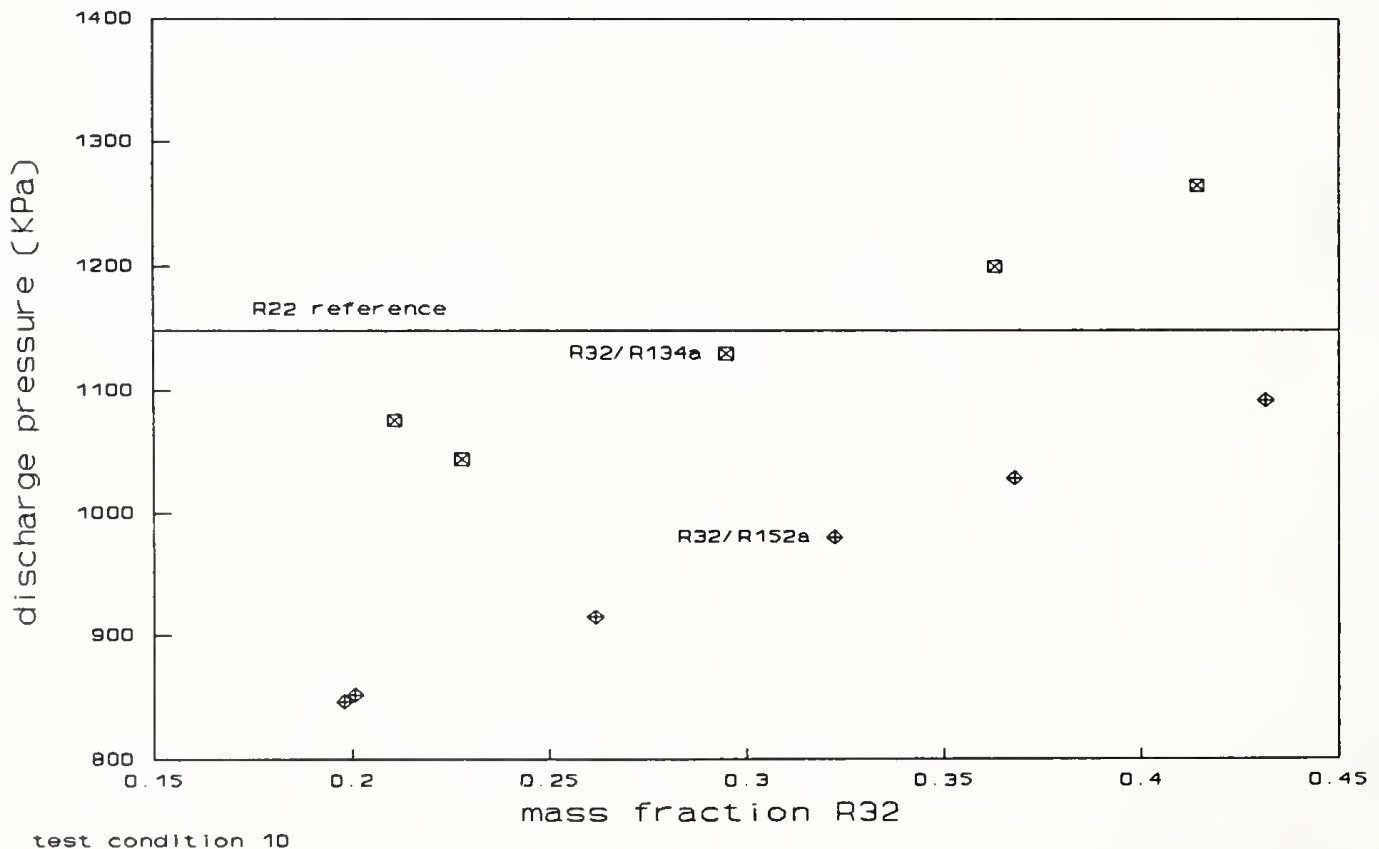

Fig. B5.4: Discharge pressure vs. R32 mass fraction; low temperature heating condition (1D) 


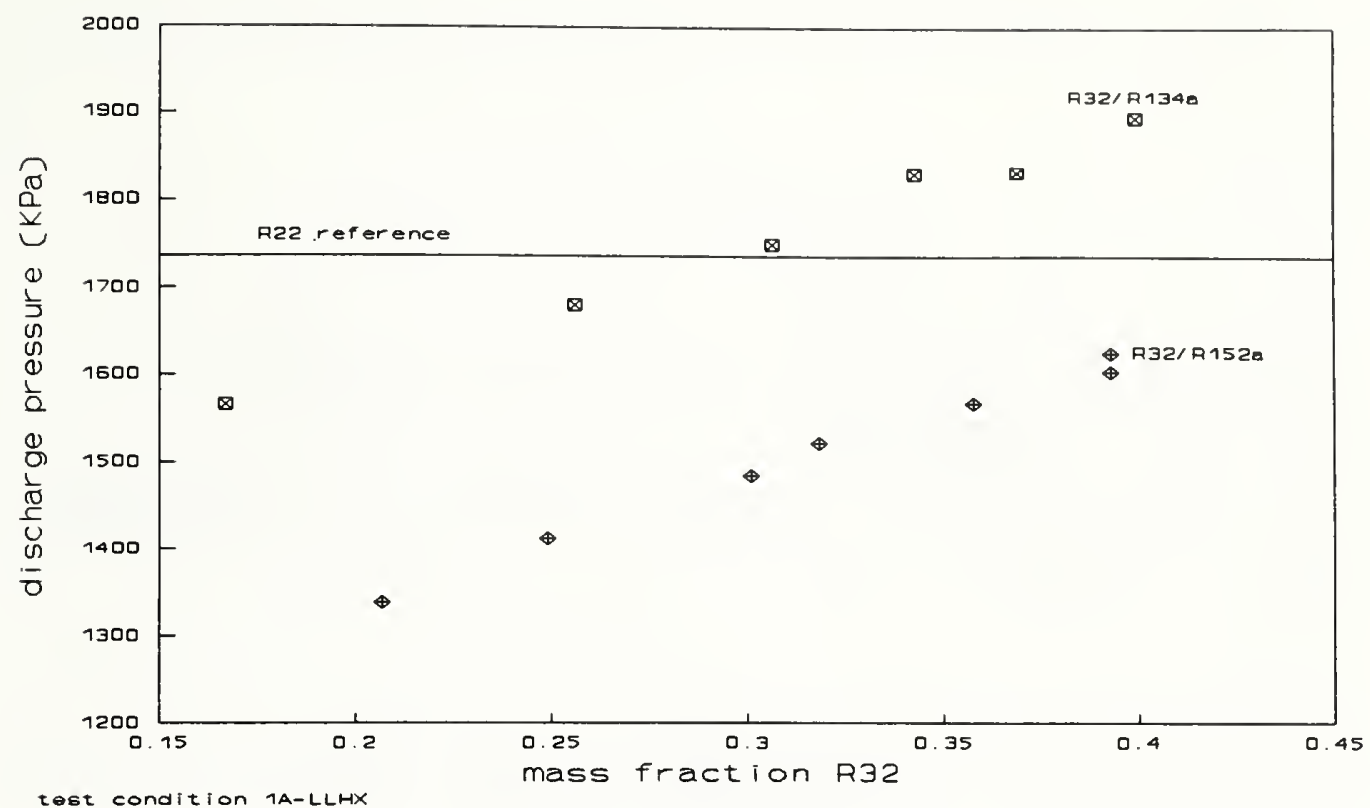

Fig. B5.5: Discharge pressure vs. R32 mass fraction; high temperature cooling condition with LLHX (1A-LLHX)

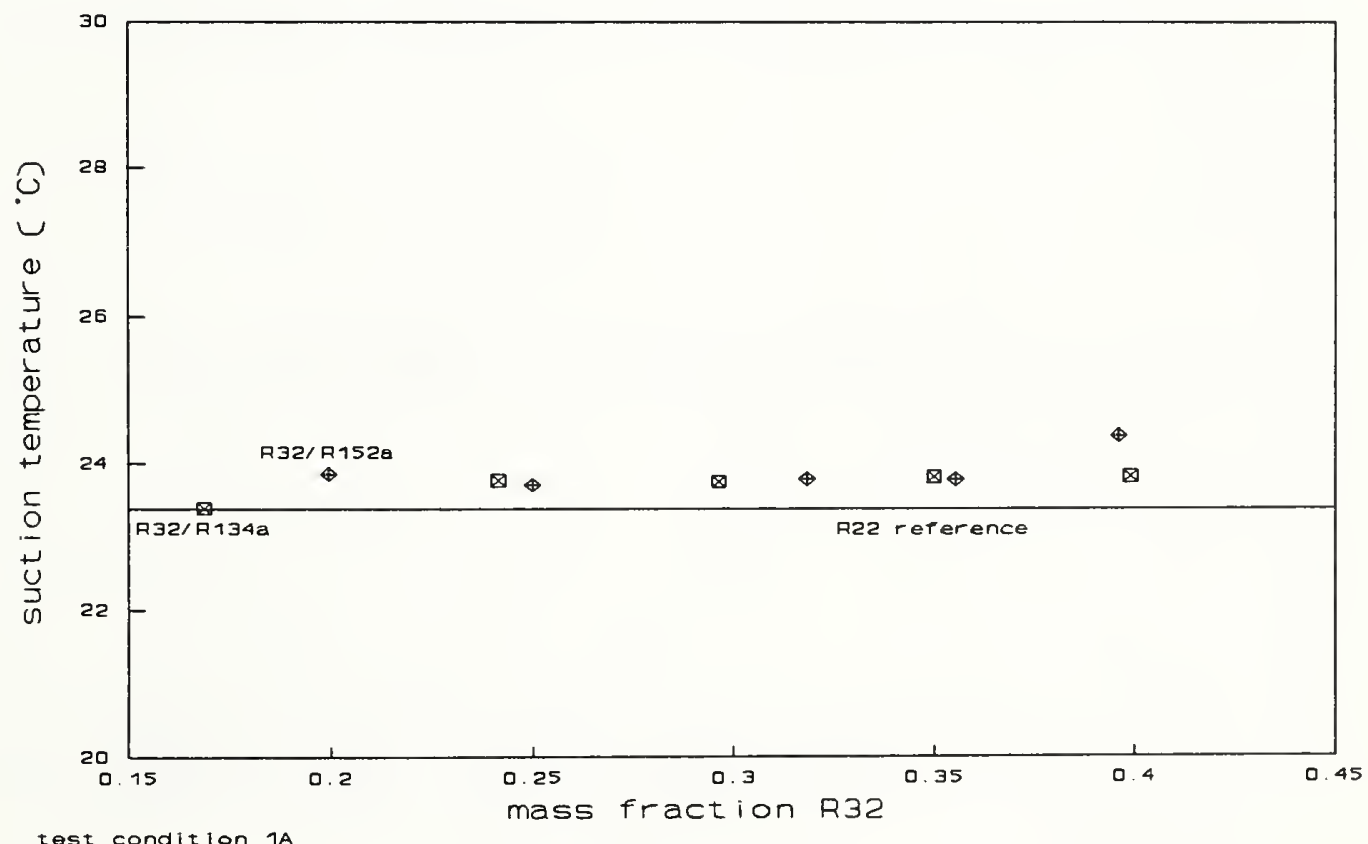

Fig. B6.1:

Suction temperature vs. R32 mass fraction; high temperature cooling condition (1A) 


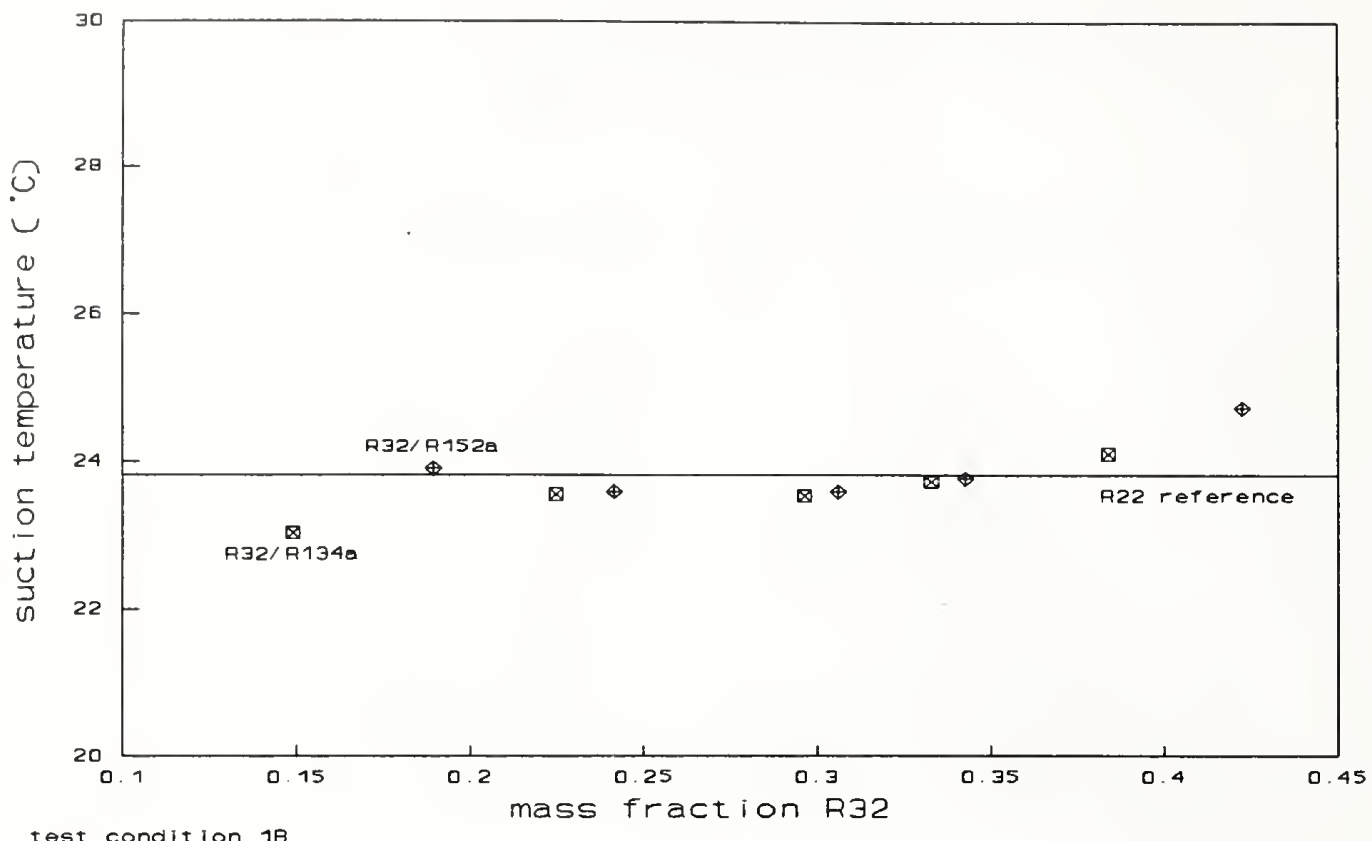

Fig. B6.2: Suction temperature vs. R32 mass fraction; low temperature cooling condition (1B)

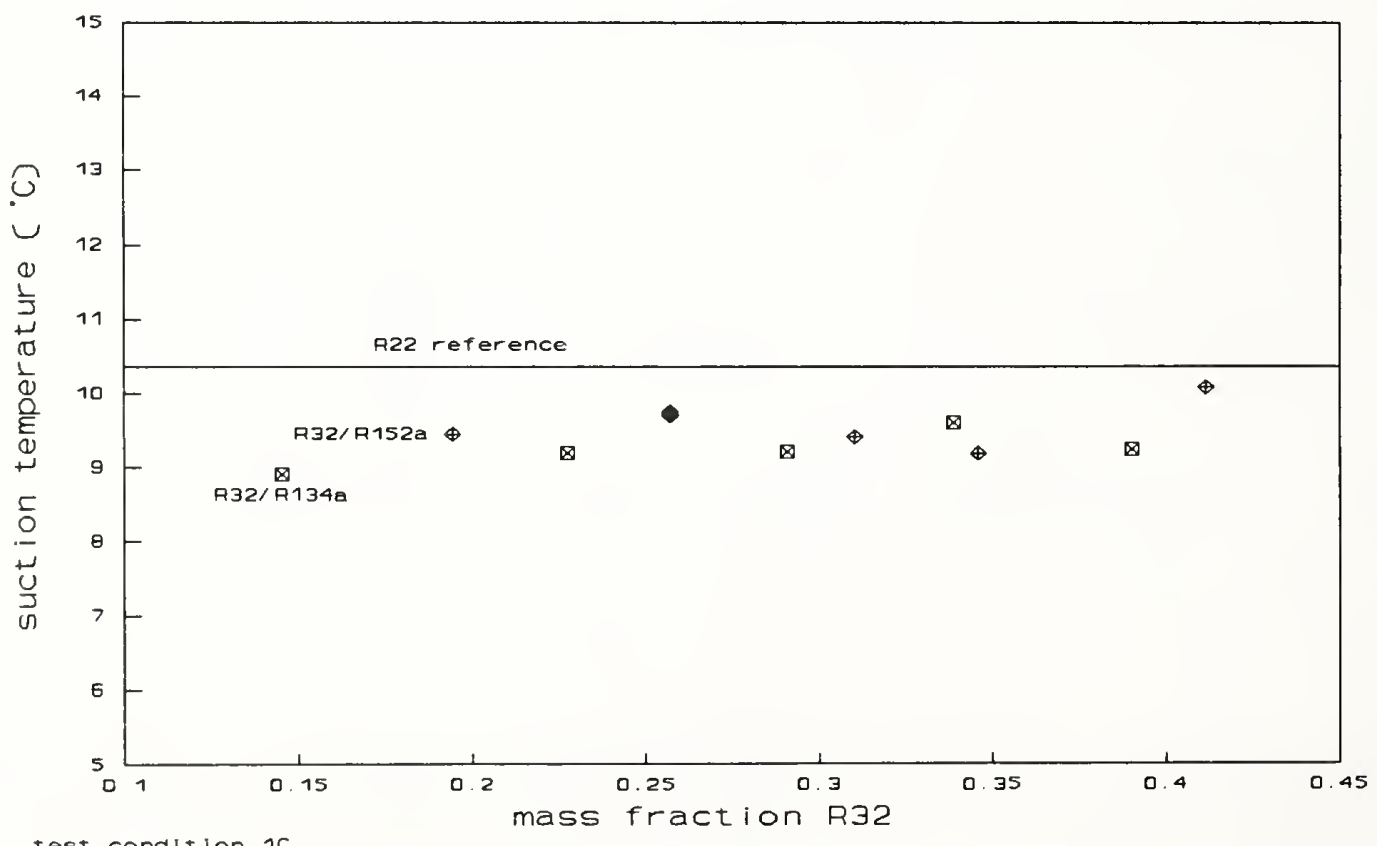

Fig. B6.3:

Suction temperature vs. R32 mass fraction; high temperature heating condition (1C) 


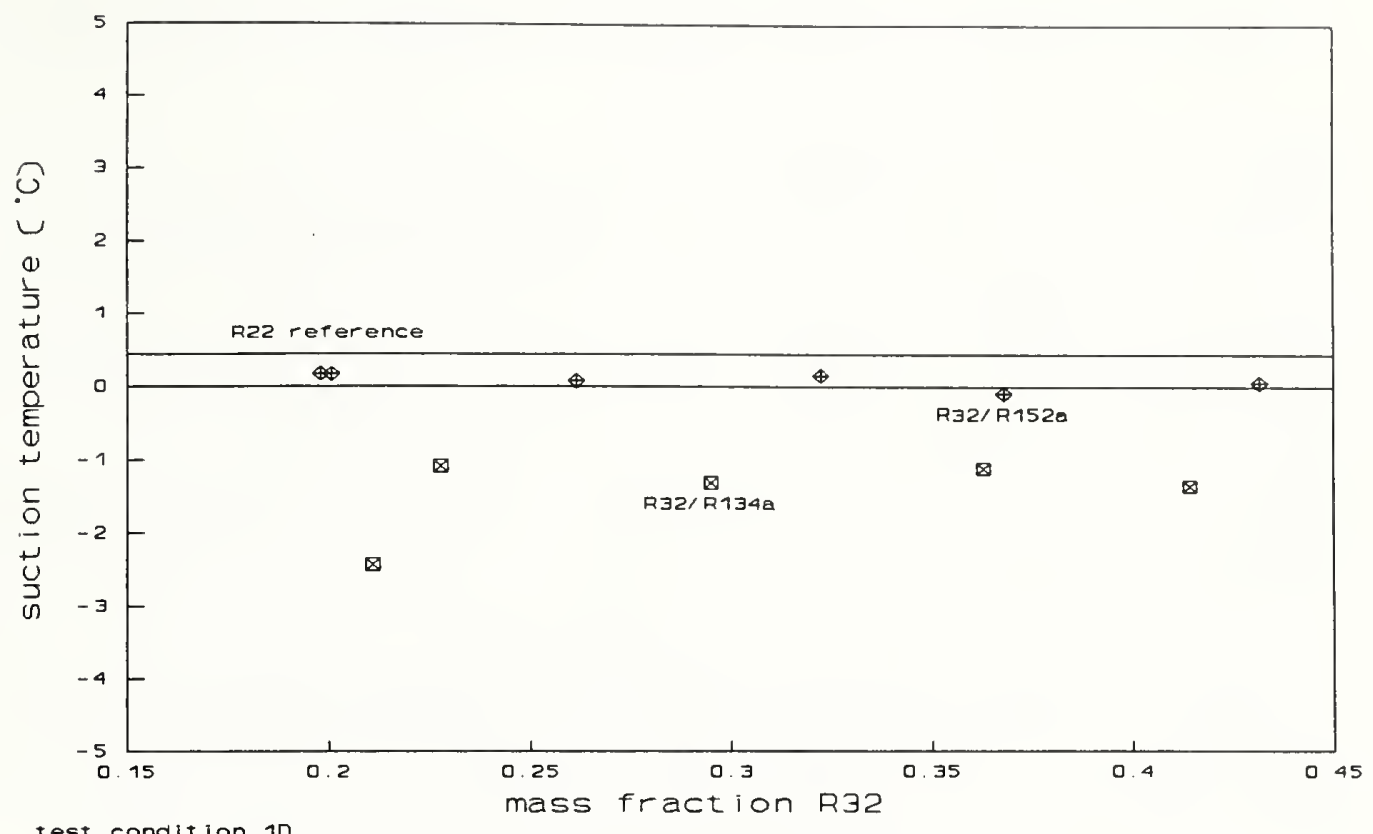

test condition 10

Fig. B6.4: Suction temperature vs. R32 mass fraction; low temperature heating condition (1D)

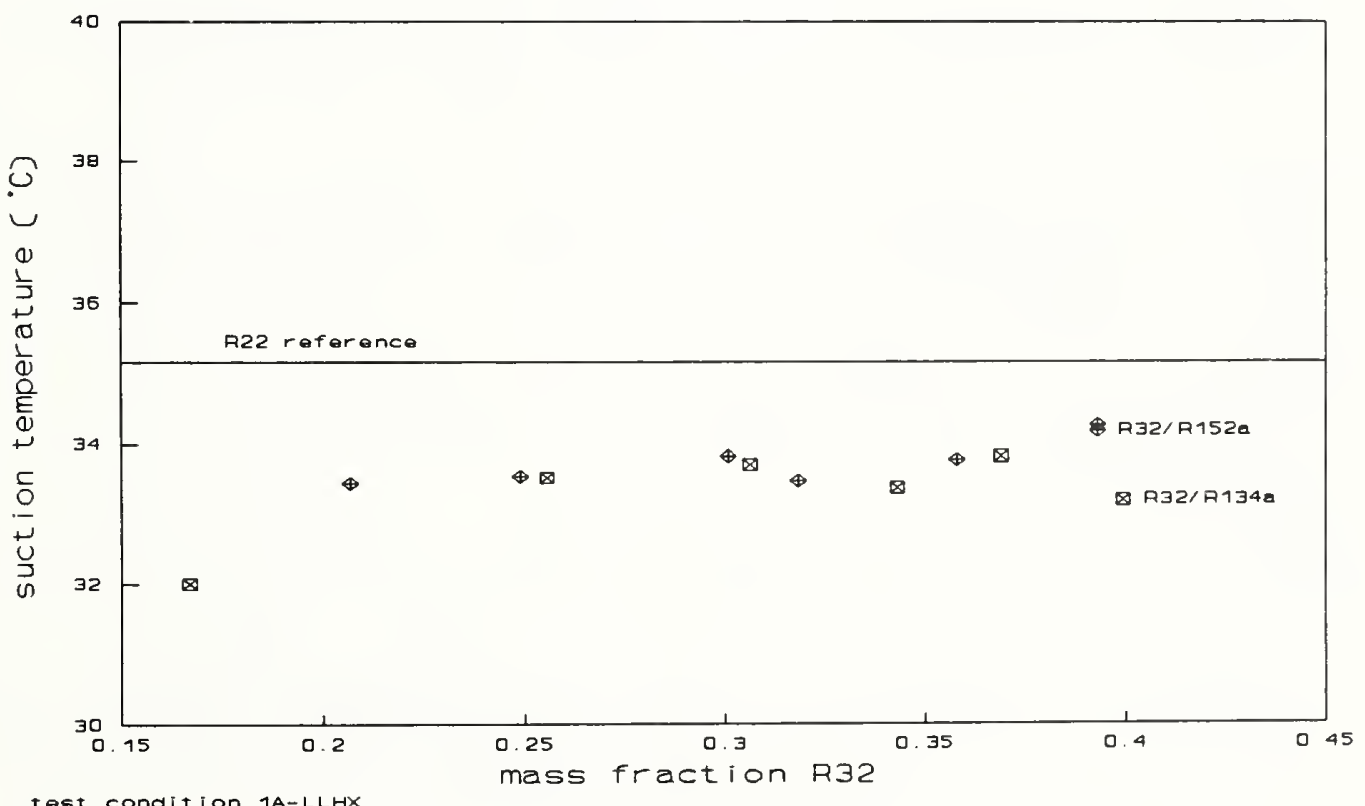

Fig. B6.5: Suction temperature vs. R32 mass fraction; high temperature cooling condition with LLHX (1A-LLHX) 


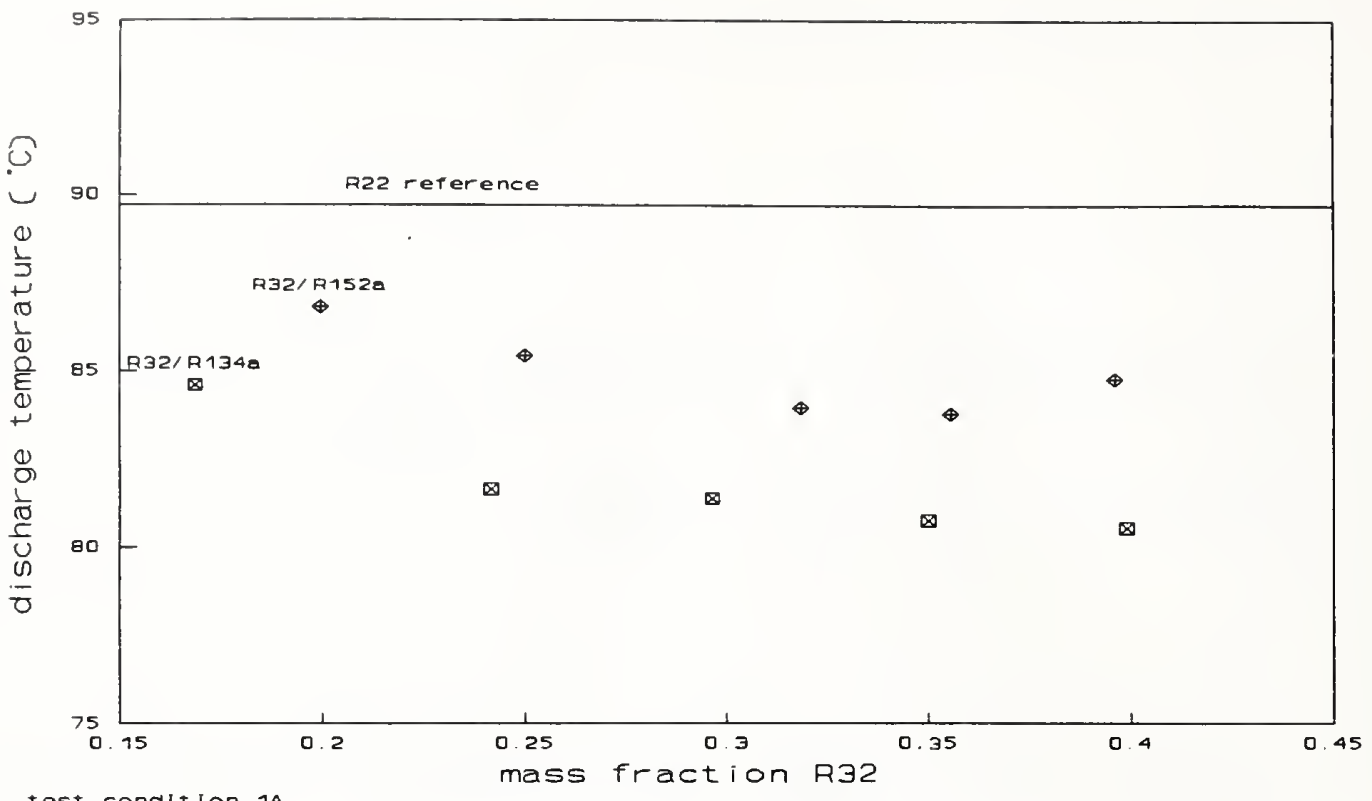

Fig. B7.1: Discharge temperature vs. R32 mass fraction; high temperature cooling condition (1A)

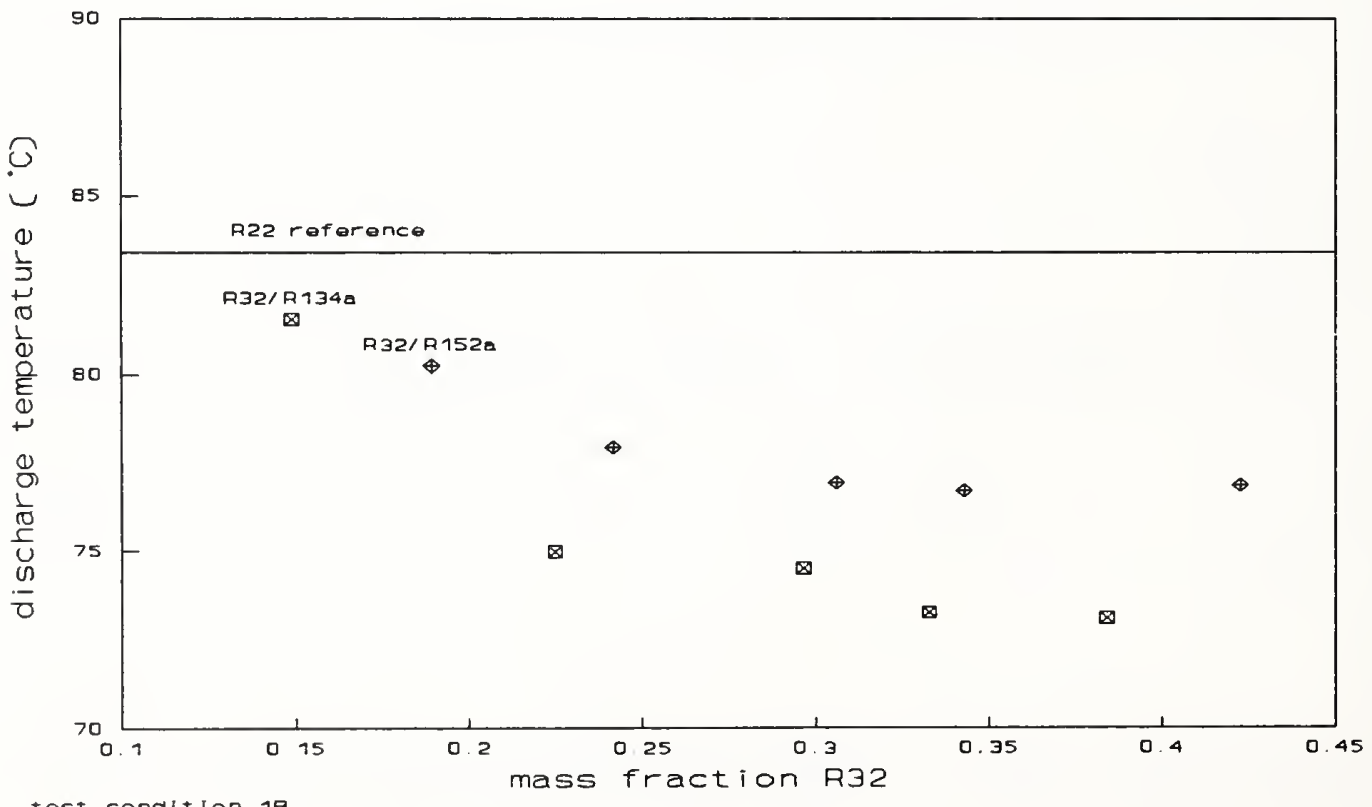

Fig. B7.2: Discharge temperature vs. R32 mass fraction; low temperature cooling condition (1B) 


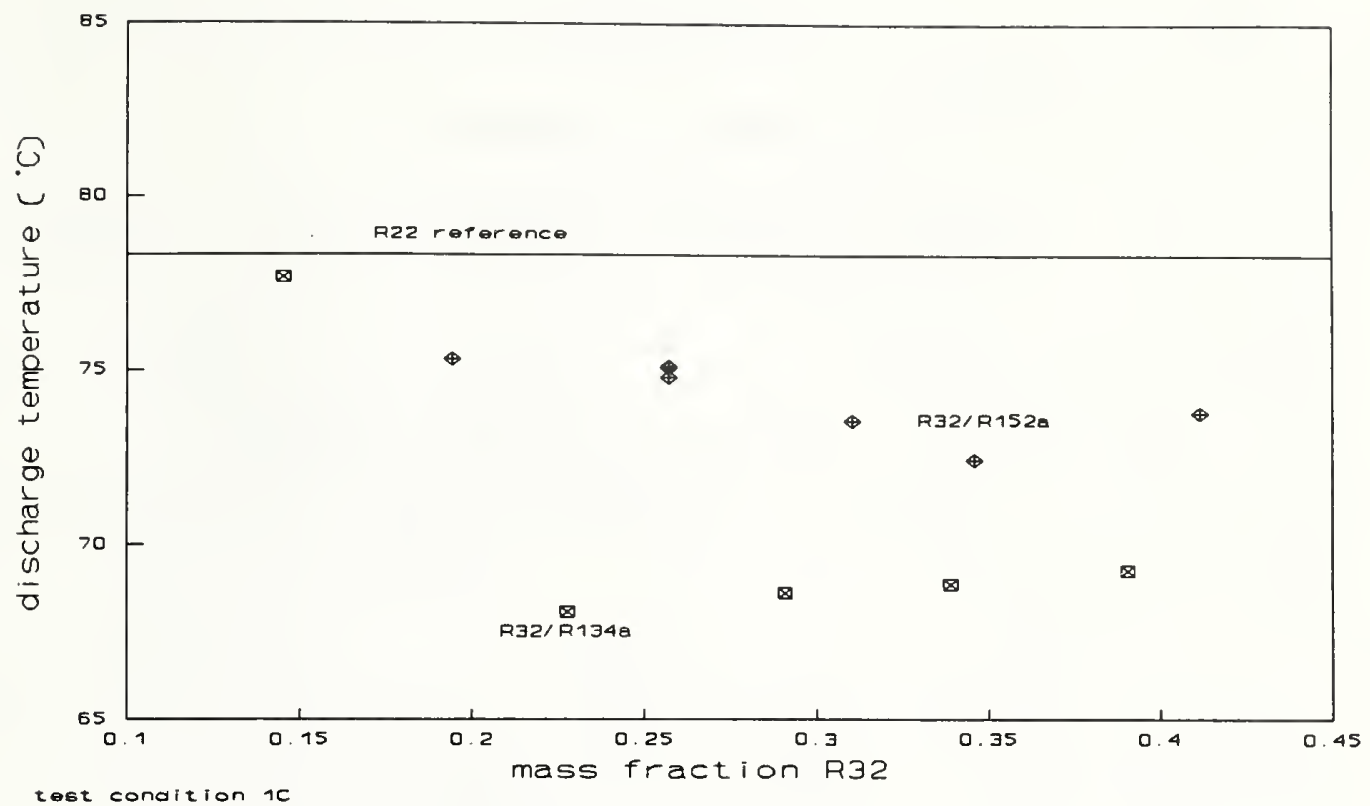

Fig. B7.3: Discharge temperature vs. R32 mass fraction; high temperature heating condition (1C)

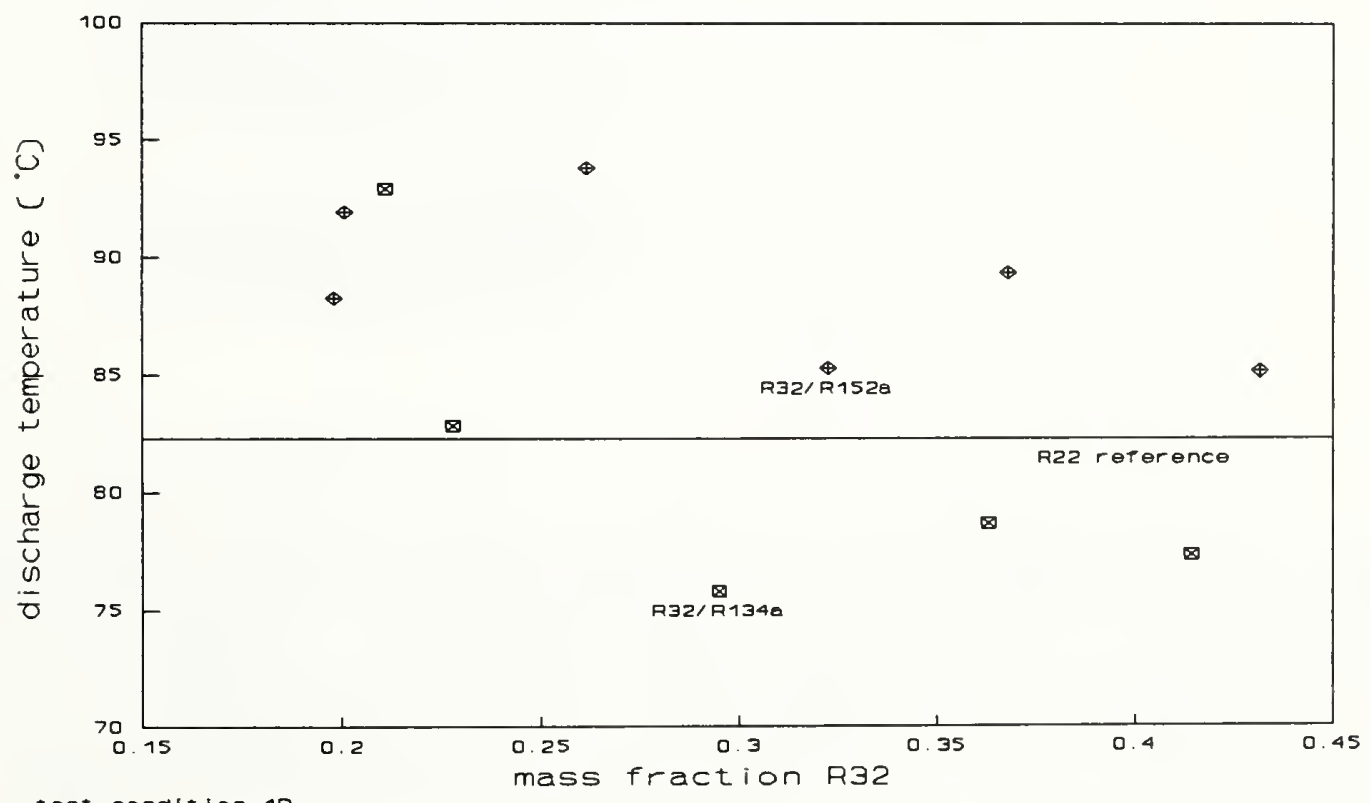

test condition 10

Fig. B7.4: Discharge temperature vs. R32 mass fraction; low temperature heating condition (1D) 


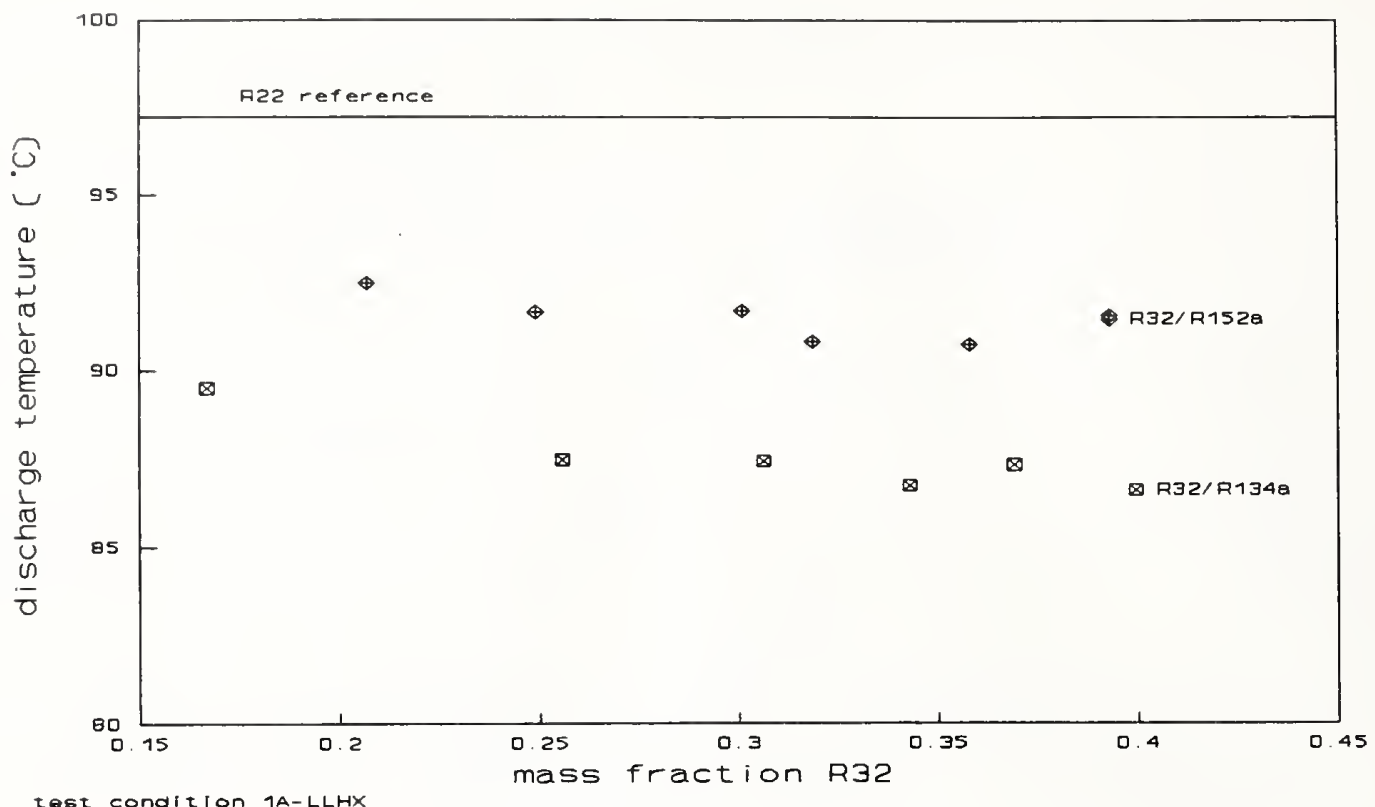

Fig. B7.5: Discharge temperature vs. R32 mass fraction; high temperature cooling condition with LLHX (1A-LLHX) 


\section{UNCERTAINTY ANALYSIS}

C.1 Symbols Used in the Uncertainty Analysis

$\begin{array}{ll}a & \text { Component a: R32 } \\ A & \text { Area } \\ b & \text { Component b: Rl34a } \\ \text { cal } & \text { Calibration Result } \\ \text { COP } & \text { Coefficient of Performance } \\ C_{p} & \text { Specific Heat Capacity } \\ d & \text { Total Derivative } \\ e & \text { Relative Error } \\ \text { eva } & \text { Evaporator } \\ \text { Con } & \text { Condenser } \\ E & \text { Absolute Error } \\ f() & \text { Function of } \\ \dot{m} & \text { Mass Flow Rate } \\ M W & \text { Molecular Weight } \\ N & \text { Dependent Variable } \\ n & \text { Compressor Speed } \\ \dot{O} & \text { Capacity } \\ T & \text { Temperature } \\ T & \text { Environment Temperature } \\ T & \text { Compressor Input Torque } \\ V & \text { Voltage } \\ \dot{H} & \text { Compressor Work } \\ X & \text { Independent Variable } \\ X & \text { Mass Fraction } \\ & \\ \partial & \text { Partial Derivative } \\ \delta & \text { Insulation Thickness } \\ \Delta & \text { Absolute Difference } \\ \dot{\lambda} & \text { Conductivity } \\ & \end{array}$

\section{C.2 General Remarks}

The uncertainty analysis reported in this appendix reflects the effort to provide the reader with information about the accuracy of the measured data. Since the significant results for this report consist of COPs, all measured data involved in calculating the heating or cooling $C O P$ are evaluated with respect to their uncertainty. Quality assurance measures that were taken to confirm or correct manufacturer data are noted in the sections concerning those devices. A large number of devices were manufacturer calibrated and used the first time, so that verification of the instrument output was chosen rather than a calibration. 


\section{3 Theory}

Doeblin [11] presents a procedure for the calculation of the accuracy of a calculation that depends on several measurements which are subjected to individual accuracy. The calculated quantity $\mathrm{N}$ is a function of $j$ independent variables $x, i . e .$,

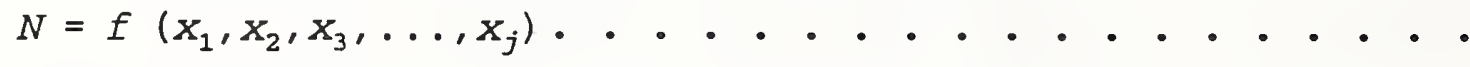

The $x^{\prime} s$ are the measurements that are used to calculate $N$. Each $x$ is in error by $\pm d x_{1}, \pm d x_{2}, \pm d x_{3}, \ldots, \pm d x_{j}$, where the $d x$ values represent \pm 3 standard deviations, respectively. The maximum error $E_{N}$ of $N$ is than given by equation II:

$$
E_{N}=\left|\frac{\partial f}{\partial x_{1}} d x_{1}\right|+\left|\frac{\partial f}{\partial x_{2}} d x_{2}\right|+\left|\frac{\partial f}{\partial x_{3}} d x_{3}\right|+\ldots+\left|\frac{\partial f}{\partial x_{j}} d x_{j}\right| \cdot \ldots . . . .
$$

However, the maximum possible error calculated using equation II does not predict the error very accurately. The root sum square error which is calculated using equation III is a more realistic approach to predict the possible errors than using equation II. With the $d x$ values representing \pm 3 standard deviations, it can be assumed that $99.7 \%$ of the measured values, $\mathrm{N}$, fall within the error limits.

$$
E_{N}=\sqrt{\left(\frac{\partial f}{\partial x_{1}} d x_{1}\right)^{2}+\left(\frac{\partial f}{\partial x_{2}} d x_{2}\right)^{2}+\left(\frac{\partial f}{\partial x_{3}} d x_{3}\right)^{2}+\ldots+\left(\frac{\partial f}{\partial x_{j}} d x_{j}\right)^{2}} \cdot
$$

The absolute errors calculated in equation III can be converted to relative errors using equation IV. The relative error, $e_{N}$, has the units of percent.

$$
e_{N}=\frac{E_{N}}{N} * 100 \text {. . . . . . . . . . . . . . }
$$

The authors choose to present the uncertainties of values $\mathrm{N}$ as:

$$
\begin{aligned}
N & =f\left(x_{1}, x_{2}, x_{3}, \ldots, x_{j}\right) \pm E_{N} \ldots . . . . . . . . . . . . .
\end{aligned}
$$

\section{4 Heat Transfer Fluid Temperature Difference Measurement}

The temperature difference across the heat exchangers and heaters in the system is determined by thermopile measurements using an amplified thermocouple voltage difference signal which is measured with the data acquisition system. The voltage difference is then converted into a temperature difference. The uncertainty analysis is conducted at a typical value for $\mathrm{V}_{1}$ and $\Delta \mathrm{V}$. The uncertainties used for the voltage measurement are manufacturer data for the data acquisition system. The voltage difference measurement with the thermopile used type $T$ thermocouple wire. A check of this thermocouple wire against a NIST calibrated quartz thermometer 
resulted in absolute temperatures that were accurate within $\pm 0.12 \mathrm{~K}$ in the range of interest, which is well within the expected range of $\pm 1 \mathrm{~K}$. However, since a thermopile measurement is used to determine the temperature differences across the heat exchangers, this test was conducted only to ensure the quality of the used thermocouple wire. The importance of this random check lies in the difference of the measured temperatures. Although the thermocouple temperatures were up to $0.12 \mathrm{~K}$ different from the NIST calibrated reference, the difference between the thermocouple temperatures did not exceed $0.025 \mathrm{~K}$, thus ensuring a high confidence in the here calculated uncertainty of the temperature difference measurements. The thermopile voltages are the sum of ten thermocouple pairs across the measured device, i.e., the result is the ten times amplified voltage difference between the thermocouple junctions on each side of the heat exchanger. Due to this method the expected error is much smaller than for the difference of two absolute temperatures. The uncertainty can therefore be calculated as follows:

$$
\begin{aligned}
& \Delta T=f\left(V_{1}+\Delta V\right)-f\left(V_{1}\right) \cdot \cdot \cdot \cdot \cdot \cdot \cdot \cdot \cdot \cdot \cdot \cdot \cdot \cdot \cdot \cdot \cdot \\
& V_{1}=2 m V \pm(0.038+6 \mu V) \cdot . . . . . . . . . . . \\
& V_{1}=2 \mathrm{mV} \pm 0.0066 \mathrm{mV} \\
& \Delta V=0.4 \mathrm{mV} \pm(0.038+6 \mu V)
\end{aligned}
$$

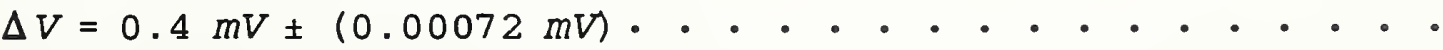

$$
\begin{aligned}
& E_{\Delta T}=\sqrt{\left(\frac{\partial f\left(V_{1}+\Delta V\right)}{\partial V_{1}} d V_{1}\right)^{2}+\left(\frac{\partial f\left(V_{1}+\Delta V\right)}{\partial \Delta V} d \Delta V\right)^{2}+\left(\frac{\partial f\left(V_{1}\right)}{\partial V_{1}} d V_{1}\right)^{2}} . \\
& \frac{\partial f\left(V_{1}+\Delta V\right)}{\partial V_{1}} d V_{1}=22.9738 \frac{{ }^{\circ} \mathrm{C}}{\mathrm{mV}} * 0.0066 \mathrm{mV}=0.15163^{\circ} \mathrm{C} . . . \\
& \frac{\partial f\left(V_{1}+\Delta V\right)}{\partial \Delta V} d \Delta V=22.9738 \frac{{ }^{\circ} \mathrm{C}}{\mathrm{mV}} * 0.00072{ }^{\circ} \mathrm{C}=0.016541{ }^{\circ} \mathrm{C} . \\
& \frac{\partial f\left(V_{1}\right)}{\partial V_{1}} d V_{1}=23.3824 \frac{{ }^{\circ} \mathrm{C}}{\mathrm{mV}} * 0.0066 \mathrm{mV}=0.15432^{\circ} \mathrm{C} . \cdots .
\end{aligned}
$$

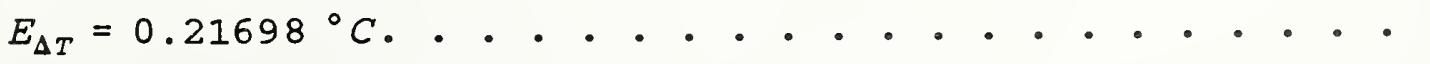

$$
\begin{aligned}
& e_{\Delta T}=2.3408 \% \\
& \Delta T=9.26953{ }^{\circ} \mathrm{C} \pm 0.21698^{\circ} \mathrm{C}=9.26953^{\circ} \mathrm{C} \pm 2.3408 \mathrm{8} \cdot{ }^{\circ}
\end{aligned}
$$




\section{C.5 Heat Transfer Fluid Specific Heat}

The specific heat capacity of the heat transfer fluid is determined using the measured fluid temperature. Therefore, its accuracy is dependent on the temperature measurement accuracy and on the uncertainty of the regression curve. The function used to determine the specific heat was interpolated from manufacturer data. Figure $\mathrm{Cl}$ shows the correlation function with respect to its

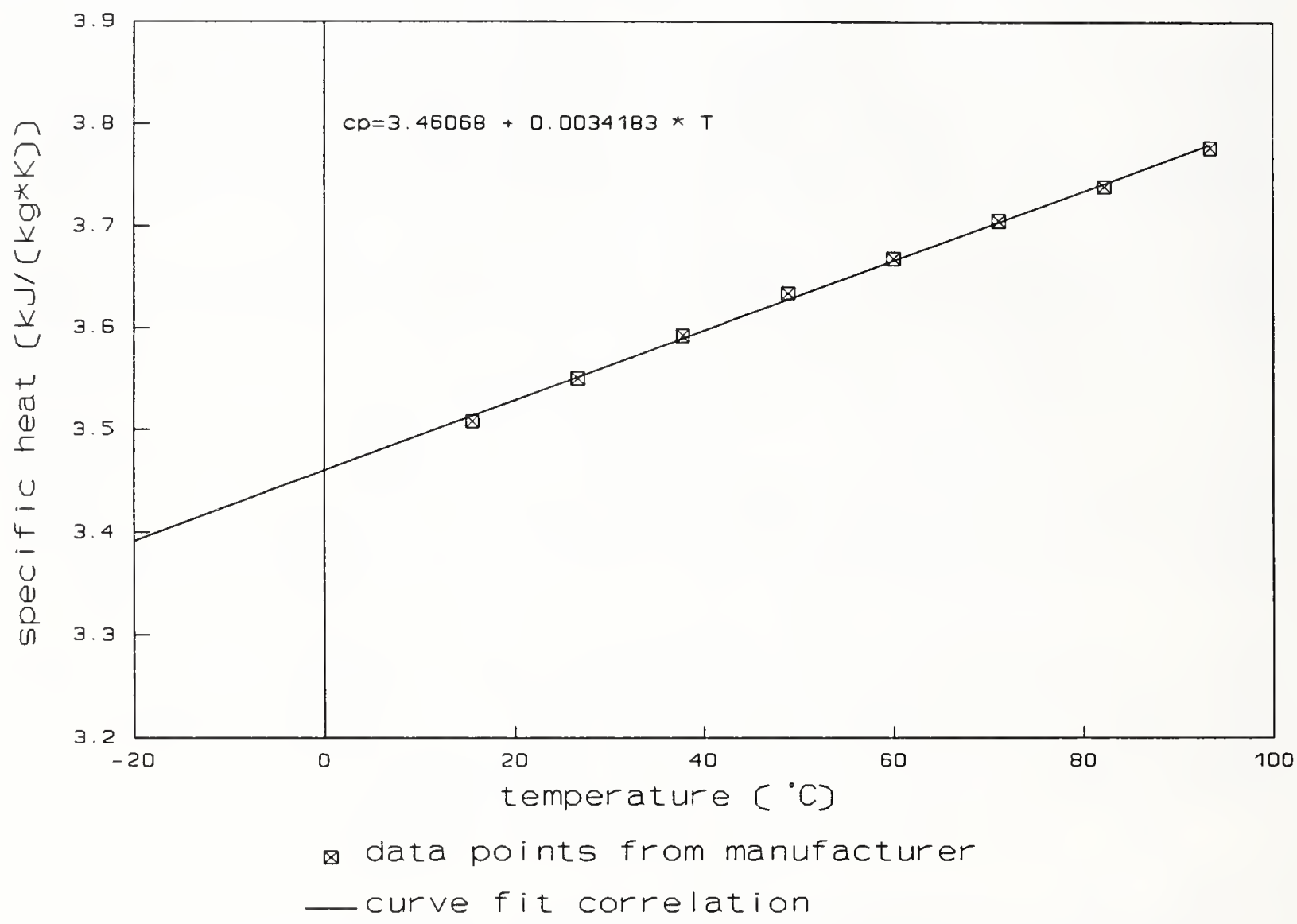

Fig. C1: Specific heat regression curve for the heat transfer fluid (40 mass- $\%$ ethylene-glycol, 60 mass $-\%$ water)

temperature dependence. The regression function represents the manufacturer data within $\pm 0.18 \%$. Since this function was used in a temperature range were no manufacturer data were available the uncertainty is chosen to be $\pm 0.25 \%$ in the following calculations. The uncertainty analysis for the specific heat is conducted at a typical value for $c_{p}=3.5 \mathrm{~kJ} /(\mathrm{kg} * \mathrm{~K})$ at $\mathrm{T}=11.5^{\circ} \mathrm{C}$. Therefore the uncertainty with respect to regression curve is $\pm 0.00875 \mathrm{~kJ} /(\mathrm{kg} * \mathrm{~K})$. otherwise $c_{p}$ is assumed to be a function of temperature only, hence: 


$$
\begin{aligned}
& E_{c_{D}}=\sqrt{\left(\frac{\partial f}{\partial T} d T\right)^{2}+0.00875^{2}} \cdot \cdots \cdot \cdot \cdot \cdot \cdot \text { (XVIII) } \\
& E_{c_{p}}=\sqrt{\left(0.0034183 \frac{k J}{k g * K^{2}} * 1 K\right)^{2}+0.00875^{2}}=0.0093940 \frac{k J}{k g * K}^{(X I X)}
\end{aligned}
$$

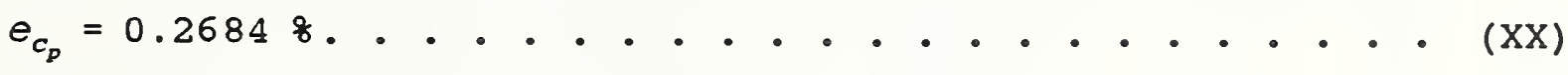

$$
\begin{aligned}
& c_{P}=3.618 \frac{\mathrm{kJ}}{\mathrm{kg} * K} \pm 0.0093940 \frac{\mathrm{kJ}}{\mathrm{kg} * K} \\
& =3.618 \frac{k J}{k g * K} \pm 0.2684 \%
\end{aligned}
$$

C. 6 Heat transfer fluid mass flow rate

The error analysis for the mass flow rate is based on the manufacturer data for the calibrated device:

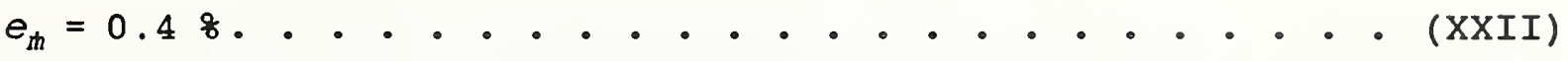

$$
\begin{aligned}
& \dot{m}=0.08 \frac{\mathrm{kg}}{\mathrm{sec}} \pm 0.00032 \frac{\mathrm{kg}}{\mathrm{sec}}=0.08 \frac{\mathrm{kg}}{\mathrm{sec}} \pm 0.4 \% \text {.... (XXIII) }
\end{aligned}
$$

In order in ensure the accuracy of the measurements, the mass flow metering device was calibrated prior to its use in the test rig. Figures $\mathrm{C} 2$ and $\mathrm{C} 3$ show the calibration curves for both mass flow meters. The values used for the calculation of the calibration curves lie within $\pm 1.2 \%$ of the calibration curves, thus showing a much higher uncertainty than expected. The value used for the mass flow rate uncertainty in the following sections is therefore chosen to be $\pm 1.2 \%$. 


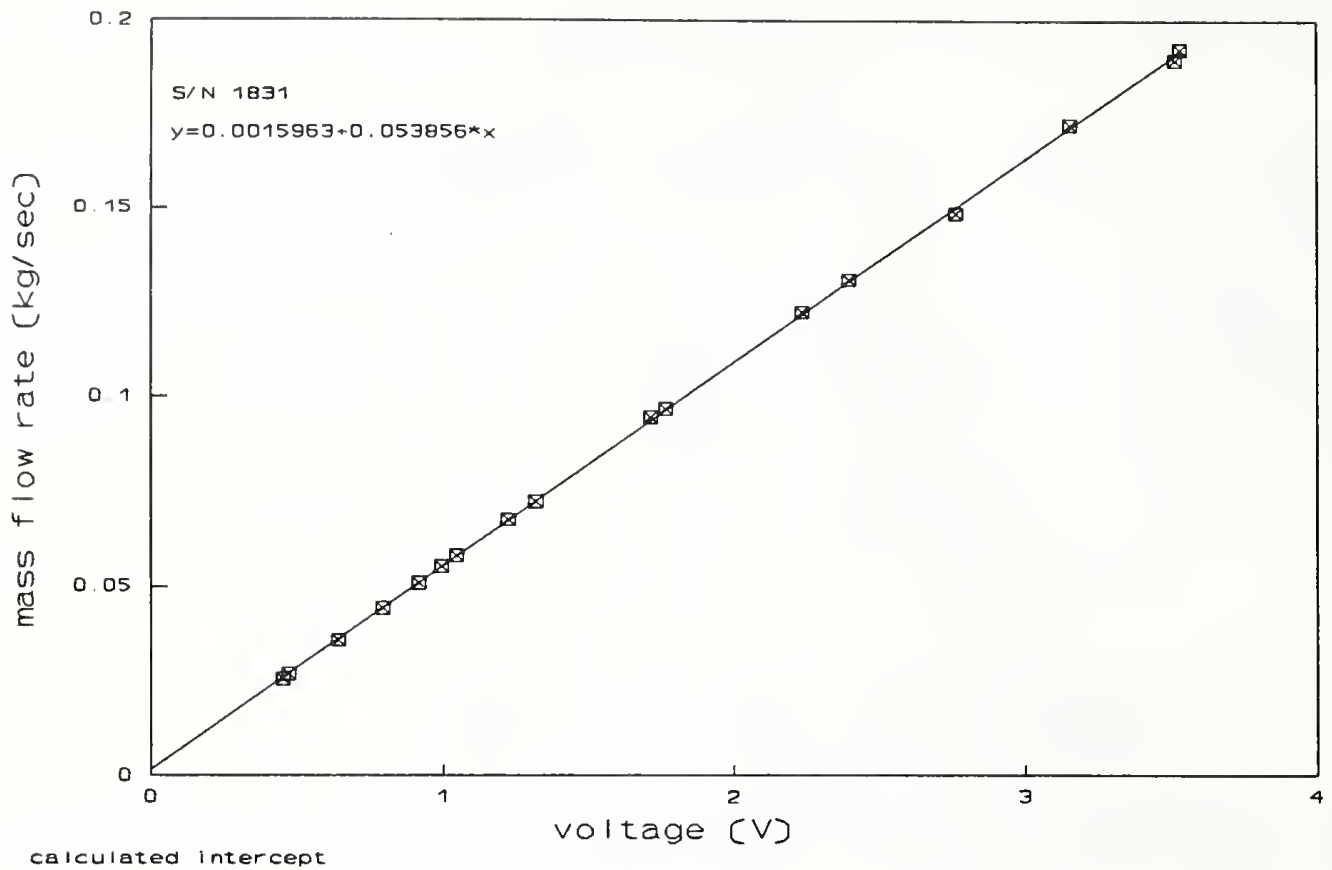

Fig. C2: Mass flow meter calibration curve for evaporator heat transfer fluid measurements

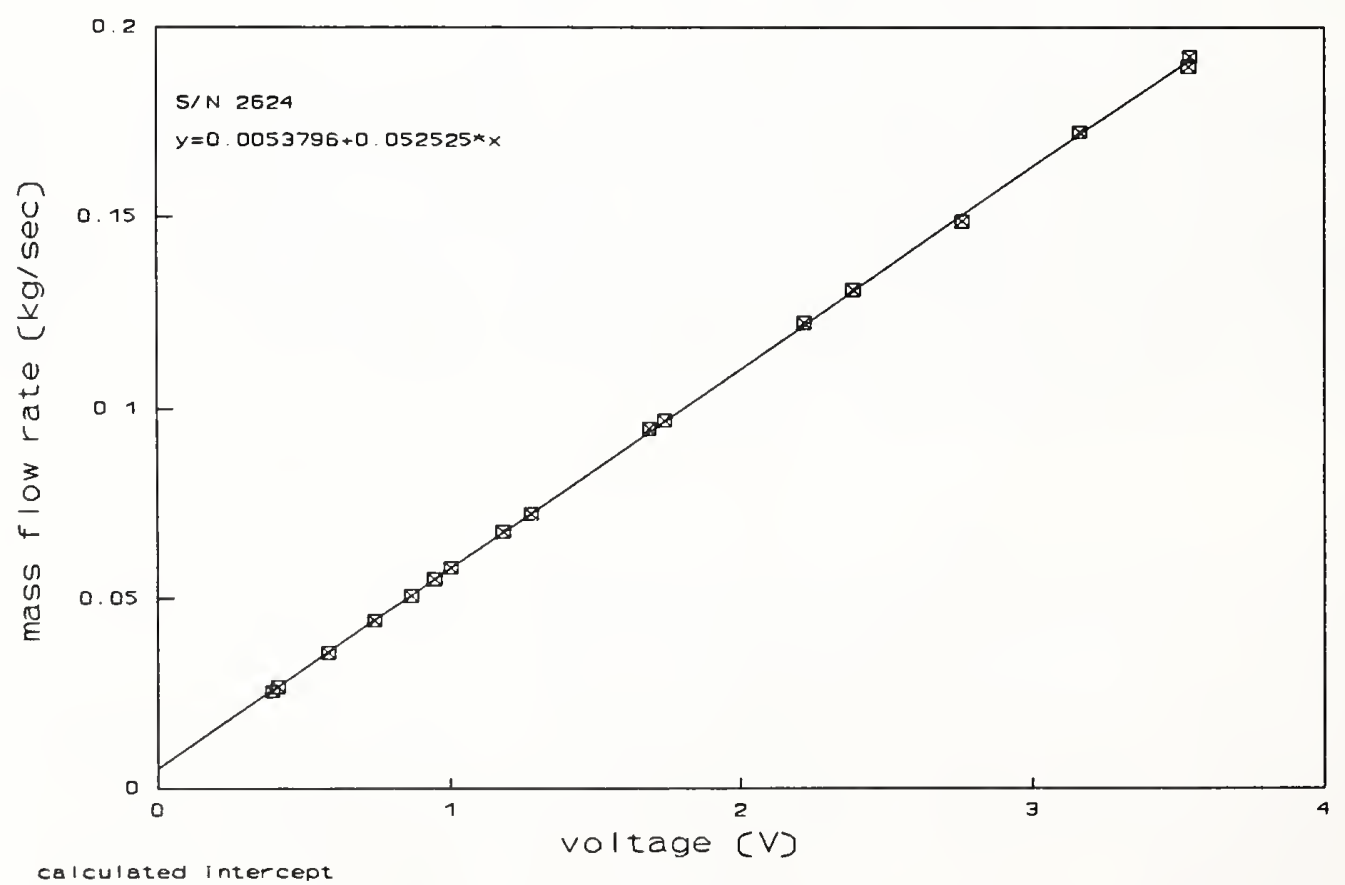

Fig. C3: Mass flow meter calibration curve for condenser heat transfer fluid measurements 
C. 7 Heat Transfer Fluid Capacity Measurement

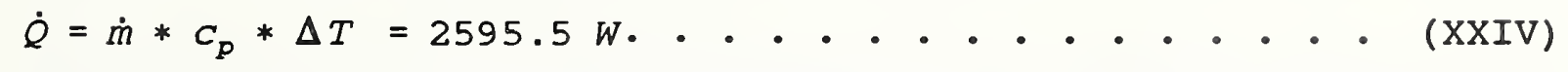

The capacity uncertainty is dependent on the uncertainties of the contributing values used in the calculation. Therefore:

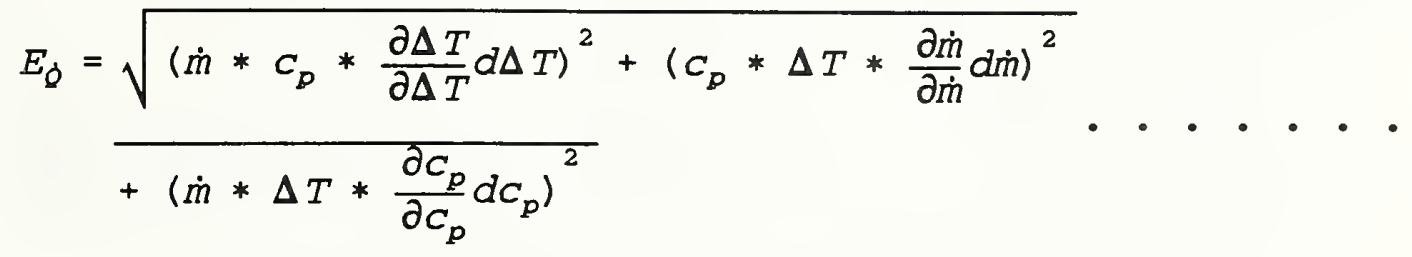

$$
\begin{aligned}
& E_{\phi}=\sqrt{\left(0.08 \frac{\mathrm{kg}}{\mathrm{sec}} * 3500 \frac{\mathrm{J}}{\mathrm{kg} * K} * 0.013844 K\right)^{2}} \\
& +\left(3500 \frac{\mathrm{J}}{\mathrm{kg} * K} * 9.2695 K * 0.00096 \frac{\mathrm{kg}}{\mathrm{sec}}\right)^{2} \text {. . . . } \\
& +\left(0.08 \frac{\mathrm{kg}}{\mathrm{sec}} * 9.2695 K * 9.3940 \frac{\mathrm{J}}{\mathrm{kg} * K}\right)^{2} \\
& \begin{aligned}
E_{\phi} & =\sqrt{(3.8764 W)^{2}+(31.146 W)^{2}+(6.9662 W)^{2}} \cdot \ldots \\
& =32.150 \mathrm{~W}
\end{aligned} \\
& e_{\phi}=\frac{32.150 W}{2595.5 W} * 100=1.2387 \% \ldots . . . . . . . \\
& \dot{Q}=2595.5 W \pm 32.150 W=2595.5 W \pm 1.2387 \% \cdot \cdots \cdot . . .
\end{aligned}
$$

\section{8 System Capacity Measurement}

Since an indirect method is used to measure the system capacity, the absolute result for the capacity is the heat transfer fluid capacity. However, the error for the system capacity is greater than that of the heat transfer fluid capacity since there is heat loss in the condenser and heat gain in the evaporator. Here the analysis is performed for a sample evaporator capacity under test condition $1 \mathrm{~A}$ and for the condenser capacity under test condition 1D. This is done because these are the capacities that are used to calculate the system COP.

$$
\dot{Q}_{e v a}=\dot{Q} \pm\left(\left(\dot{Q}_{10 s s}\right)_{e v a}+\left(\frac{e_{\phi}}{100}\right) * \dot{Q}\right) \cdot \ldots . . . . . . . .
$$




$$
\begin{aligned}
& \dot{Q}_{\text {con }}=\dot{Q} \pm\left(\left(\dot{Q}_{10 s s}\right)_{c o n}+\left(\frac{e_{\dot{Q}}}{100}\right) * \dot{Q}\right) \cdot \ldots . . . . . . . . . \quad \text { (XXXI) } \\
& \dot{Q}_{\text {loss }}=\frac{\lambda}{\delta} * A *\left(T_{H X}-T_{0}\right) \cdot \cdot \cdot \cdot \cdot \cdot \cdot \cdot \cdot \cdot \cdot(\mathrm{XXXII}) \\
& \text { with: } \lambda=0.036 \frac{W}{m * K} \\
& \delta=0.0128 \mathrm{~m} \\
& A=1.5 \mathrm{~m}^{2} \\
& \left(T_{\text {eva }}-T_{0}\right)=2.5 \mathrm{~K} \\
& \left(T_{\text {con }}-T_{0}\right)=5.5 \mathrm{~K} \\
& \left(\dot{Q}_{\text {loss }}\right)_{\text {eva }}=\frac{0.036}{0.0128} * 1.5 * 2.5 W=10.55 W . \cdots \cdot . \cdot(\mathrm{XXXIV}) \\
& \left(\dot{Q}_{\text {loss }}\right)_{\text {con }}=\frac{0.036}{0.0128} * 1.5 * 5.5 W=23.20 \mathrm{~W} \cdot \cdots \cdot \cdot \cdot \cdot(\mathrm{XXXV}) \\
& \dot{Q}_{\text {eva }}=3520 W \pm(10.55 W+0.012387 * 3520 W) \\
& =3520 W \pm 54.152 W \\
& =3520 W \pm 1.5384 \% \\
& \dot{Q}_{\text {con }}=1970 W \pm(23.20 W \pm 0.012387 * 1970 W) \\
& =1970 \mathrm{~W} \pm 47.602 \mathrm{~W} \\
& =1970 \mathrm{~W} \pm 2.41648
\end{aligned}
$$

\section{C.9 Compressor Power Measurement}

The compressor power is measured with a torque and speed meter which provides the data acquisition system with analog signals. The device was manufacturer calibrated and is accurate within the used uncertainties. Since the torque and speed meter 
was new at the beginning of the test series the authors did not see a need for recalibration. Therefore:

$$
\begin{aligned}
& \dot{W}=\frac{n}{60} * \operatorname{Tor} * 2 * \pi=900 W \pm E_{\dot{W}} \\
& \text { with: } \text { Tor }=5.73 \mathrm{Nm} \pm 18 \\
& n=1500 \frac{1}{\min } \pm 5 \frac{1}{\min } \\
& E_{\dot{W}}=\sqrt{\left(\frac{\partial \dot{W}}{\partial n} d n\right)^{2}+\left(\frac{\partial \dot{W}}{\partial T O r} d T O r\right)^{2}} \text {. . . . . . . . . } \\
& E_{\dot{\dot{W}}}=\sqrt{\left(\frac{\operatorname{TOI}}{60} * 2 * \pi * d n\right)^{2}+\left(\frac{n}{60} * 2 * \pi * d T O r\right)^{2}} \\
& =\sqrt{\left(\frac{5.73 \mathrm{Nm}}{60 \frac{\mathrm{sec}}{\mathrm{min}}} * 2 * \pi * 5 \frac{1}{\mathrm{~min}}\right)^{2}} \\
& +\left(\frac{1500 \frac{1}{\mathrm{~min}}}{60 \frac{\mathrm{sec}}{\mathrm{min}}} * 2 * \pi * 0.0573 \mathrm{Nm}\right)^{2} \\
& E_{\dot{W}}=9.486 W \\
& e_{\dot{W}}=1.05418 \\
& \dot{W}=900 W \pm 9.486 W=900 W \pm 1.05418
\end{aligned}
$$

\section{10 COP Calculations}

To calculate the uncertainty of the COP, the uncertainties of the system capacity measurement and of the compressor power measurements are used. The data used represent typical values for the high temperature cooling condition (evaporator) and low temperature heating condition (condenser).

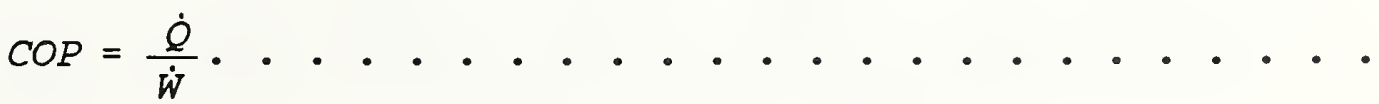

$$
\begin{aligned}
& E_{C O P}=\sqrt{\left(\frac{\partial\left(\frac{\dot{Q}}{\dot{W}}\right)}{\partial \dot{W}} d \dot{W}\right)^{2}+\left(\frac{\partial\left(\frac{\dot{Q}}{\dot{W}}\right)}{\partial \dot{Q}} d \dot{Q}\right)}=\sqrt{\left(-\frac{\dot{Q}}{\dot{W}^{2}} d \dot{W}\right)^{2}+\left(\frac{1}{\dot{W}} d \dot{Q}\right)^{2}}(\mathrm{XLV})
\end{aligned}
$$




$$
\begin{aligned}
& \left(E_{C O P}\right)_{e v a}=\sqrt{\left(-\frac{3520 W}{(900 W)^{2}} * 9.4867 W\right)^{2}+\left(\frac{1}{900 W} * 54.152 W\right)^{2}} \\
& =0.072938 \\
& \left(E_{C O P}\right)_{\text {COn }}=\sqrt{\left(\frac{1970 W}{(900 W)^{2}} * 9.4867 W\right)^{2}+\left(\frac{1}{900 W} * 47.602 W\right)^{2}} . \\
& =0.057705 \\
& \left(e_{C O P}\right)_{\text {eVa }}=1.8649 \text { \% . . . . . . . . . . . . . } \\
& \left(e_{C O P}\right)_{C O N}=2.6363 \text { \% . . . . . . . . . . . . . . . }(\mathrm{XLIX)} \\
& \operatorname{COP}_{\text {eva }}=3.911 \pm 0.072938=3.911 \pm 1.8649 \text { \& } . . . . . . . \\
& C O P_{\text {con }}=2.188 \pm 0.057705=2.188 \pm 2.63638 . \cdots . . . .
\end{aligned}
$$

\section{C.11 Refrigerant Composition}

In order to find the composition of the mixtures actually used in the test rig, samples of the discharge gas are taken during each test. That sample is then analyzed in a gas chromatograph. The chromatograph reports areas that are proportional to the number of moles of each substance contained in the injected sample. In order to calculate the mole fraction of each component it is necessary to establish the areas for the pure components. From tests and measurements at NIST it is known that the calibration areas are reported within $\pm 0.1 \%$ with this particular machine. The areas of each component in a mixture sample are typically repeatable within $\pm 0.3 \%$. The error of the mole fraction is neglected in this consideration. Therefore the uncertainty analysis for the mass fraction $x$ can be performed using typical area values of $a$ R32/R134a composition measurement: 
with :

$$
\begin{aligned}
& A_{a}=750590 \pm 0.38=750590 \pm 2251.8 \\
& A_{b}=1267100 \pm 0.38=1267100 \pm 3801.3 \\
& A_{c a 1, a}=1726967 \pm 0.18=1726967 \pm 1727.0 \\
& A_{c a 1, b}=2342467 \pm 0.18=2342467 \pm 2342.5 \\
& M W_{a}=52.024 \frac{\mathrm{g}}{\mathrm{mole}} \\
& M W_{b}=102.030 \frac{\mathrm{g}}{\mathrm{mole}}
\end{aligned}
$$

$$
X_{a}=\frac{\frac{A_{a}}{A_{c a l, a}}}{\frac{A_{a}}{A_{c a 1, a}}+\left(\frac{A_{b}}{A_{c a l, b}} * \frac{M W_{b}}{M W_{a}}\right)}=0.2906 \pm E_{X_{a}} \text {....... }
$$

$$
\begin{aligned}
& E_{X_{a}}=\sqrt{\left(\frac{\partial X_{a}}{\partial A_{a}} d A_{a}\right)^{2}+\left(\frac{\partial X_{a}}{\partial A_{b}} d A_{b}\right)^{2}+\left(\frac{\partial X_{a}}{\partial A_{c a l, a}} d A_{c a l, a}\right)^{2}} \cdot \ldots \cdot \text {. . . (LV) } \\
& +\left(\frac{\partial X_{a}}{\partial A_{c a l, b}} d A_{c a 1, b}\right)^{2} \\
& \begin{aligned}
\frac{\partial X_{a}}{\partial A_{a}} & =\frac{\frac{1}{A_{c a 1, a}} *\left[\frac{A_{a}}{A_{c a l, a}}+\left(\frac{A_{b}}{A_{c a l, b}} * \frac{M W_{b}}{M W_{a}}\right)\right]-\frac{1}{A_{c a l, a}} * \frac{A_{a}}{A_{c a l, a}}}{\left[\frac{A_{a}}{A_{c a 1, a}}+\left(\frac{A_{b}}{A_{c a l, b}} * \frac{M W_{b}}{M W_{a}}\right)\right]^{2}} \cdot \cdot \text { (LVI) } \\
& =2.7467 * 10^{-7}
\end{aligned}
\end{aligned}
$$

71 


$$
\begin{aligned}
& \frac{\partial X_{a}}{\partial A_{b}}=\frac{0-\left(\frac{1}{A_{c a 1, b}} * \frac{M W_{b}}{M W_{a}}\right) * \frac{A_{a}}{A_{c a 1, a}}}{\left[\frac{A_{a}}{A_{c a 1, a}}+\left(\frac{A_{b}}{A_{c a 1, b}} * \frac{M W_{b}}{M W_{a}}\right)\right]^{2}}=-1.6270 * 10^{-7} . . . . \\
& \frac{\partial X_{a}}{\partial A_{c a l, a}}=\frac{-\frac{A_{a}}{A_{c a l, a}{ }^{2}} *\left[\frac{A_{a}}{A_{c a l, a}}+\left(\frac{A_{b}}{A_{c a l, b}} * \frac{M W_{b}}{M W_{a}}\right)\right]-\frac{A_{a}}{A_{c a l, a}} *\left[-\frac{A_{a}}{A_{c a l, a}{ }^{2}}\right]}{\left[\frac{A_{a}}{A_{c a l, a}}+\left(\frac{A_{b}}{A_{c a l, b}} * \frac{M W_{b}}{M W_{a}}\right)\right]^{2}} \text { (LVIII) } \\
& =-1 \cdot 1938 * 10^{-7} \\
& \frac{\partial X_{a}}{\partial A_{c a 1, b}}=\frac{0-\frac{A_{a}}{A_{c a 1, a}} *\left[-\frac{A_{b}}{A_{c a l, b}{ }^{2}} * \frac{M W_{b}}{M W_{a}}\right]}{\left[\frac{A_{a}}{A_{c a 1, a}}+\left(\frac{A_{b}}{A_{c a l, b}} * \frac{M W_{b}}{M W_{a}}\right]^{2}\right.}=8.8011 * 10^{-8} \cdot . . . .
\end{aligned}
$$

from equation LIII:

$$
\begin{aligned}
& d A_{a}=2251.8 \\
& d A_{b}=3801.3 \\
& d A_{c a 1, a}=1727.0 \\
& d A_{c a 1, b}=2342.5
\end{aligned}
$$

$$
\begin{aligned}
& E_{X_{a}}=\sqrt{\left(6.1850 * 10^{-4}\right)^{2}+\left(-6.1847 * 10^{-4}\right)^{2}} \\
& +\left(-2.0617 * 10^{-4}\right)^{2}+\left(2.0617 * 10^{-4}\right)^{2} \cdot \text { • . . . . . } \\
& =9.2199 * 10^{-4}
\end{aligned}
$$

$e_{x_{s}}=0.31727 \%$ 


$$
X_{a}=0.2906 \pm 9.2199 * 10^{-4}=0.2906 \pm 0.317278 \cdot \cdots \cdot \cdot \cdot \cdot \text { (LXIII) }
$$

At the end of the tests a quality assuring recalibration of the gas chromatograph was conducted. As expected, the values for the areas representing the mole numbers of a substance were well within the $0.1 \%$ of the calibration that was conducted at the beginning of the mixture tests. 


\section{.}




\begin{tabular}{|c|c|c|}
\hline \multirow[t]{3}{*}{$\begin{array}{l}\text { NIST-114A } \\
\text { (REV. 3-80) }\end{array}$} & \multirow{3}{*}{$\begin{array}{l}\text { U.S. DEPARTMENT OF COMMERCE } \\
\text { NATIONAL INSTITUTE OF STANDARDS AND TECHNOLOGY } \\
\text { BIBLIOGRAPHIC DATA SHEET }\end{array}$} & $\begin{array}{l}\text { 1. PUELCATION OR REPORT NUMBEA } \\
\text { NISTIR } 4748 \\
\end{array}$ \\
\hline & & 2 PERFORMING ORQANIZATION AEPORT MUMBER \\
\hline & & $\begin{array}{l}\text { 3. PUEUCATION DATE } \\
\text { DECEMBER } 1992\end{array}$ \\
\hline
\end{tabular}

4. TITLEAND SUBTITLE

The Performance of Chlorine-Free Binary Zeotropic Refrigerant Mixtures in a Heat Pump

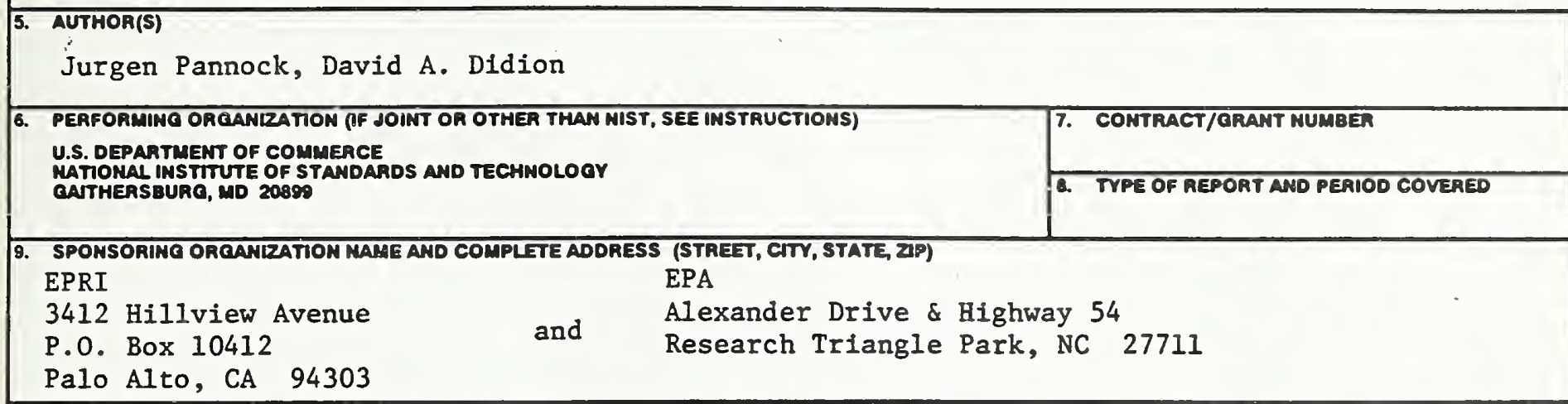

10. SUPPLEMENTAAY MOTES

11. ABSTRACT (A 200-WORD OA LESS FACTUAL SUMMARY OF MOST SIONIFICANT INFOAMATION. IF DOCUMENT INCLUDES A SIONIFICANT BIBUOORAPHY OR LTERATURE SURVEY, MENTION TT HERE)

The phase-out of the currently used refrigerants during the next decade requires fast and accurate methods to evaluate possible alternatives for the existing refrigerants. This report investigates possible replacement refrigerants for $\mathrm{R} 22$, where the replacements are binary zeotropic mixtures of the following hydrofluorocarbons (HFCs): R23, R32, R125, R134a, and R152a. The method, that was chosen, is based on three steps:

1) determining possible mixture components,

2) evaluating all fifteen possible mixtures using a simulation program developed by NIST and determining the best performing mixtures,

3) evaluating the best performing mixtures in a NIST build test facility.

Following this path, two refrigerant mixtures, $R 32 / R 134 a$ and $R 32 / R 152 a$ were found to perform better than $\mathrm{R} 22$ with respect to $C O P$ and volumetric capacity for certain composition ranges.

The used simulation model proved to be a very precise tool in finding possible replacement fluids and their possible performance advantages.

The results give the confidence that this time saving combination of simulation and testing is a very powerful engineering tool.

12. KEY WORDS (6 TO 12 ENTRIES; ALPHAEETICAL ORDEA; CAPTALIE OHLY PAOPER MAMES; AND SEPARATE KEY WORDS BY SEMICOLONS)

binary zeotropic mixtures; COP; performance advantage; R22; R23; R32; R125; R134a; R143a;

R152a; test facility; volumetric capacity

\section{AVALABIUTY}

\section{$\mathrm{x}$ UNUMTTEO}

FOR OFFICLAL DISTAIBUTION. DO NOT REEASE TO MATIOMAL TECHMICAL INFORMATION SERVCE (NTIS).

ORDER FROM SUPERINTENDENT OF DOCUMENTS, U.S. OOVERMMEMT PRINTINO OFFICE WASHINOTOH, DC 20402.

ORDER FROM MATIONAL TECHMICAL INFORMATION SERMCE (MTIS), SPRINOFIEU, VA 20161.
14. NUMBEA OF PAINTED PACES

15. PRICE 
